\title{
Le péché par l'excès : quelques vices de style selon Nicolas Caussin. Présentation, édition, traduction et notes
}

\section{Lise Charles et Suzanne Duval}

\author{
(2) OpenEdition \\ Journals \\ Édition électronique \\ URL : http://journals.openedition.org/rhetorique/1088 \\ DOI : $10.4000 /$ rhetorique. 1088 \\ ISSN : 2270-6909 \\ Éditeur \\ UGA Éditions/Université Grenoble Alpes
}

Édition imprimée

ISBN : 978-2-37747-248-2

Référence électronique

Lise Charles et Suzanne Duval, «Le péché par l'excès : quelques vices de style selon Nicolas Caussin. Présentation, édition, traduction et notes », Exercices de rhétorique [En ligne], 15 | 2020, mis en ligne le 30 novembre 2020, consulté le 03 décembre 2020. URL : http://journals.openedition.org/rhetorique/ 1088 ; DOI : https://doi.org/10.4000/rhetorique.1088

Ce document a été généré automatiquement le 3 décembre 2020.

\section{c) (i) (-)}

Les contenus de la revue Exercices de rhétorique sont mis à disposition selon les termes de la Licence Creative Commons Attribution - Pas d'Utilisation Commerciale - Partage dans les Mêmes Conditions 4.0 International. 


\title{
Le péché par l'excès : quelques vices de style selon Nicolas Caussin. Présentation, édition, traduction et notes
}

\author{
Lise Charles et Suzanne Duval
}

«Ô styli importunitatem!»

Nicolaus Caussinus, Parallela, II, IX

\section{Présentation}

1 En 1619, alors qu'il est professeur au collège de Clermont, le jésuite Nicolas Caussin publie les Parallèles de l'éloquence sacrée et humaine ${ }^{1}$, essai monumental dont les seize livres rassemblent la somme de tous les savoirs rhétoriques alors disponibles en Europe, assortis d'amples citations aux langues bigarrées, puisées dans la littérature de l'Antiquité grecque, latine, classique et tardive, païenne et chrétienne. Orientés, selon la formule de Marc Fumaroli, par un cicéronianisme «nouveau style ${ }^{2}$ » qui n'exclut ni le modèle de Sénèque ni celui des auteurs sulfureux de la seconde sophistique, les treize premiers livres sont consacrés à l'éloquence humaine : éclatante et ornée, celle-ci n'est bornée que par la règle souple de la juste mesure. Cet héritage profane est " dépassé ${ }^{3}$ " dans les trois derniers livres, qui dressent le portrait idéal d'une éloquence proprement chrétienne, dominée par la figure de saint Jean Chrysostome et par les vertus oratoires de la gravité, de la majesté et de la véhémence ${ }^{4}$.

2 Nous proposons ici, sous la forme d'une version de travail, une traduction partielle du deuxième livre, qui traite du "meilleur genre d'éloquence», titre qui fait écho au chapitre de l'Institution oratoire de Quintilien intitulé «De optimo charactere eloquentiae ${ }^{5}$ ». Par la question qu'il soulève, ce livre de Caussin s'inscrit dans la lignée 
du débat sur le meilleur style, qui agita les humanistes de la Renaissance européenne et opposa, notamment, cicéroniens et anti-cicéroniens, partisans de l'abondance rhétorique et zélateurs de l'écriture serrée et allusive. Les neuf chapitres que nous avons retenus se situent au début de ce livre, et traitent, après une brève introduction (chap. I), de l'enflure (chap. II), de l'imitation ridicule (la «cacozélie », chap. III), du style froid (chap. IV), du style puéril (chap.V), de la fureur affectée (ou " parenthyrson ", chap. VI), du style d'écolier (chap. VII), du style poétique (chap. VIII), et enfin du style allégorique et périphrastique (chap. IX). Au lieu de s'attaquer directement à la définition de l'éloquence idéale que l'orateur doit viser, Caussin développe donc au préalable une description raisonnée des vices de style qui pèchent contre les normes du bien-dire, en commençant par les vices par excès ${ }^{7}$. Ces derniers, au nombre de neuf ${ }^{8}$, sont opposés aux quatre vices des chapitres suivants, qui sont fondés sur un manque (bassesse, sécheresse, langueur et rudesse). Le détour par le négatif, qui consiste à définir une vertu ou une qualité prisée en commençant par les vices menaçants qui l'avoisinent, est de bonne méthode, si l'on en croit un autre professeur de rhétorique, Quintilien, qui, après avoir affirmé que la "première des vertus, c'est de ne pas avoir de vice " ", observe qu'il y a " autant de manières de gâter le style que de lui donner de l'ornement ${ }^{10} »$. C'est en tout cas le chemin qu'emprunte la référence majeure de l'ouvrage de Caussin, le traité Du Sublime, qui, posant au début de son propos la question cruciale de savoir s'il existe un art du sublime ou s'il faut, dans ce domaine de l'éloquence, laisser libre cours aux natures douées, prend le parti de l'art en représentant d'abord les trois écueils auxquels s'expose quiconque s'en remettrait à son seul génie pour atteindre les sommets: enflure, froideur puérile et faux enthousiasme $e^{11}$.

3 Montrer du doigt les mauvaises routes pour orienter vers la bonne s'inscrit, de manière plus large, dans un cadre de pensée aristotélicien qui définit la juste mesure comme un équilibre entre deux précipices $^{12}$. La catégorisation des vices de style que propose Caussin relève donc d'une tradition ancienne mais non figée, qui accouple de manière plus ou moins systématique un caractère du bon style à son jumeau défectueux, malformé et parfois monstrueux ${ }^{13}$ : pour Aristote, l'ornement du lexique, s'il est outré, confine à la froideur ${ }^{14}$; Denys d'Halicarnasse met en miroir le grand style et le style froid, l'élégance et l'affectation, la simplicité et la sécheresse, la véhémence et le style disgracieux ${ }^{15}$, perspective également présente dans la Rhétorique à Herennius où les genres élevé, moyen et simple sont respectivement menacés par la boursouflure, le flasque et le $\sec ^{16}$. Au regard de ces listes relativement restreintes, Caussin offre donc, avec ses treize catégories, une somme dont le caractère pléthorique s'explique non seulement par l'érudition du professeur, mais aussi, s'il est permis d'interpréter les écrits d'un jésuite en utilisant le langage de Pascal, par un certain esprit de finesse. Caussin, en effet, ne prétend pas définir des catégories stylistiques fermes et abstraites. Il précise au contraire à plusieurs reprises que tel ou tel vice ressemble à tel autre, se confond à certains égards avec lui, ne s'en différencie que par quelques traits subtils, sans qu'il soit possible de dégager un schéma cohérent de ces rapports complexes d'inclusion et de distinction. La méthode du professeur reste celle d'un lecteur assidu et passionné, pour qui la mémoire des auteurs prime sur le surplomb théorique. Aussi les exemples de styles défectueux que Caussin cite longuement et critique parfois sans dissimuler son amusement ne vont-ils pas sans une certaine séduction ${ }^{17}$. Ils témoignent d'une connaissance sensible des textes antiques, de leur fréquentation suffisamment 
intime pour en avoir retenu les moindres défauts, et d'une curiosité pour les textes bizarres et non canoniques.

4 Produit d'une culture sensible, cette démultiplication des types de vices est aussi due à l'intention pédagogique de Caussin: tout en cernant l'échec stylistique dans ses diverses manifestations attestées par la littérature, cet enseignant habitué à corriger les erreurs veut tendre à ses contemporains un miroir où ils reconnaîtront leurs propres excès. L'analyse stylistique des vices s'accompagne donc, en creux, d'une galerie des caractères enclins à les commettre. Or, bien plus qu'à la théorie des humeurs ou à la décadence des mœurs qui servent traditionnellement de principe explicatif à la corruption du style, celle-ci est fréquemment assimilée par Caussin à un péché de jeunesse. À une époque où la littérature mondaine prend son essor et où son style moyen fera bientôt concurrence aux orateurs de la chaire et du barreau ${ }^{18}$, Caussin, zélateur de la grande éloquence de Du Vair et Du Perron ${ }^{19}$, entend certainement modérer la gloriole des jeunes gens qui, pour faire carrière dans les belles-lettres, n'attendent pas le nombre des années et peuvent se tromper de modèles ${ }^{20}$. En effet, les outrances stylistiques qui conduisent aux vices s'expliquent selon Caussin par une ambition excessive, un goût naif pour le clinquant et l'ostentation, une puérile confiance dans son talent singulier, une sentimentalité exacerbée par les romans d'amour ou encore une mollesse et une affectation contractées à l'abri du monde adulte, dans les salles confinées du collège. De tels traits de caractère étaient certainement typiques des élèves de bonne famille que Caussin rencontrait au cours de ses enseignements et qui, quelques années après la publication des Parallela, feraient leurs délices du langage héroïque de Corneille et du style sophistiqué des lettres de Guez de Balzac. Caussin du reste n'est pas le seul à s'inquiéter de ces nouvelles générations de lecteurs et d'écrivains : elles suscitent la défiance, non seulement de l'école jésuite, mais de tous les tenants du « cicéronianisme dévot ${ }^{21}$ ».

5 L'approche stylistique de Caussin, conforme en cela à l'esprit le plus traditionnel de la rhétorique qui définit le "caractère " d'une l'éloquence comme la synthèse d'une pensée et d'une forme, ne se réduit pas aux ornements de l'elocutio. Il est à ce titre tout à fait notable que Caussin emploie le terme de stylus, mis en avant dans les titres de chacun de ses chapitres, pour désigner les différents types de vice, alors que le latin classique de même que celui du Moyen Âge et de la Renaissance lui préfèrent bien souvent celui d'oratio ou de character pour évaluer l'éloquence de tel ou tel orateur. Le mot de style, plus générique, pointe le caractère englobant des différents vices qui sont recensés, et qui sont appréhendés à l'échelle des mots, des figures, de l'agencement et du rythme et enfin des pensées. Si les figures, et en particulier la métaphore, offrent une cible privilégiée pour exemplifier un vice de style, celui-ci se présente toujours comme une constellation d'erreurs touchant à toutes les dimensions du discours. Cela explique la terminologie plus ou moins technique qu'emploie Caussin pour les disqualifier. Les notions les plus classiques de la rhétorique (res, verba, compositio, sensus...) sont associées à des réseaux métaphoriques parfois entièrement étrangers à notre sensibilité contemporaine : le froid, qu'on associe aujourd'hui plutôt à la raideur et à la distance, désigne chez Caussin une pensée exubérante et hors de propos ${ }^{22}$; le pur, connoté aujourd'hui positivement, caractérise une éloquence doucereuse et superficielle, de même que le parfumé, tandis que toute une imagerie de l'enflure, de l'ampoule, de la tumeur, des bulles et de la grenouille envieuse du bœuf rendent compte du style qui se veut faire plus grand que le sublime lui-même. Autre symptôme de cette pensée du style qui n'est pas strictement technique, Caussin use parfois de 
calques grecs pour désigner efficacement le vice qu'il convient d'éviter : or, l'obscurité de termes comme le parenthyrson, que Boileau éclaircira en le traduisant par la « fureur hors de saison ${ }^{23}$ ", ou le cacozelon, traditionnellement traduit par l'«affectation vicieuse ", n'est pas seulement, de la part du rhétoricien, l'expression de son pédantisme et de son goût pour le bilinguisme et la bigarrure (qu'il condamne par ailleurs au chapitre $\mathrm{X}$ !). Ces mots étranges et composites, dont nous avons choisi de conserver l'opacité dans notre propre traduction, expriment le caractère intrinsèquement flou et confus de ces vices de style, qui saisissent de manière synthétique un agrégat de mauvais choix et se perçoivent intuitivement, sans que l'analyse rhétorique dispose de termes toujours clairs et distincts pour les appréhender. $\mathrm{Au}$ risque de se rendre lui-même coupable des vices dont il se fait le censeur ${ }^{24}$, le langage incarné et parfois énigmatique dont use Caussin et sa prose enthousiaste traduisent ainsi une sensibilité d'époque imprégnée de cadres rhétoriques ancestraux mais réactualisés par les tendances stylistiques de son temps. À ce titre, la lecture de son texte est une plongée dans le goût et les imaginaires langagiers du XVII ${ }^{e}$ siècle, et elle nous offre un magnifique témoignage pour une histoire de l'esthétique du style sous l'Ancien Régime.

\section{Principes d'édition}

6 Pour le texte latin: nous éditons celui de l'édition originale de 1619 (N.Caussin, Eloquentiae sacrae et humanae parallela libri XVI, Paris, S. Chapelet, L. II, chapitres I-IX), que nous avons ponctuellement amendée en consultant les rééditions ultérieures (Paris, Henault et alii, 1630; De Eloquentia sacra et humana, Paris, Henault, 1637 et Lyon, Pierre André, 1651). Dans le cas d'erreurs manifestes, nous ne signalons pas notre intervention. Les nombreuses citations antiques et médiévales, en latin, grec et même hébreu, sont données sous la forme où elles apparaissent chez Caussin, que cette forme corresponde ou non aux éditions actuelles des œuvres citées.

7 Nous supprimons les accents ; remplaçons l'esperluette par et, les lettres ramusiennes $v$ et $j$ par $u$ et $i$ (à l'exception du $V$ majuscule) et les lettres liées par ae et oe. Mais nous conservons la ponctuation, ainsi que l'alternance entre italiques et romain - alternance inversée, puisque le texte de 1619 est en romain (ici, en italiques), et les mots qu'il souligne, en italiques (ici, en romain).

8 Les soulignements de Caussin ou bien mettent en exergue tel ou tel mot, ou bien signalent la reprise textuelle de tel auteur. Dans ce dernier cas, il utilise parfois des crochets, ou même un seul crochet (ouvrant): nous ne reprenons pas ce ou ces crochets, et transposons en mettant en romain la citation ainsi signalée. Très souvent, aucune indication typographique n'indique qu'on a affaire à une citation: nous introduisons alors les guillemets les plus simples, 'et', qui seront donc toujours de notre fait.

9 Pour le texte français: la terminologie technique de Caussin et son langage métaphorique posant d'importants problèmes de traduction, nous insérons parfois, entre crochets et en italiques, les mots latins les plus spécifiques ou les plus problématiques.

10 Toutes les citations sont signalées par l'emploi des italiques, et leur traduction reprend généralement celle des éditions critiques modernes. Dans les cas où celles-ci suivent un texte qui n'est pas tout à fait celui de Caussin, nous traduisons le texte de 1619, en 
signalant en note les modifications apportées aux traductions modernes. Caussin redouble souvent la citation qu'il donne en grec par sa propre traduction en latin, en général très exacte: nous ne traduisons sa traduction latine que dans les cas où elle apporte des éléments interprétatifs. Pour Quintilien, Sénèque et le traité Du Sublime, nous avons utilisé plusieurs traductions modernes et avons parfois traduit nous-mêmes afin d'obtenir le lexique métarhétorique qui nous paraissait le plus fidèle à l'idée que Caussin veut illustrer.

11 Enfin, notre traduction a voulu être la plus fidèle possible à la " pensée abondante » et au «style généreux ${ }^{25}$ » de Caussin : à son abondance cicéronienne, à son goût pour la synonymie et les doublons rhétoriques, à l'ampleur de ses périodes. Néanmoins, pour faciliter la lisibilité du texte, nous avons segmenté chaque chapitre en parties et sousparties qui soulignent sa structuration, en nous inspirant généralement des manchettes de l'édition originale; les intertitres entre crochets sont nôtres. Ces manchettes, que nous n'avons pas reproduites, servaient à préparer l'index général, mais remplissaient aussi la fonction pédagogique de référencer certaines citations, de souligner l'idée centrale des différentes sections du texte et d'en faciliter la « mémoration ${ }^{26}$ ».

\section{Remerciements}

Nous remercions l'équipe RARE de l'Université Grenoble Alpes, qui a accompagné ce projet de traduction tout au long de sa gestation, et en particulier Francis Goyet et Christine Noille qui ont relu et amendé notre travail, et lui ont apporté leurs lumières. Nous remercions également Sophie Conte de nous avoir généreusement aidées à documenter cette édition.

\section{Nicolas Caussin, Eloquentiae sacrae et humanae parallela libri XVI, L. II, chap. I-IX : édition, traduction et notes}

\section{Chapitre I. Du meilleur genre d'éloquence, et en premier lieu de sa variété / De optimo charactere eloquentiae ac primum de ejus uarietate [Fin du chapitre]}

13 Dionysius Longin ${ }^{27}$, dans le traité $\mathrm{Du}$ Sublime, rapporte les vices de style à trois points :

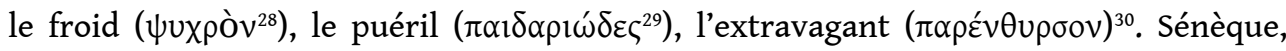
dans la lettre 114, parle de l'enflé, du haché, de l'audacieux, du coupé, de l'allégorique en ces termes: Par quelle raison, dis-tu, un style corrompu a-t-il fait son apparition à certaines époques? Comment une pente des esprits vers tel ou tel vice a-t-elle mis à la mode, tantôt l'enflure, tantôt un rythme haché comme celui du chant? Pourquoi s'est-on épris, à tel moment, de pensées audacieuses qui passaient la vraisemblance, à tel autre de phrases abruptes et suggestives laissant à penser plus qu'elles n'expriment? Pourquoi s'est-il vu un temps où le droit de métaphore ne reculait devant rien ${ }^{31}$ ? D'autres auteurs mentionnent d'autres erreurs, à partir desquelles je rassemble cette somme des principaux vices de style : l'enflure, la cacozélie $^{32}$, la froideur, le parenthyrson ${ }^{33}$, le style puéril, le style d'écolier, le poétique, l'allégorique, la bigarrure, le style humble, le sec, le lent, l'abrupt; certains de ces vices se repéreront à un excès, les autres, à un manque ${ }^{34}$. 


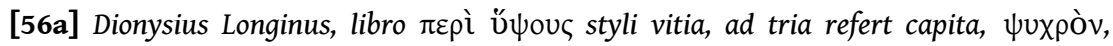
$\pi \alpha 1 \delta \alpha \rho \iota \omega ́ \delta \varepsilon \varsigma, \pi \alpha \rho \varepsilon ́ v \theta u \rho \sigma o v$ : hoc est, frigidum, puerile, insanum. Seneca epistola centesima decima quarta, inflatum, infractum, audax, praeruptum, allegoricum, attingit his verbis. 'Quare quibusdam temporibus prouenerit corrupti generis Oratio, quaeris? et quomodo in quaedam uitia inclinatio ingeniorum facta fit, ut aliquando inflata explicatio uigeret, aliquando infracta, et in morem Cantici [56b] ducta? Quare alias sensus audaces, et fidem egressi placuerint? alias abruptae sententiae, et suspiciosae, in quibus plus intelligendum est, quam audiendum? quare aliqua aetas fuerit, quae translationis iure uteretur inuerecunde?' alii alios errores notant, ex quibus ad summum colligo praecipua styli uitia ; tumidum, cacozelum, frigidum, parent[h]yrsum, puerile, scholasticum, poeticum, allegoricum, miscellaneum, humile, siccum, lentum, abruptum ; quorum alia in excessu, alia etiam in defectu reperientur.

\section{Chap. II. Du style enflé / De stylo inflato}

Le plus fréquent est le vice de style qu'on appelle enflure. En effet, quand la nature tente de son propre élan d'atteindre des sommets trop élevés, il arrive que, trompée par une fausse image de grandeur qu'elle s'est figurée, elle soit précipitée tête la première dans des sottises enflées et des bagatelles "phalérées », comme on dit $^{35}$. Ainsi la grenouille de la fable admire-t-elle la haute stature du bœuf et son embonpoint ; aussitôt, elle est tout enflammée du désir de ressembler au bœuf; mais la malheureuse, alors qu'elle enfle et se gonfle au-delà de ses forces chétives et de sa condition naturelle, manque de souffle, éclate et succombe. Cette même leçon vaut pour de très nombreux imitateurs, qui élèvent leur regard vers la grandeur de Virgile ou de Cicéron et brûlent, y compris dans des sujets de peu d'importance, de l'exprimer et même de la surpasser : au lieu de produire du vrai et du solide, ils ne font voir que de la fumée et du vent, et, maigres et décharnés, ils dépérissent ${ }^{36}$.

Frequentissimum uitii genus illud est, quod tumorem appellant. Nam, cum ad altiora quaeque suo (ut assolet) impetu natura contendat, fit, ut peruersae magnitudinis, quam sibi deformauit, simulachro quodam illusa, in tumidas ineptias, et phaleratas, ut aiunt, nugas praeceps abripiatur. Rana certe in apologo miratur grandem illam bouis speciem, et succulentam corporis habitudinem: nec mora, in eius amorem tota exardescit, et cupit quoquo modo boui similis fieri; sed misera, dum supra corpusculi uires, et naturae conditionem tumet, atque inflatur, spiritum egerit, ac mortua disrumpitur. Idipsum profecto permultis contingit imitatoribus, qui dum Virgilii, aut Ciceronis magnitudinem suspiciunt, auentque in leuiculis etiam argumentis, eandem exprimere, et uincere, in id deueniunt, ut pro uero, et solido corpore nihil nisi fumos, et uentos ostentent, tandemque strigosi, et macilenti dispereant.

15 Ce style est dit enflé par analogie avec un embonpoint malsain, qui, à la place de la chair et de la sève ${ }^{37}$, a contracté une tumeur pleine de pituite ${ }^{38}:$ cela se produit, comme le note Cicéron, lorsque le discours utilise des néologismes ${ }^{39}$, ou des archaïsmes, ou bien des métaphores forcées, ou bien lorsque l'on dit quelque chose en des termes plus graves que ce qui convient au sujet ${ }^{40}$. Longin le nomme l'excès par rapport à la juste grandeur ${ }^{41}$, en donnant les exemples suivants, tirés d'un poète enflé :

et qu'ils arrêtent la lumière qui sort à longs traits de l'âtre,

car si je vois un seul gardien du foyer,

j'introduirai une boucle de feu au cours torrentiel,

j'embraserai la demeure et la réduirai en charbon. ${ }^{42}$. 
Une boucle ${ }^{43}$ de feu au cours torrentiel pour dire un tourbillon de fumée, dit Longin, est une expression trop audacieuse. Que dire, chez ce même poète, de ces mots outrés, vomir contre le ciel et Borée transformé en joueur de flûte $e^{44}$ ?

Hoc genus tumidum nominatur, similitudine ducta, a praua corporis habitudine, quae pro carne, et succo degenerem pituitae tumorem nacta est : fit autem, ut notat M. Tullius, cum oratio 'nouis, aut priscis uerbis, aut duriter aliunde translatis, aut grauioribus, quam res postulat, aliquid dicitur'. A Longino definitur, excessus iustae magnitudinis, et haec exempla proferuntur ex tumido poeta, qui ita loquutus fuerat.

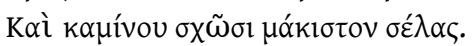

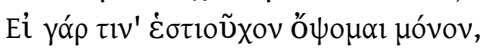

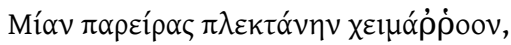
$\Sigma \tau \dot{\varepsilon} \gamma \eta v \pi v \rho \omega ́ \sigma \omega, \kappa \alpha \grave{~} \kappa \alpha \tau \alpha v \theta \rho \alpha \kappa \omega ́ \sigma o \mu \alpha \mathrm{l}$.

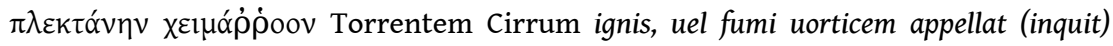
nimis audaci nomine. Quid, quod idem, et uomere in caelum usurpat, et Tibicinem facit Boream.

Car, dit encore Longin, ces expressions ne sont pas tragiques, elles vont au-delà [excedunt] du cothurne de la tragédie lui-même. Le style en est trouble, et les images déconcertent plutôt qu'elles ne frappent; à regarder au grand jour chacune de ces expressions, elles se réduisent peu à peu à un objet de juste mépris ${ }^{45}$.

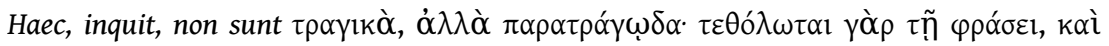

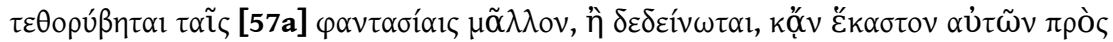

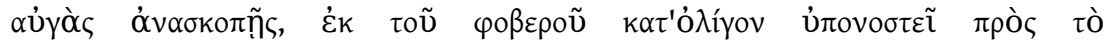

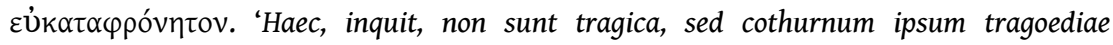
excedunt. Sunt enim inquinatissima locutione, et tumultuariis sententiis turbida potius quam gravia. Quod si singula in lucem dispexeris; paulatim ex inani specie grauitatis, in rem contemptissimam recident.'

\section{[1. Enflure par les mots: a. les néologismes]}

18 Il convient d'observer que, pour Cicéron ${ }^{46}$ comme pour Longin, il existe trois types de discours enflés: l'un ne se gonfle que par les mots, l'autre que par les pensées, le troisième s'enfle et s'élève à la fois par les mots et par les pensées. Les types de mots sont eux aussi au nombre de trois : les néologismes, les archaïsmes et les métaphores forcées. Voici des exemples.

Porro notandum occurrit, ex utroque, et Ciceronis, et Longini sensu, triplex inflatae orationis genus; alia enim uerbis duntaxat intumescit, alia solis sensibus, alia sensibus simul, et uerbis inflari, atque attolli solet. Verba quoque ipsa, aut noua sunt, aut prisca, aut duriter aliunde translata ; exempla omnium subiicio.

19 Le vice qu'on appelle kainospoudia, recherche de nouveautée ${ }^{47}$, fut commun aux auteurs inexpérimentés et aux auteurs ambitieux. Ils affectaient en effet d'inventer de nouveaux noms pour chaque chose, au point d'inventer un nouveau langage. Ce défaut fut particulièrement présent chez le tyran Denys, dont Athénée rappelle certaines inepties. Il répugnait à dire parthenos pour une vierge, car le nom lui paraissait trop commun. Que faisait-il donc? Il disait menandron, parce qu'elle attend [menei] un homme [andron]. Pour désigner une colonne, il disait ménékratè, parce qu'elle reste [menei] forte [kratos]; pour un javelot, ballantion, parce qu'il est jeté [balletai] contre [enantion] quelqu'un.

Fuit illud imperitis, et ambitiosis scriptoribus commune uitium, quod uocatur

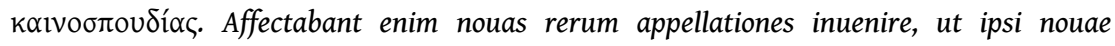
alicuius linguae fierent auctores: quod Dionysio tyranno supra caeteros extitit peculiare, cuius aliquas ineptias commemorat Athenaus: Quippe $\pi \alpha \rho \theta \varepsilon$ ćv uirginem nominare, ut 


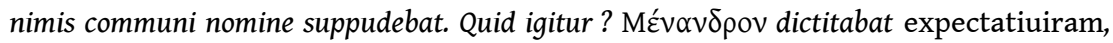

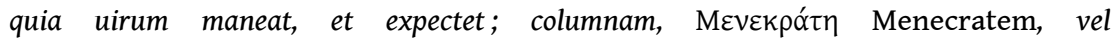
ualidipotentem, quod ualida perduret; iaculum $\beta \alpha \lambda \lambda$ óv $\tau \iota \mathrm{v}$, quod aduersus iaciatur.

20 Alexarque, frère du roi de Macédoine Cassandre et fondateur d'Uranopolis, avait la même tendance : à son propos, Héraclide Lembus ${ }^{48}$, dans son $37^{\text {ème }}$ livre, rapporte: Alexarque, qui édifia Uranopolis, introduisit des manières de parler singulières: il appelait par exemple un coq orthro-boas, crieur du matin ${ }^{49}$, un barbier broto-kertès, tondeur de mortels, une drachme argyris, pièce d'argent, une chénice héméro-trophis, nourriture de la journée ${ }^{50}$, un héraut apyte, le retentissant ${ }^{51}$.

Eodem ingenio fuit Alexarchus, Cassandri Macedoniae regis frater, Vranopolidis conditor: de quo Heraclides Lembus histor. lib. trigesimo septimo, ad hunc modum prodit, et refert. 'Alexarchus, qui Vranopolin aedificauit, loquendi peculiares formas inuexit, ut qui gallum

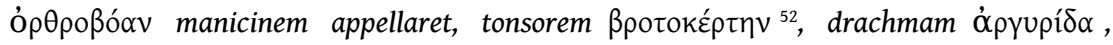

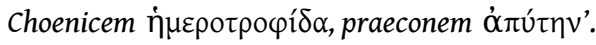

21 Lucien manie ce style avec beaucoup d'esprit : sous le masque de Lexiphanès, il a écrit un dialogue entier qui grouille de ces mots corrompus. Par exemple: les oreilles obstruées-à-la-cire ${ }^{53}$, je dresse un anti-banquet au fils d'Ariston ${ }^{54}$, Que se tienne loin Dame Cire obstrue-les-oreilles ${ }^{55}$ et encore un nombre infini de termes inintelligibles pour les Grecs, qu'ils soient des néologismes ou des mots forgés par composition à partir d'une métaphore forcée ${ }^{56}$, comme dans l'expression le troupeau qui-courbe-la-nuque ${ }^{57}$.

Lucianus ut est in hoc genere festiuissimus, sub persona Lexiphanis, dialogum integrum

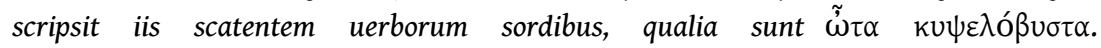

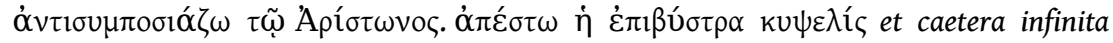
Graecis hominibus intellectu perquam difficilia, nihil interest autem an noua sint, an per compositionem nouata, et durius interpolata, ut incuruiceruicum pecus.

\section{[Enflure par les mots : $b$. les archaïsmes]}

La seconde catégorie de mots recouvre ce qu'on appelle les archaïsmes, qui, enfouis depuis longtemps dans les ténèbres de l'oubli, sont déterrés et réexposés au grand jour par des styles affectés. Par exemple: Vous en viendrez aux mains à l'endroit où les confluents répandent l'humidité sur la terre ${ }^{58}$. [...]

Secundum est genus uerborum, quae prisca uocantur, et ea iamdiu obliuionis oppressa tenebris, a putidis stylis effodiuntur, atque eruuntur in lucem, qualia sunt ista. 'Confluges, ubi conuentum campum totum inhumigant.' [...]

On raconte que, pour avoir usé d'un tel discours, un avocat s'attira les moqueries de tous devant le préfet de la ville : alors qu'il voulait dire qu'un homme vivait misérablement, sans ressources, et mangeait du pain de son en buvant un vin tourné et fétide, il s'écria: "Ce chevalier romain mange de l'apluda et boit des flocces." Tous ceux qui étaient là se regardèrent, d'abord très sérieusement, le visage troublé et interrogateur: qu'est-ce que c'était que ces deux mots? Puis enfin comme s'il avait dit je ne sais quoi en étrusque ou en gaulois, ils éclatèrent tous de rire. Or il avait lu que les anciens paysans avaient appelé apluda le son de froment et que Plaute s'est servi de ce mot dans une comédie - si elle est de Plaute - intitulée Astraba. De même il avait entendu dire que le très ancien mot flocces désignait la lie tirée du marc de raisin comme les fraces, du marc d'olive. Un autre, comme l'adversaire réclamait le renvoi du procès, s'écria : "Préteur, je t'en prie, à l'aide, au secours! jusqu'à quand ce bovinator va-t-il nous retarder?" Et il cria le mot trois ou quatre fois à grands éclats de voix: "C'est un bovinator." Un brouhaha se mit à s'élever de la plus grande partie de l'assistance, exprimant l'étonnement devant un mot monstrueux. Mais lui tout fier et exultant : "C'est que vous n'avez 
pas lu Lucilius, qui appelle un tergiversateur bovinator. » Or il y a dans le livre XI de Lucilius ce vers : "S'il est maigre et tergiversateur [bovinator], de mauvaise foi, à la bouche impudente ${ }^{59}$. " $[\ldots]$

[57b] Hac, et simili oratione usus, magno omnium risu, fertur quidam caussidicus, apud urbis praefectum: 'nam cum significare uellet inopi quendam, miseroque uictu uivere, et furfureum panem esitare, uinumque eructum, et foetidum potare. Hic, inquit, eques Romanus apludam edit, et flocces bibit. Aspexerunt omnes, qui aderant, alius alium, primo tristiores turbato, et requirente uultu, quidnam illud utriusque uerbi foret: Post deinde, quasi nescio quid Tusce, aut Gallice dixisset, uniuersi riserunt. Legerat autem ille apludam ueteres rusticos, frumenti furfurem dixisse : idque Plauto in comoedia (si ea Plauti est) quae Astraba inscripta est, positum esse. Item Flocces audierat, prisca uoce, significare uini faecem, e uinaceis expressam, sicut fraces, ex oleis. Alter, cum aduersarius caussam differri postularet. Rogo Praetor, inquit, subueni, succurre: Quonam usque nos bouinator hic demoratur? Atque id, uoce magna, ter, quaterue inclamauit Bouinator. Commurmuratio fieri coepta est, a plerisque qui aderant, quasi monstrum uerbi admirantibus. At ille iactans, et gestiens : non enim Lucilium, inquit, legistis, qui tergiuersatorem, bouinatorem dicit. Est autem in Lucilii undecimo uersus hic. Hic strigosus ${ }^{60}$, bouinatorque ore improbus duro $^{61} \cdot[\ldots]$

\section{[Enflure par les mots : c. les métaphores forcées]}

La troisième classe de mots corrompus recouvre les métaphores hardies et audacieuses: Longin rapporte que le style de Gorgias, de Callisthène, de Clitarque, d'Amphicratès, d'Hégésias et de Matris ${ }^{62}$ en regorgeait. Chez Gorgias, il signale celles-ci parmi d'autres: Xerxès, le Jupiter des Perses ${ }^{63}$ et les vautours, tombeaux vivants ${ }^{64}$. Ces expressions, manifestement ingénieuses, le critique s'en moque énergiquement, et il n'épargne pas Xénophon, qui, pour dire pupilles, avait utilisé l'expression de vierges des yeux, sous prétexte que les Grecs appellent jeune fille [puella] et pupille [pupilla] du même nom de korè ${ }^{65}$. Voici le passage de Xénophon: Vous ne les entendriez parler non plus que des statues de marbre; vous ne détourneriez leurs regards pas plus que ceux des images de bronze; vous les croiriez plus modestes que les vierges mêmes des yeux ${ }^{66}$. C'est dans cette dernière expression, plus modestes que les vierges mêmes des yeux, que se situe l'enflure. Mais Timée ne se contente pas de cette métaphore déjà bien hardie de Xénophon: Est-ce là ce qu'aurait fait un homme qui aurait eu aux yeux des pupilles et non des courtisanes ${ }^{67}$ ?

Tertia corruptorum uerborum series est in translatis audacibus, et inuerecundis, quorum abundantem stylum Gorgiae, Callisthenis, Cleitarchi, Amphicratis, Hegesiae, Matridis

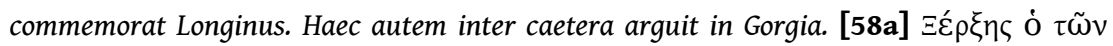

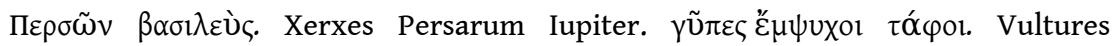
sepulchra animata. Haec, inquam, ingeniose (ut apparet) dicta sugillat acriter uir Criticus, nec parcit Xenophonti, qui pro pupillis Virgines oculorum dixerat, quod puella, et pupilla

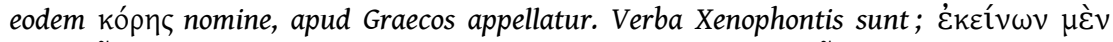

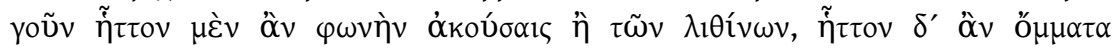

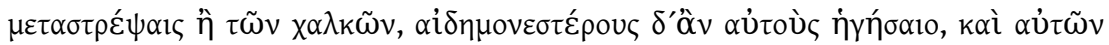

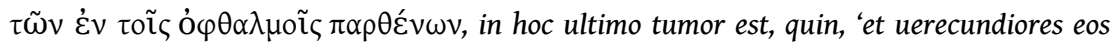
existimaris, ipsis oculorum uirginibus'. At Timaeus Xenophontaea illa satis audaci

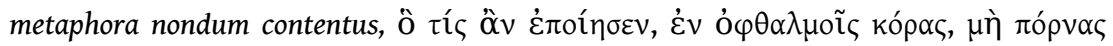
है $\chi \omega v$; 'Hoc utique faceret alius, qui non Meretrices in oculis : sed uirgines haberet'.

Quelle place occupent les métaphores grandiloquentes dans le style de l'Africain ${ }^{68}$ ! Par exemple : la canicule de la persécution s'allume par les mains de Cynocéphale lui-même ${ }^{69}$; mais ses yeux, ou pour mieux dire, ses deux points de lumière, placés à fleur de tête, se portent rapidement à droite et à gauche, dans leur éblouissante mobilité $e^{70}$; le rassemblement par étages $^{71}$ au sujet des habits; et, chez Sidoine, la dent de vipère des aboyeurs ${ }^{72}$, fautes qui 
doivent plutôt être imputées à l'époque qu'aux hommes. Quant à Apulée, tout à son plaisir, il se plonge dans ces métaphores, par exemple : l'eau à la bouche, j'allais saisir les roses entre mes lèvres ${ }^{73}$, écrit-il au sujet de l'âne qui les engloutissait déjà en pensée; de même : je les dévorais avidement de baisers passionnés ${ }^{74}$, et autres expressions semblables.

Haec quota portio grandium metaphorarum, quae in Africano stylo reperiuntur? Ut, Ipsa canicula persecutionis, ab isto scilicet Cynocephalo. Circumspectu emissitii ocelli : imo luminis puncta uertiginant, et tabulata congregatio in uestibus, et colubrini oblatratorum molares, apud Sidonium, qui temporis potius errores, quam uirorum censendi sunt. At Apuleius, prae gaudii affluentia, totus istis immergitur, quale est, labiis undantibus affectare rosas, inquit, de asino, qui iam spe easdem deuorabat: item sorbillantibus suauiis sitienter haurire, et similia.

\section{[2. Enflure par les pensées]}

La seconde catégorie d'enflure réside dans les pensées immodérées, même si les mots semblent par ailleurs réglés sur l'usage commun. Les auteurs tragiques tombent très souvent dans ce défaut, lorsque leur discours outrepasse la nature.

Secundum tumoris genus, est in ipsis sensibus immoderatis, licet alioqui uerba, ad legem usus communis uideantur exacta. Hoc genere peccant saepissime tragici, dum res supra naturam extollunt.

De telles bulles d'air [bullis] ${ }^{75}$ surabondent dans Hercule sur l'œta de Sénèque (si cette tragédie est bien de lui). Voyez avec quelle morgue le fils réclame le ciel à son père Jupiter : Qui t'arrête encore? Est-ce la crainte qu'Atlas ne puisse porter Hercule, ajouté au poids de l'olympe $e^{76}$ ? Si c'était Typhon qui prononçait ces paroles, elles seraient à peine supportables : car qui voudrait offrir le ciel à quelqu'un qui le réclame d'une manière aussi impudente?

His bullis redundat Hercules Oeteus Senecae, si modo eius est, quo enim fastu coelum petit a Joue, filius a parente.

... Quid tamen nectis moras?

Numquid timemur? numquid impositum sibi

Non poterit Atlas ferre cum caelo Herculem.

Si haec Typhon diceret, tamen uix essent tolerabilia : quis enim largiri coelum uellet, tanta oris improbitate, expostulanti?

Ensuite : Si le monde est épuisé par les monstres, si la colère de Junon est lasse, appelle-moi donc dans l'olympe, ou comme ton fils, ou pour récompenser mon courage $e^{77}$.

Puis interviennent des figures emportées, qui finissent par tomber dans le style froid.

Et de nouveau: Si tu crains que la terre n'enfante d'autres monstres, eh bien! qu'elle se hâte, tandis qu'elle possède et voit encore Hercule $e^{78}$. Comme ce Jupiter est à plaindre et misérable, lui qui craint les monstres et ne pourrait sans Hercule se sentir en sécurité !

Deinde :

... Si negat mundus feras

Animum Nouerca : redde nunc gnato patrem,

Vel astra sorti.

Apparent uiolentae figurae, quae desinunt in frigidum.

Rursus :

Vel si times, ne terra concipiat feras :

Prosperet malum quodcumque, dum terra Herculem

Habet, uidetque.

Quam miser, et miserabilis ille Iupiter, qui a ferarum metu, sine Hercule tutus esse non poterat? 
le passage qui suit surpasse toutes les enflures: Charge-moi du moins, Jupiter, de la défense des dieux; tu n'auras pas besoin de protéger de ta foudre la partie du ciel que tu m'auras confiée. Que ce soit le pôle glacé ou la zone brûlante, les habitants de l'Olympe y seront en sûretée $e^{79}$.

Hoc uero, quod sequitur, supra omnem tumorem inflatum.

[58b] Da da tuendos Iupiter saltem Deus.

Illa licebit fulmen a parte auferas,

Ego quam tuebor ; siue glacialem polum,

Seu me tueri feruidam partem iubes,

Hac esse superos parte securos puta.

Tantôt il dit que le ciel le redoute, tantôt il se pose en puissance protectrice des dieux. Quoi de plus enflé? Les dieux sont donc bien faibles, selon lui, pour qu'ils aient ainsi besoin du secours d'un mortel! Quelles demandes, quelles supplications! Ces propos sont des bulles d'air, où tombent bien souvent ceux qui prétendent à des pensées élevées sans se soucier de la convenance. Ensuite, ceux qui les imitent ajoutent quelque chose de leur cru, et entassent enflure sur enflure, jusqu'à ce que l'outre éclate et ne laisse plus voir qu'une matière des plus méprisables ${ }^{80}$. [...]

Modo timeri se a coelo dicit, modo se tutelare Deorum numen profitetur. Quid hoc tumidius? quam imbecilles deos censet, qui mortali tutore egeant! Haec postulans, et supplex! Illae igitur sunt bullae, in quas saepissime incidunt, qui magnitudinem sensuum praeter decorum affectant. Deinde, qui imitantur, addunt aliquid de suo, et tumida tumidis adstruunt, donec diplosus follis, in contemptissima quaeque euanescat. [...]

\section{[3. Enflure par les mots et par les pensées]}

Dans ce même exemple ${ }^{81}$, on peut remarquer la troisième catégorie d'enflure, lorsque le sujet n'est pas seulement enflé par les pensées, mais aussi par les mots. Il en va de même dans l'exemple que voici : Tu réduis en poussière les rochers, les forêts, les pierres ${ }^{82}$. Comme si ce n'était pas assez d'avoir dit que les montagnes devinrent poussière, sans y ajouter ce mot grandiloquent, tu réduis en poussière.

\section{Ô la méchante bête! ô l'infatigable-bavarde ${ }^{83}$ !}

[59a] In eodem exemplo licet animaduertere tertium tumoris genus, ubi res non modo sensibus, sed ipsis quoque uerbis inflatur, quale est etiam illud saxa, sylvas, lapides, montes disjicis, dispulueras. Non satis fuerat solutos in puluerem montes dixisse, nisi grande quoque uerbum addidisset dispulueras, etc.

'O pestifera Pontica fera, trux, tolutiloquentia!'

Ce style fut toujours, à juste titre, l'ennemi des hommes avisés : car bien qu'il plaise à certains jeunes gens dont l'éloquence, trop facile, est avide de nouveauté, dès qu'on le rencontre trop souvent, il suscite le dégoût. Ainsi Lucien avertit bien Lexiphanès, qui ne cessait d'importuner les oreilles attiques de ce genre de paroles :

Assez, Lexiphanès! Assez de boisson et de lecture! Pour ma part, je suis à présent ivre à cause de toi, j'ai le mal de mer et si je ne vomis pas le plus vite possible tout ce que tu as raconté, j'ai l'impression, sache-le, que je vais danser comme les Corybantes, pris dans le bourdonnement de tous les mots que tu as déversés sur moi.

D'abord, j'ai eu envie d'en rire, mais devant la quantité de toutes ces formules toujours identiques, j'ai eu pitié de ton infortune, te voyant tombé dans un labyrinthe sans issue, en proie à une maladie très grave, ou plutôt à la mélancolie. Je cherche à part moi à quel endroit tu as pu ramasser de si grands vices, en combien de temps et où tu as pu enfermer une si grande foule de termes absurdes et tortueux, dont tu as forgé les uns toi-même, et déterré les autres en les 
arrachant je ne sais où. Quelle masse de boue tu as amassée pour la déverser sur moi, alors que je n'ai rien fait de mal! J'ai l'impression que tu n'as ni ami, ni parent, ni personne qui te veuille du bien, et que tu n'as jamais rencontré un homme libre, pratiquant la franchise, pour te dire la vérité et faire cesser l'hydropisie dont tu es atteint. Cette maladie risque de te faire éclater, mais tu t'imagines être bien portant, et tu prends ton malheur pour de la robustesse. Des insensés qui ignorent ce dont tu souffres te louent, alors que les gens instruits te plaignent, comme tu le mérites $^{84}$.

Hoc styli genus merito prudentibus uiris fuit semper inuisum, quod si nonnullos leuioris facundiae iuuenes, ipso nouitatis aucupio delectet, ubi tamen crebrius fuerit iteratum, transit in satietatem. Itaque bene monet Lucianus Lexiphanem, qui eiusmodi uocibus non desinebat atticis auribus obstrepere.

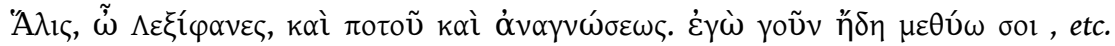
'Satis, ô Lexiphanes, et potus, et lectionis istius: Ego enim tibi ebrius iam sum, et nauseo, et nisi quamprimum euomuero ista omnia, quaecumque recitando persequutus es, uideor mihi insanus, ac furiosus fore, obstrepentibus mihi undique uerbis istis, quae mihi modo offudisti. Quamquam mihi a principio ridere illorum gratia ueniebat in mentem. Verum postquam ea multa, atque omnino similia erant, miserebat me tuae istius aerumnosae infelicitatis, quippe quem uiderem in labyrinthum quendam irremeabilem incidisse, morbumque aegrotare grauissimum; imo uero atra bile percitum. Cogito itaque apud me ipsum, unde tam multa mala collegeris, et quam longo tempore, et ubi denique conclusum habueris tantum examen absurdarum, ac distortarum uocum, quarum alias quidem ipse finxisti, alias autem defossas alicunde eruens : tantum coenum undequaque cogens, in me exhausisti. Porro uideris mihi neminem amicum, aut familiarem, aut beneuolum habere, neque etiam in uirum liberum, et qui loquendi libertate uteretur, unquam incidisse, qui uera monendo, te quamprimum expediret, a morbo isto intercutaneo, quo quidem correptus es, et prae malo illius periculum, ne disrumparis, sustines. Tibi autem bene sanus esse uideris, et calamitatem istam, ualetudinem censes, atque ab imperitis laudaris, qui morbum tuum ignorant, a doctis autem miseratione dignus existimaris.'

Il confie alors notre homme au médecin Sopolis, et, après que Lexiphanès a accepté de prendre un vomitif, il évacue cette lie de paroles ${ }^{85}$.

Mais ce remède tient du comique, et ne fait rien pour la guérison. Pour ceux qui se plaisent à ce genre de discours [genere dicendi], il n'existe qu'un seul remède vraiment excellent et en même temps vraiment utile: c'est de s'accoutumer aux meilleurs auteurs, qui leur insuffleront à la fois la juste mesure [moderatio] et un style sain. Selon Aulu-Gelle, le philosophe Favorinus dit à un jeune homme très curieux de mots anciens et émaillant les conversations quotidiennes et ordinaires de vocables trop antiques et inconnus: "Curius, Fabricius et Coruncianus, hommes de la plus haute antiquité, et, plus anciens qu'eux, les Horaces, les trois jumeaux, s'entretenaient simplement et clairement avec les leurs, et, sans emprunter leur vocabulaire aux Aurunques, aux Sicanes ou aux Pélages qui, dit-on, furent les premiers habitants de l'Italie, ils parlèrent la langue de leur temps. Toi, comme si tu t'entretenais avec la mère d'Évandre, tu te sers d'un langage désuet depuis bien des années, car tu veux que personne ne comprenne et n'entende ce que tu peux dire. Pourquoi, homme incongru, afin d'y réussir largement, ne gardes-tu le silence? Mais tu prétends que l'antiquité te plaît pour être belle, morale, frugale et sage. Vis donc suivant les mœurs du passé, parle avec les mots d'à présent $^{86}$ \#. Et c'est ainsi que peuvent se soigner ceux qui souffrent d'enflure, si du moins ils le veulent. Chez la plupart d'entre eux, il y a plus de folie, mais aussi, plus de fonds : on est toujours plus près de la santé, quand on peut être guéri par quelque saignée ${ }^{87}$.

Mox hominem committit Sosipoli medico, a quo uomitorio accepto, istam uerborum sentinam egerit.

Hoc quidem remedium comicum est, et nihil ad sanitatem facit. [59b] Unum autem praestantissimum, idemque utilissimum erit, si qui eiusmodi dicendi genere delectantur, 
optimis auctoribus assuescant, a quibus, et moderatio, et styli affletur salubritas. 'Phauorinus Philosophus (ut ait Gellius) adolescenti ueterum uerborum cupidíssimo, et plerasque uoces, nimis priscas, et ignotissimas in quotidianis, communibusque sermonibus expromenti, Curius, inquit, et Fabricius, et Coruncanus, antiquissimi uiri nostri, et his antiquiores Horatii illi trigemini plane, ac dilucide cum suis confabulati sunt: neque Auruncorum, et Sicanorum, aut Pelasgorum, qui primi incoluisse Italiam dicuntur: sed aetatis suae uerbis loquuti sunt: Tu autem perinde, quasi cum matre Euandri loquare, sermone abhinc multis annis iam desito uteris: quod scire, atque intelligere neminem uis, quae dicas. Nonne homo inepte, ut quoduis abunde consequaris, taceres? sed antiquitatem tibi placere ais, quod honesta, et bona, et sobria, et modesta sit. Viue ergo moribus praeteritis, loquere uerbis praesentibus.' Et ita quidem possunt inflati sanari, si uelint, quorum multi, 'plus habent furoris, sed plus etiam corporis. Semper autem ad sanitatem procliuius est, quod potest detractione curari'.

\section{Chap. III. De la cacozélie / De cacozelo} nombreux traits communs avec le style enflé, et on les confond parfois, malgré leurs différences. Je ne m'appesantirai pas ici sur la cacozélie, parce que sa vraie place est dans un traité sur l'imitation: il s'agit d'un discours trop affecté, défaut dû à une mauvaise imitation. Lucien le dit bien: la cacozélie, c'est le fait de dépasser la mesure de l'imitation et forcer le trait ${ }^{89}$.

Quae sequuntur orationis uitia, cacozelum, ac frigidum, magnam habent cum inflato affinitatem, et nonnumquam inter se confunduntur, differunt tamen nonnihil. Atque, ut de cacozelo dicam obiter, quod plenius in tractatu de imitatione explicandum est, Est praua affectatio orationis, ducta ex errore uitiosae imitationis : quod indicat Lucianus his

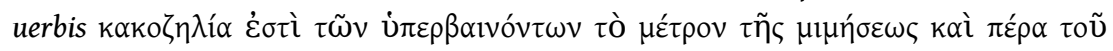

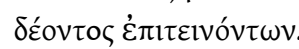

41 C'est pourquoi la cacozélie est presque toujours enflée, ou froide, ou quelque chose de similaire, alors que tout style enflé ne relève pas de la cacozélie, puisque ce dernier peut aussi bien ne pas provenir d'une imitation. Par exemple, si quelqu'un lit chez Virgile : un antique rocher, énorme, soulevé par Turnus ${ }^{90}$, et qu'après cela, dans une autre circonstance, il veuille l'imiter et dise qu'il y avait une roche, où les chèvres allaient même pour paitre, après avoir prononcé je ne sais quelle fadaise en rivalisant avec le poète grec $^{91}$, alors surgit ce monstre de l'imitation que l'on appelle cacozélie. Ainsi, Lucien, lorsqu'il décrit la métamorphose d'un homme en âne, le fait avec beaucoup de grâce: Tous mes doigts disparurent je ne sais où, et il ne me restait plus au total que quatre ongles, qui n'étaient autres que des sabots. Mes mains et mes pieds étaient devenus les pattes d'un animal, mes oreilles s'étaient allongées et mon visage était énorme $e^{92}$.

Itaque omne cacozelum ferme tumidum est, aut frigidum, aut quid simile, non omne tamen tumidum, est cacozelum, cum praesertim possit ex imitamentis esse non expressum. Itaque, si quis apud Virgilium legens ; 'sublatum a Turno saxum antiquum ingens': hoc postea in alio argumento imitatus dicat fuisse scopulum, cui caprae etiam pascentes insidebant, nescio quid nugarum, cum Graeco poeta nugatus, tunc fit prodigium illud imitationis, quod

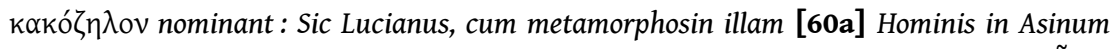

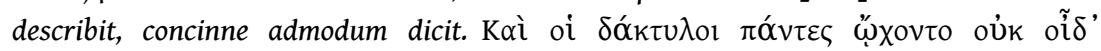

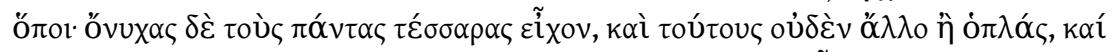

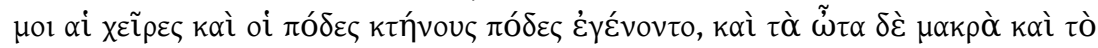

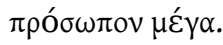

Mais Apulée, non content de ce discours plein de douceur, dit : Mes oreilles grandissent démesurément et se hérissent de poils ${ }^{93}$, et autres formules semblables, qui rendent le 
discours démesuré et rugueux. Veux-tu encore un exemple, particulièrement remarquable, de cette cacozélie? On connaît la fameuse histoire du peintre Parrhasius $^{94}$ : il avait peint un adolescent portant des grappes de raisin, avec tant d'ingéniosité et d'habileté que des oiseaux, trompés par cette image, volaient à elles, et de leur bec fripon s'en approchaient; et pourtant, le peintre, poussé par un orgueil sincère, maudit son œuvre, en disant que l'enfant ${ }^{95}$ n'était pas assez bien peint, puisque les oiseaux n'avaient pas peur de lui. Le rhéteur Spyridion, à la lecture de ce trait, voulut l'imiter. Que fit-il donc? Il pensait à cette Controverse où il est raconté que Parrhasius aurait torturé cruellement un pauvre vieillard olynthien afin de tirer de ce visage tourmenté par d'atroces souffrances l'expression de Prométhée déchiqueté sur le Caucase, et aurait ensuite consacré ce tableau au temple de Minerve ${ }^{96}$.

At Apuleius non contentus hac lenitate sermonis; Aures, inquit, immodicis horripilant auctibus, et caetera similia, quae uastam, atque horridam faciunt orationem. Vis aliud cacozeliae exemplum praeclarissime expressum? Extat notissima de Parrhasio pictore historia, qui adolescentulum uuas ferentem, tanta ingenii, artisque subtilitate depinxit, ut aues imagine delusae, aduolarent, rostrisque improbulis racemos appeterent; quanquam ille ingenuo fastu opus suum damnauit, quod non uideretur puer satis eximie depictus, ut quem aues aduolantes non timerent. Hoc cum legisset Spiridion Rhetor uoluit imitari. Quid agit? controuersiam illam agitabat, in qua Parrhasius dicitur miserum senem Olynthium saeuissime cruciasse, ut ex eius ore, inter acerbissimos cruciatus aestuantis, Prometheum in Caucaso laniatum exprimeret, et hanc deinde tabulam in Mineruae templo consecrasse.

Spyridion, comme il louait la main de cet excellent artiste, et la beauté de ce tableau si raffiné, fut tellement transporté qu'il dit que, lorsque ce tableau de Parrhasius fut placé dans le Parthénon, de toutes parts les vautours volaient à lui en grand nombre, croyant voir un cadavre déchiqueté. Tous les orateurs qui étaient présents trouvèrent ce discours froid et fondé sur une insigne cacozélie. Vraiment ? Des vautours auraient volé dans ce sanctuaire d'Athènes si fameux, alors qu'il avait un toit et qu'il était fermé ? À moins peut-être que Spyridion n'ait pensé que les vautours fréquentent les temples situés dans la lumière des villes, tout comme les moineaux et les hirondelles, et que parfois ils pénètrent par une ouverture ${ }^{97}$.

Spiridion, cum praestantissimi illius artificis manum, et exquisitissimae tabellae decus uerbis commendaret, eo usque prouectus est, ut diceret, ad hanc Parrhasii tabulam, cum esset in Parthenone posita, uultures undique laniatum, cadauer ratos, frequentes aduolasse,

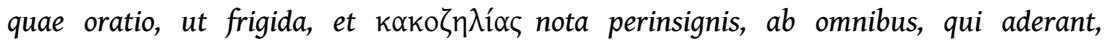
declamatoribus est excepta. Qui fieri enim poterat, ut uultures in celeberrimum istud Atheniensium fanum, cum esset undique tectum, et clausum aduolarent? nisi forte putauit, uultures, templa in luce urbium posita, non secus, ac passeres, et hirundines frequentare, atque in ea sese aliquando per foramina penetrare.

Combien de sottises de ce genre parviennent chaque jour aux oreilles des enfants! Dès qu'ils ont lu ou entendu quelque chose, ils s'empressent de l'imiter, sans se demander si les deux situations qu'ils mettent ainsi en parallèle se répondent, avec des circonstances semblables. Aussi, ceux pour qui l'imitation devrait être particulièrement profitable et formatrice tombent finalement dans l'erreur, par manque de jugement et d'esprit.

Quam multa similia quotidie admittuntur a pueris, qui cum aliquid legerint, aut audiuerint, statim in imitationem trahunt, id minime ponderantes, an res, quae comparantur, similibus inter se adiunctis congruant. Ex quo fit, ut ab imitatione, qui plurimum iuuari, conformarique deberent, iudicii, et mentis penuria saepissime deriuent errorem. [60b] 


\section{Chap. IV. Du style froid / De stylo frigido}

\section{[1. Définition et considérations générales]}

Démétrios de Phalère, par exemple, en atteste : Souvent, l'idée est froide en elle-même et, comme nous disons maintenant, affectée. Aristote, de même, appelle froids les mots enflés ${ }^{98}$. Et Longin ajoute, après avoir traité du style enflé et du style puéril : Le second défaut dont nous parlions, je veux dire la froideur, abonde dans les écrits de Timée ${ }^{99}$. Mais si nous voulons approfondir le sujet, nous verrons que le style froid, qui a été commenté par Longin luimême, est plutôt lié aux pensées nouvelles, étrangères et empruntées qu'à l'enflure des mots; on n'appelle pas froid ce qui est languissant et distendu (car d'ordinaire, rien ne paraît plus chaud aux esprits qui affectent cette recherche $d u$ nouveau $\left.{ }^{100}\right)$, non: on appelle froid tout ce qui est mauvais et nuisible à l'équilibre qu'est la santé, comme le note Servius dans son commentaire des Bucoliques de Virgile ${ }^{101}$. Ainsi, ce qui corrompt un bon équilibre équivaut au froid: il a été appelé ainsi par emprunt au vocabulaire médical. On l'appelle aussi gorgeion, parce que l'on raconte que le sophiste Gorgias abusait de ce genre de pensées. Pourtant, ce que Denys ${ }^{102}$, Longin et Hermogène ${ }^{103}$ critiquent tant, à propos des tombeaux vivants, ne semble pas si saugrenu. Le Comique Aristophane, lui, évoque non seulement la froidure, mais même les neiges que répandrait le style d'un poète inepte, quand il écrit ces mots : s'il n'était tombé tant de neige que la Thrace entière en fut couverte. Suidas le commente en disant: pour railler [Théognis], il nous parle d'une neige abondante, à cause de la froidure de ses poèmes ${ }^{104}$.

Frigidum quoque saepe cum ipso cacozelo misceri, testis est, uel hic Demetrii Phalerei locus.

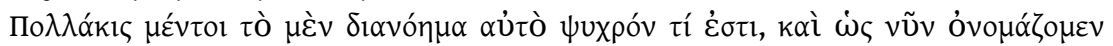

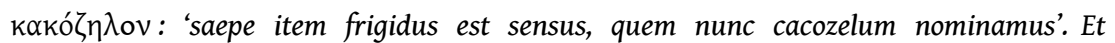
Aristoteles inflata uerba uocat $\psi u x \rho \alpha ́$ : Longinus uero postquam de tumido, et puerili

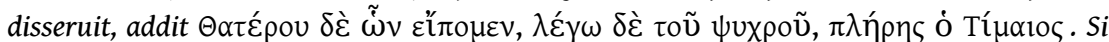
tamen disquisitius enucleare uelimus, inueniemus frigidum, quod ab ipso Cassio annotatum est, esse magis circa nouos, hospites, et peregrinos sensus, quam circa tumorem uerborum; frigidum autem appellatur, non quod languidum sit, et remissum (nihil enim ferme istis

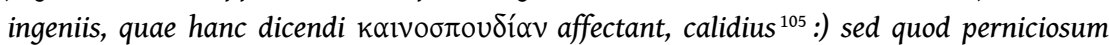
quodlibet, et nocens temperaturae, ut annotat Seruius ad Bucolica Virgilii, uocetur

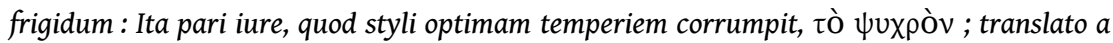
Medicis nomine, est appellatum. Aliter yopүeĩov, nominatur, quod Gorgias sophista, multus in his sensibus fertur extitisse. Quanquam, quod Dionysius, Longinus, et Hermogenes adeo exagitant, de animatis sepulchris, non ita uideatur absurdum. Aristophanes autem Comicus non modo frigus, sed et niues, stylo alicuius inepti poetae inspersas commemorat

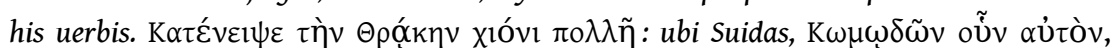

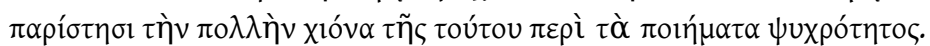

De ces considérations ${ }^{106}$, il ressort que le style froid est celui qui recherche des pensées nouvelles: nouvelles et étranges ${ }^{107}$, et j'ajoute même affectées. L'enflure, qu'elle porte sur les choses ou sur les mots, est supportable avec tout son vacarme, quand elle a une forme de grandeur ; la cacozélie est souvent languissante, parce qu'elle est défectueuse et déplaisante ; le style froid, lui, répand des pensées contournées et emportées, qui sont pour ainsi dire le fruit d'un esprit avide de nouveauté, et dépourvues de la lumière du bon sens.

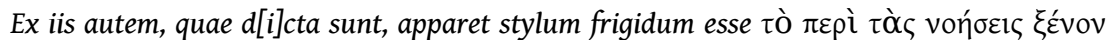
'eum, qui constat sensibus nouis, et peregrinis', addo etiam putidis. Inflatus rerum, et uerborum strepitus ferri solet, cum aliqua specie magnitudinis: Cacozelus in infelici, et 
aerumnosa imitatione consenescit: frigidus tortos, et uiolentos sensus; ueluti nouatoris ingenii foetus, iudicii lumine orbatos egerit.

\section{[2. Exemples tirés de l'antiquité païenne]}

Alexandre, le compare avec Isocrate, et fait fortement valoir que le premier ait soumis l'Asie en moins d'années qu'il n'en a fallu à Isocrate pour composer son seul Panégyrique. Le critique le raille en s'exclamant: Étonnante comparaison, certes, entre le héros macédonien et le rhéteur ${ }^{110}$ ! À en croire cette froide pensée, Isocrate était donc censé être bien plus courageux que toute la République des Lacédémoniens, puisqu'il mit dix ans pour terminer son Panégyrique, alors qu'il leur en fallut trente pour prendre la ville de Messène ${ }^{111}$.

Alterum exemplum profertur a Cassio Longino, quod sumptum est ex Timaeo. Quippe, hic Alexandrum magnis laudibus efferens, cum Isocrate comparat, et uehementer commendat, quod paucioribus annis Asiam subegerit, quam unam orationem Panegyricam scripserit

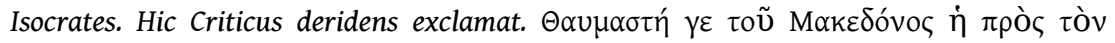

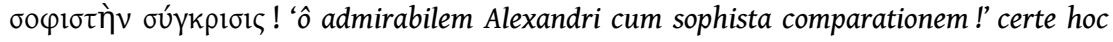
frigido hominis sensu, Isocrates tota Lacaedemoniorum Republica longe fortior haberetur, quando intra decennium Panegyricum absoluit; At illi, non nisi intra annorum triginta spatium, Messenam expugnarunt.

Le troisième exemple est du même acabit: à propos de la défaite des Athéniens en Sicile, qui fut l'œuvre d'un certain Hermocrate, Timée s'exclame : C'est bien la marque de la volonté divine si les Athéniens, qui avaient mutilé les statues d'Hermès, reçurent le châtiment de cette impiété de la main d'Hermocrate, le fils d'Hermon ${ }^{112}$. Longin juge que ces propos sont froids et déplacés, alors qu'il eût été facile de les excuser.

Tertium est ex eadem officina, concisis Sicula clade Atheniensium uiribus, opera cuiusdam Hermocratis, exclamat, Non sine magnae mentis consilio factum esse, ut Athenienses, qui in Mercurii statuas fuerant impii, per Hermocratem filium Hermonis, uiolatae religionis poenas persoluerent. Haec frigida, et inepta Longinus iudicat, quae tamen excusari facile possent. 


\section{[3. Exemples tirés de la Bible]}

51 Mais dans ce genre, rien n'est plus puéril que les auteurs hébreux qu'on appelle rabbins, dont les écrits regorgent d'exemples de pensées froides au ridicule achevé, comme dans ce passage où le commentateur du psaume 61 écrit : Les bêtes sur les montagnes, ainsi que les boeufs, le texte hébreu portant Behemot beharre aleph, Les bêtes sur les montagnes mille; le froid commentaire raconte qu'il n'y avait eu qu'une seule bête, d'une taille prodigieuse, désignée au pluriel par le prophète, et que Dieu lui avait attribué, pour sa nourriture quotidienne, les herbes de mille montagnes ${ }^{113}$.

Sed in hoc genere nihil est Hebraeorum scriptoribus, quos Rabinos uocant, infantius, apud quos frigidorum sensuum exempla, et plurima sunt, et maxime ridicula, quale illud est eius, qui in haec uerba psal. 61. scribens, Jumenta in montibus, et boues : ubi textus Hebraeus habet Behemot beharre aleph בהמות בהררי אלף Jumenta in montibus mille, hic frigidus commentarius belluam unam fuisse uastissimam narrat, plurali numero designatam a Propheta, cui ad diurnum pabulum, mille montium herbae a Deo essent assignatae.

52 Un autre, à propos de ce passage (Exode, 4), Je t'en supplie, Seigneur, je ne suis pas un homme éloquent ${ }^{114}$, commente en disant que Moïse, à trois ans, fut présenté au Pharaon, et que le roi, charmé par le caractère de cet enfant doux comme le miel, lui posa la couronne sur le front par jeu ; mais Moïse l'ayant jetée à terre et foulée aux pieds, on considéra ce geste comme un funeste présage ; et comme la fille du roi l'avait attribué à l'ignorance de l'enfant, le Pharaon suivit le conseil habile d'un des plus sages Hébreux, pour s'assurer de l'innocence du bambin et savoir s'il avait agi avec ou sans jugement : on présenta à l'enfant des charbons ardents, et lorsqu'il les eut portés à sa bouche, il se brûla le bout de la langue et devint à jamais bègue et hésitant ${ }^{115}$.

Alius in illud Exod. 4 Obsecro Domine, non sum eloquens, commentatur Mosen, cum esset trium annorum puer, Pharaoni fuisse oblatum, delectatumque Regem melliti infantis indole, diadema illi inter ludendum imposuisse, quod cum Moyses deiecisset in terram, pedibusque conculcasset, id pro infausto quodam omine acceptum; cumque [61b] Regis filia tribuisset infantis inscitiae, de consilio, et industria uiri apud Hebraeos imprimis sapientis, ad explorandam pusionis simplicitatem, sciens-ne illud, an imprudens fecisset? prunae illi ardentes sunt appositae, quas cum ore contigisset, inde extremae linguae adustionem, perpetuamque balbutiem, atque haesitantiam contraxit.

Sont sujets à ce vice ceux qui recherchent partout dans les Écritures saintes des sens allégoriques et déforment tout ce qu'ils lisent pour en faire des images qu'ils ont inventées eux-mêmes. Origène et Philon ${ }^{116}$ en abusent généralement : à cause de leur goût pour les allégories, ils sont très souvent contraints de tomber dans le froid.

Huic uitio obnoxii sunt, qui in sacris literis allegoricos ubique consectantur sensus, et omnia in eas, quas sibi finxerunt imagines efformant. Qua in re nimii sunt plerunque Origenes, et Philo, qui allegoriarum studio, in frigida saepissime deferri coguntur.

En effet, même si les allégories peuvent avoir une douceur agréable et fleurie, cependant, quand elles sont trop nombreuses et emportées, elles ne peuvent que déplaire à des oreilles bien éduquées. Car qui pourrait aimer de telles interprétations ${ }^{117}$ ? «Le Portique de Salomon est la conversation du Christ ${ }^{118}$. L'étoile Arcturus est la loi du Nouveau Testament, et les Pléiades en sont la grâce ${ }^{119}$. Les joncs sont les jugements pénétrants des saints ${ }^{120}$. La salive est le goût de la contemplation intime ${ }^{121}$. Les chèvres sauvages sont les maîtres spirituels ${ }^{122}$. Le saphir, les évangélistes ${ }^{123}$. La perdrix, le diable ${ }^{124}$. Les moustiques, les dialecticiens ${ }^{125}$. J'admets que cette dernière comparaison, de la part d'Origène, est exprimée avec une certaine pénétration : cet animal vole dans les airs et il 
est si fin et menu qu'il échappe à nos yeux, à moins qu'on ne le regarde avec attention; pourtant lorsqu'il se pose sur notre corps, il le pique cruellement, si bien que celui qui ne pouvait le voir voler, ressent la vive impression de sa piqûre.

Cette espèce d'insecte, dit-il, je pense qu'on peut tout à fait la comparer à l'art de la dialectique, qui pique nos esprits par les menus et subtils aiguillons de ses mots, tout en trompant les yeux de notre intelligence ${ }^{126}$.

Nam, etsi allegoriarum grata sit, ac uernans amoenitas, ubi tamen nimis crebrae sunt, et uiolentae, placere doctis auribus nullo modo possunt. Cui enim semper istae interpretationes arrideant? Porticus Salomonis, est conuersatio Christi. Arcturus lex, et Pleiades noui testamenti gratia. Sudes acuta sanctorum consilia. Saliua intimae contemplationis sapor. Ibices magistri spirituales. Sapphirus praedicatores noui testamenti. Perdix diabolus. Scynifes Dialectici : quanquam hoc postremum subtiliter ab Origene dictum; 'Hoc enim animal pennis quidem suspenditur per aera uolitans, sed ita subtile est, et minutum, ut oculi uisum, nisi acute cernentis effugiat, corpus tamen cum insederit, acerbissimo terebrat stimulo, ut quem uolitantem uidere quis non ualeat, sentiat stimulantem.'

'Hoc ergo animalis genus (inquit) dignissime puto arti Dialecticae comparari, quae minutis, et subtilibus uerborum stimulis animos terebrat, et intelligentiae oculos decipit.'

\section{Chap. V. Du style puéril / De stylo puerili}

\section{[1. Définition et premiers exemples (puérilité des mots)]}

Le style puéril est proche des précédentes catégories, et Longin le nomme mauvais, petit et sans nobless ${ }^{127}$. Il tient en effet de l'enflure, de la cacozélie, et s'accompagne d'une multitude d'expressions froides; mais ce qu'il a de particulier, c'est qu'il recherche le plus avidement possible une vaine douceur, plus stérile que les jardins d'Adonis ${ }^{128}$. C'est pourquoi les pensées en sont d'ordinaire inconsistantes, avec un attrait pour le plaisir le plus superficiel, de pauvres jeux d'esprit, des digressions inappropriées, des jeux de mots, des descriptions artificielles, des figures exubérantes, peu de jugement, des répétitions dans le discours, un entassement de mots plein d'ostentation, et un agencement affecté de rythmes et de périodes. Ce passage de Mécène, plus efféminé que son auteur lui-même, en offre un exemple. Voit-on rien plus net et plus pur ${ }^{129} q u$ ' « une rivière et les forêts qui épandent leur chevelure sur la rive»? Vois comme "ils sillonnent son canal avec gondoles, et laissant le plus profond de l'eau, vont se récréer dans les jardins ». Que si quelque femme "se frise les cheveux, de ses lèvres elle baise comme font les colombes, elle commence en soupirant, elle se traîne le col lâche et penché" "Pas un des tyrans, faction contre laquelle il n'y a nul remède, n'épient: ils essayent à prendre les maisons par banquets et bouteilles et tâchent à les faire mourir. " «La mère ou la femme investissent le Genius, qui n'est à grand' peine témoin de sa fête, et les filets d'un cierge, et le foyer dans lequel la fouace craquète. »

Quels jeux d'enfants! En lisant de pareilles choses, dit Sénèque, ne songeras-tu pas aussitôt : voilà celui qui toujours s'avançait dans Rome en tuniques dénouées ${ }^{130}$ ?

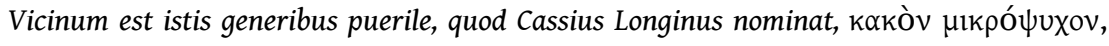

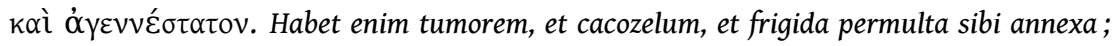
hoc autem proprium obtinet, ut inanem quamdam suauitatem, Adonidis hortis steriliorem quam auidissime uenetur. Itaque sensus in eo ferme sunt tenuiculi, cum aliqua illecebra uanissimae iucunditatis, lusus minuti, digressiones ineptae, allusiones ad uerba, affectatae rerum descriptiones, luxuriantes [62a] figurae, inopia iudicii, redundantia sermonis, uerba 
undique ad ostentationem collecta, et rhytmorum, circumscriptionumque putida elaboratio. Talis est ista Moecenatis, authore suo mollior oratio.

Quid purius 'amne siluisque ripa comantibus'? Vide ut 'alueum lintribus arent uersoque uado remittant hortos'.

Quid si quis 'foemina cirro crispat, et labris columbatur : incipitque suspirans, ut ceruice laxa feratur. Nemo tyranni, irremediabilis factio, rimantur epulas, lagenaeque tentant domos, et saepe mortem exigunt.

Genium festo uix suo testem, tenuis cerei fila, et crepacem mola focum mater, aut uxor inuestiunt.'

Quae pueritiae ludicra? Num statim haec cum legeris (inquit Seneca) hoc tibi occurret, hunc esse, qui solutis tunicis in urbe semper incesserit.

Âmelette, vaguelette, tendrelette,

Hôtesse et compagne de mon corps

Vers quels lieux maintenant vas-tu aller

Palotte, raide, toute nue,

Sans désormais le goût de la moquerie ${ }^{131}$ !

Ou bien ces mots d'Apulée : Il avait les cheveux longs, un visage gracieux, une peau douce, de jolies boucles qui tombaient en gracieux anneaux sur son front. Un vêtement de fine étoffe, douce au toucher, et teinte d'un pourpre éblouissant. Et qu'importe sa lyre éblouissante d'or, éclatante d'ivoire et aux miroitements de diamant ${ }^{132}$ ?

Adiunge huic molliculae orationi, Hadriani Imperatoris uersus.

Animula, uagula, blandula,

Hospes, comesque corporis,

Quae nunc abibis in loca,

Pallidula, rigida, nudula :

Nec ut soles dabis iocos.

Aut Apuleii : 'Erat intonsus, et genis gratus, et corpore glabellus. Crines eius praemulsis antiis, promulsis caproneis anteuentuli, et propenduli. Vestis textu tenuis, tactu mollis, purpura radians. Quid ? quod et lyra eius auro fulgurat, ebore candicat, gemmis uariegat.'

Ces discours sont des hochets, qui ne peuvent amuser que les petits garçons. Mais que des hommes plus avancés en âge se laissent aller aux inepties que nous venons de citer, voilà qui est intolérable.

Ce qui souvent donne naissance à ces fadaises, c'est l'amour, et l'état d'hébétude où se trouve un homme assiégé par les vices : on voit bien ces froids jolis-cœurs rechercher avidement ces discours extravagants dans les livres en langue vernaculaire : ils pensent qu'en agitant leurs roses et leurs anémones ${ }^{133}$, ils répandent leur si agréable parfum. Mais elles empestent plus que les écuries d'Augias ${ }^{134}$.

Haec plane crepundia, quibus permittuntur aliquando pusiones lusitare. At uero iam prouectae aetatis homines, in eas ferri nouissimorum uerborum ineptias, minime tolerandum est.

Saepe istarum nugarum parens est amor, et uitiis obsessae mentis hebetudo : quippe uideas istos frigidos amatorculos, ex libris uernacula lingua scriptis, haec deliramenta auide conquirere, quae illi rosas suas, et anemonas dum uentilant, putant odorem omnium naribus periucundum afflari : sed haec ita foetent, ut Augaeae stabulum non sit impurius.

\section{[2. Exemples : puérilité des pensées]}

61 Il existe un autre type de discours qui n'est pas puéril par les paroles, mais par les pensées; ainsi, ce discours d'une ânesse à son mari qui émasculait leur petit a fait tomber dans la puérilité un poète par ailleurs doué : Mon époux, mon époux, pourquoi ton 
visage est-il maintenant dur et tes yeux rouges, alors qu'ils étaient autrefois resplendissants? Ce n'est pas le visage de Méduse qui pétrifie que tu as vu de tout près (apparemment, cette ânesse connaissait le mythe de Méduse, et avait jadis fréquenté les académies poétiques), ni l'enfant venimeux d'une cruelle femelle dragon, ni l'injuste petit d'une lionne montagnarde, mais bien l'enfant que moi, malheureuse, je mis au monde et pour lequel nous avons prié les dieux. Tu ne vas tout de même pas enlever le membre viril de ton fils avec tes propres mâchoires? Arrête, mon ami! Ne le mutile pas! Pourquoi l'as-tu mutilé ? Qu'as-tu fait? $\mathrm{Tu}$ as fait de l'enfant un moins que rien, tu as rendu son corps entièrement aveugle! Me voilà malheureuse et infortunée dans mon accouchement inopportun et toi, mon fils, te voilà misérable par le fait de ton criminel géniteur! Malheureuse que je suis, trois fois misérable, moi qui ai souffert l'accouchement en vain et toi, mon fils, mutilé, non par les griffes des lions, mais par les odieuses mâchoires léonines d'un père ${ }^{135}$.

Alia est etiam non uerbis, sed sensibus puerilis oratio : qualis est ista Onagri foeminae ad marem foetum suum euirantem, his uerbis expressa, quae bonum alioqui poetam, ad inclinatam puerilitatem dimisit.

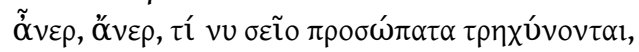

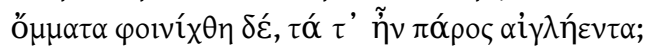

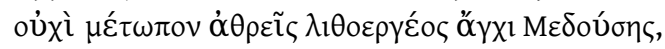

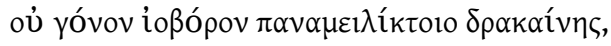

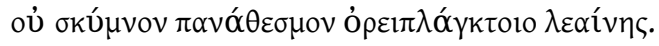

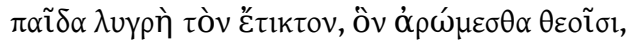

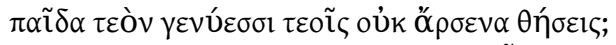

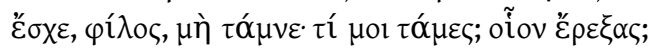

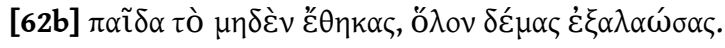

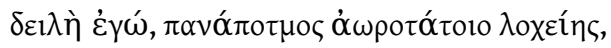

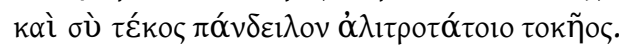

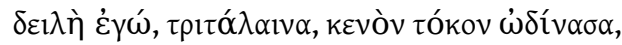

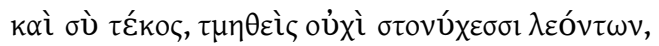

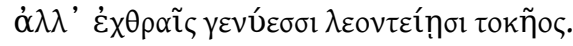

Vir, uir, quare tuus uultus exasperatur? Oculi rubuerunt, qui prius erant splendidi? An frontem intueris saxificae Medusae? (Sciebat quippe hic Onager Medusae fabulam, et scholas olim poeticas frequentarat.) Non foetum ueneficum efferi Draconis, Non catulum nefandum montiuagae Leaenae?

Filium, misera quem peperi, quem exorauimus a Diis.

Filium tuum maxillis tuis euirabis.

Cohibe te, amice : ne scinde, quod resecuisti, qualem Fecisti filium? ad nihilum redegisti, toto corpore mutilatum Misera ego, atque aerumnosa, intempestiuum ob partum !

Et tu fili miserrime, sceleratissimi parentis caussa!

Misera ego, ter misera, inanem partum enixa,

Et tu fili dissectus, non unguibus Leonum ; Sed inimicis maxillis Leonininem parentis.

Arrêtons là cette lamentation pathétique, et vraiment puérile: lorsque l'ânesse fait mention de Méduse qui pétrifie, lorsqu'elle dit avoir prié les dieux pour son fils, et semblables fadaises, qui peut se retenir de rire? Mais, dira-t-on, des auteurs d'importance n'ont-ils pas souvent écrit ce genre de choses ? Je le reconnais, mais ils ne les mêlent pas à leurs œuvres sérieuses ; au contraire, ils disent clairement que ces récréations puériles, ces fables et ces jeux ont été composés pour rire. En revanche, ceux qui tiennent ces discours avec sérieux et savoir-faire, et qui ont l'habitude de les mêler à des poèmes fort nobles, non par jeu, mais pour montrer leur éloquence, ceux-là 
se comportent, à mon avis, de manière puérile. Ce sont en effet des vices dans lesquels les jeunes gens, toujours légers dans leur usage des hyperboles, tombent trop souvent: s'ils composent un poème ou une oraison funèbre sur la murène de Crassus ${ }^{136}$, ou sur le perroquet de Melior $^{137}$, alors que tous ces sujets devraient être traités dans un style à la sécheresse élégante, ils recourent aux figures imposantes de Démosthène et de Cicéron. Un perroquet, vous dis-je, ou un moineau, ils le loueront comme un héros, et feront même de lui le compagnon de Minos et de Rhadamanthe aux champs Élysées, en répétant le mot de Démosthène: On peut sans invraisemblance dire qu'ils sont les assesseurs des dieux d'en-bas ${ }^{138}$. Et bientôt ils s'adresseront à lui par une apostrophe: Et toi, traitée admirablement de ton vivant, ô âme si délicate, tu l'es de même aujourd'hui, ô âme très sainte, après ton envol loin de cette terre: car ayant rejoint le séjour des bienheureux, tu sièges au côté de Proserpine.

Hactenus lamentabilis naenia, et uere puerilis : cum enim mentionem facit Onager saxificae Medusae, cum dicit 'se filium a Diis exorasse', et similes nugas, quis risum teneat? At dices, nulla saepe eiusdem argumenti, a uiris grauibus esse conscripta? fateor equidem, sed huiusmodi, si quae scribunt, non seriis operibus immiscent: uerum pueriles remissiones, et fabellas, et ludos ad risus compositos profitentur. At, qui haec serio, et callide dicunt, carminumque grauitati, non ioco, sed eloquentiae ostentandae gratia solent intexere, pueriliter mea quidem sententia, faciunt ; haec enim uitia sunt, in quae pueri, in hyperbolis semper leues, frequentius incidunt, qui si in Crassi muraenam, aut psittacum, Melioris carmen, uel orationem funebrem texant, cum omnia ad rotundam styli exilitatem deberent esse accommodata, illi ad grandes Demosthenis, et Ciceronis figuras conuertentur: psittacum inquam, uel passerem, ut heroem laudabunt, etiam apud Elysios campos Minois,

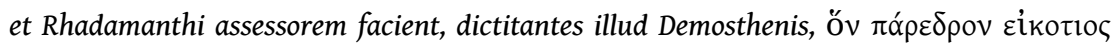

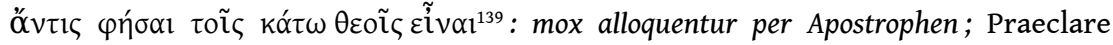
igitur, tecum actum est, dum uiueres, anima delicatissima, nunc autem, postquam ex his terris euolasti, sanctissima: nam beatorum locum consequuta, assides Proserpinae. [63a]

\section{Chap. VI. Du parenthyrson / De parenthyrso}

\section{[1. Définition et considérations générales]}

63 Le rhéteur Théodore ${ }^{140}$, cité par Longin dans son traité Du Sublime, mentionne le vice de style le plus fameux, qu'il appelle lui-même parenthyrson, parce qu'il se rapproche du thyrse, c'est-à-dire qu'il se trouve tout près de la fureur ${ }^{141}$. Chacun savait qu'on appelle thyrse le bâton orné de feuilles que portaient les bacchantes, et qu'il est l'éternel signe distinctif de Bacchus, conformément à ce que dit la formule épigrammatique : Biton a consacré à Pan un chevreau, aux Nymphes des roses, à Lyaios des thyrses ${ }^{142}$. C'est pourquoi on nomme thyrsoplèges ceux qui sont frappés par le thyrse, c'est-à-dire les fous. On peut donc appeler parenthyrson un discours dont les affects ont de la grandeur, mais sont inopportuns, et qui, tout en traitant d'une matière mince, est rendu fou par les figures. On peut inférer cette définition de ce passage où Longin décrit le parenthyrson : À côté de ce défaut [l'enflure], il en est un troisième qui concerne le pathétique. Théodore l'appelait le parenthyrson. C'est un pathétique inopportun et vide, dans un moment où il n'est pas de mise, ou démesuré là où il faut de la mesure ${ }^{143}$. Il se distingue du style puéril, parce que ce dernier, tout au plus, part à la chasse aux arguments plaisants et aux formulations séduisantes ; le parenthyrson, lui, réside fondamentalement dans les affects inopportuns de la plus grande douleur et de la plus grande colère, en laissant de côté toute attention aux mots. 
En effet, il ne vise pas ce genre d'élégance, mais seulement les figures de la grandeur, appliquées à une matière anodine : c'est en cela qu'il est plein de folie.

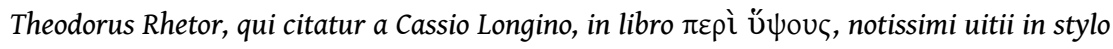
meminit, quod ipse appellat $\pi \alpha \rho \varepsilon ́ v \theta u \rho \sigma o v$, quasi ad Thyrsum accedens, hoc est, furori proximum. Norunt omnes Thyrsum appellari hastulam frondibus uestitam, quam

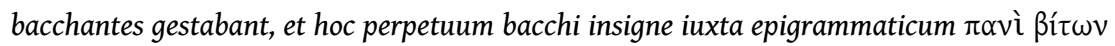

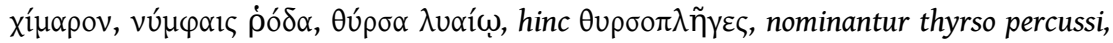
hoc est insani : unde parenthyrsum dici potest, Oratio grandibus, et intempestiuis affectibus, et figuris in re parua insaniens, quam definitionem licet colligere ex Dionysio Longino, in qua

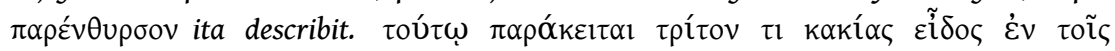

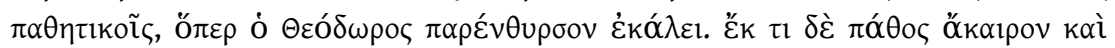

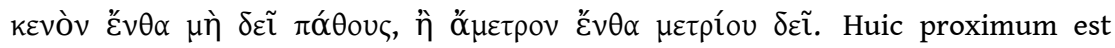
tertium prauitatis genus in affectibus, quod Theodorus uocat parenthyrsum : est autem affectus intempestiuus, et uanus, ubi nihil opus est affectu, uel immoderatus, ubi opus est moderato: differt a puerili, quod hoc in laetis argumentis, et illecebrosae dictionis aucupio uersetur, ut plurimum; illud propriam sedem habeat in affectibus intempestiuis, maxime doloris, et iracundiae, sine ulla etiam affectatione uerborum. Non enim istam concinnitatem spectat, sed grandes tantum figuras, in rebus ludicris consectatur : ex quo plenum est insaniae.

\section{[2. Exemples]}

Ainsi peut-on citer, à propos de l'incendie du temple de Daphné ${ }^{144}$, la lamentation pathétique du sophiste Libanios, que saint Chrysostome critique admirablement dans son discours sur saint Babylas martyr. Là, en effet, le sophiste se laisse entraîner sans mesure vers des affects pathétiques, déréglés, bas ou tendant vers le bas; dans l'emportement de sa douleur et de sa fureur il en vient à tenir un discours froid et inapproprié, comme lorsqu'il dit que l'empereur Julien, en entendant parler de l'incendie du temple, demanda les sandales ailées de Mercure pour se hâter d'éteindre les flammes $^{145}$. Car où devait-il les trouver? Assurément, l'aide allait être un peu tardive, s'il fallait attendre ces sandales ailées. Ainsi, alors que Libanios désire inspirer d'immenses émotions, il tombe dans des propos absurdes, plus susceptibles de provoquer le rire que la douleur.

Talis est illa, de incendio Daphnitici templi, miserabilis Naenia Libanii sophistae, quam diuus Chrysostomus egregie perstringit, in oratione de sancto Babyla martyre. Ibi enim sophista praeter modum fertur in miserabiles, inconditos, humiles, inclinatos affectus, et prae doloris, ac furoris impotentia, in frigida quaeque, et inepta transit, ut, cum dicit Iulianum Imperatorem, ubi de templi incendio afflauit eum rumor, quaesiuisse talaria Mercurii, ut ad flammam restinguendam properaret. Vbi tandem erat inuenturus? Certe tardum oportuit fuisse auxilium, si haec talaria sunt expectata. Ita dum motus cupit ingentes excitare, delabitur in [63b] absurda, quae risum potius, quam dolorem efficiant.

Usant du même style, le sophiste Aristide ${ }^{146}$, dans sa fameuse monodie pleine de larmes sur la chute de Smyrne, ajoute, entre autres lamentations : si les Gorgones ressuscitaient, elles ne pleureraient pas la Méduse, ni son œil, mais Smyrne, l'œil commun de toute l'Asie.

Eodem stylo Aristides sophista, in illa flebili monodia, de Smyrna collapsa, inter caeteras naenias addit: Si Gorgones reuiuiscerent, non iam Medusam, aut oculum suum flerent, sed Smyrnam, communem Asiae oculum deplorarent.

\section{[3. Caractérisation ${ }^{147}$ plus fine, suivie d'un nouvel exemple]}

Mais s'agit-il vraiment de pseudo-tragique ${ }^{148}$ et de parenthyrson? Analysons plus en profondeur les affects. 
D'autres sont encore plus fâcheux et déroulent leur discours de manière prétentieuse, en pleurant, en se fâchant, en jurant, ou en invoquant tous les dieux, toutes les déesses, pour des choses indifférentes, et qui ne sont presque rien. Ils demandent à leurs auditeurs, qui sont d'ordinaire des hommes froids et polis, pourquoi ils ne se lamentent pas, pourquoi ils ne s'indignent pas, pourquoi ils n'expriment pas leur horreur devant une telle abomination. Or, ces derniers ne sentent rien de tout cela, et restent assis bien tranquillement: ils disent que la pâleur et les larmes qu'ils remarquent, les lamentations qu'ils entendent sont le fait d'hommes qui ne sont pas plus émus que des statues.

Num uero ista $\pi \alpha \rho \alpha \tau \rho \alpha ́ \gamma \omega \delta \alpha$ et $\pi \alpha \rho \varepsilon ́ v \theta v \rho \sigma \alpha$ ? sed plenius in affectibus examinabimus.

Alii etiam magis importuni ambitioso orationis tractu, aut plorant, aut irascuntur, aut detestantur, aut Deos, Deasque omnes, in rebus ludicris, et pene nullis inuocant. Quaerunt ab auditoribus, hominibus plerumque frigidis, et urbanis, num lugeant, num indignentur, num auersentur, num tantum nefas abominentur? cum illi interim nihil horum experiantur, sed tranquilli omnino sedeant: Aduertere se dicunt pallorem, et lachrymas, et eiulatus eorum audire, qui non magis mouentur, quam statuae.

Assurément, ce type de style est particulièrement pitoyable et fou, et ce n'est pas pour rien qu'on le nomme parenthyrson, puisqu'il tient beaucoup du thyrse et de la fureur. Car être emporté, pour des sujets de peu d'importance, par le bouillonnement d'un esprit en folie, c'est comme imiter l'orateur qui, chez Apulée, devant trois outres perforées par un jeune homme ivre, plaide comme s'il défendait des jeunes gens assassinés, et dit :

"Le cas dont il s'agit, très honorables Quirites, n'est pas de petite importance; il y va de la paix de la cité entière qu'on en fasse un sévère et salutaire exemple. Il convient donc qu'individuellement et tous ensemble, comme l'honneur public le commande, vous ayez soin de ne pas laisser un infâme assassin échapper au châtiment de la sanglante tuerie à laquelle il s'est livré $^{149}$.»

70 C'est un fou rire général ${ }^{150}$. Sur ces entrefaites une femme éplorée traverse le théâtre en courant. Tout en larmes et vêtue de noir, elle portait un petit enfant sur son sein. Une autre la suivait, une vieille, couverte d'affreux haillons, pareillement navrée et comme elle pleurant. L'une et l'autre agitaient des rameaux d'olivier. Se plaçant au côté du lit où gisaient sous des voiles les cadavres des victimes, elles se mirent à pousser des lamentations et des hurlements lugubres:

71 "Par la pitié publique », disent-elles, "et le droit commun de l'humanité, ayez compassion de ces jeunes hommes indignement massacrés, et consolez en les vengeant notre abandon et notre solitude. Secourez au moins l'infortune de ce petit être laissé sans protection dès ses premiers ans; offrez le sang de ce brigand en expiation à vos lois et à l'ordre public ${ }^{151}$."

72 Ces paroles, si elles étaient prononcées sérieusement devant trois outres, constitueraient un excellent exemple de parenthyrson; mais comme elles ont été inventées pour faire rire et divertir le public, il s'agit de tout autre chose.

Hoc certe genus, inter caetera miserabile est, et insanum, nec immerito $\pi \alpha \rho \varepsilon ́ v \theta v \rho \sigma o v$ nominatur, habet enim multum de thyrso, et furore: Nam quid est aliud in rebus modicis? tam insanae mentis aestu iactari, quam Oratorem illum imitari, qui apud Lucium Apuleium pro tribus utribus, ab ebrio iunene multis ictibus perforatis, quasi pro caesis iunenibus perorat, et ait.

Neque parua res, ac praecipue pacem ciuitatis cunctae respiciens, et exemplo serio profutura tractatur, Quirites sanctissimi. Quare magis congruit, sedulos, atque uniuersos uos pro dignitate publica prouidere, ne nefarius homicida, tot caedium lanienam, quam cruenter exercuit : impune commiserit. 
Ad haec omnes 'risu dissoluuntur'. Mox 'quaedam mulier, per medium lachrymosa, et flebilis, atra ueste contecta, paruulum quendam sinu tolerans, decurrit; ac pone eam, anus alia pannis horridis obsita, paribusque moesta fletibus, ramos oleaginos utraeque quatientes, quae circumfusae lectulum, quo peremptorum cadauerum contecta fuerant, plangore sublato lugubriter eiulantes.'

Per publicam misericordiam, per commune ius humanitatis, aiunt, miseremini indigne caesorum iuuenum, nostraeque uiduitati, ac solitudini, de uindicta solatium date: Certe paruuli huius, in primis annis destituti fortunis succurrite, et de latronis huius sanguine legibus uestris, et disciplinae publicae litate.

[64a] Haec si pro tribus utribus serio dicerentur $\pi \alpha \rho \varepsilon ́ v \theta u \rho \sigma o v$ facerent manifestissimum ; sed cum ad risum, publicamque lasciuiam ficta sint, nihil habent istius generis.

73 Ce sont surtout les orateurs dont les pensées sont élevées, abondantes et amplifiées, qui tombent dans ce défaut : comme ils pensent qu'il est très louable de rehausser grâce à la majesté du discours des matières pauvres a priori, ils ne se contentent pas d'ajouter ponctuellement un peu de sel à ce qu'ils disent, mais ils transforment des grenouilles en Minerve, des Pygmées en Polyphème, bref : des choses très légères en cothurnes tragiques, ce qui prête à rire.

Porro in id saepe uitium incurrunt Oratores sensibus grandes, uberes, et amplificatorii, qui cum summae laudis esse existiment, res alioqui exiles orationis maiestate plenius attollere: hoc ne mica quidem salis adhibita faciunt in rebus singulis, et ranas in Mineruam, Pygmaeos, in Polyphemum, res denique leuissimas in cothurnos tragicos non sine risu deformant.

\section{Chap. VII. Du style d'écolier / De stylo scholastico}

\section{[1. Définition et considérations générales]}

Longin ${ }^{152}$ mentionne aussi la skholastikè noèsis, c'est-à-dire la pensée et le style d'écolier : on la rencontre quand un discours qui affronte la vie publique se plie de manière trop affectée aux minuties de préceptes réservés à la salle de classe. En effet, il arrive souvent que des jeunes gens, à peine sortis de l'école, ou même des hommes trop longtemps éduqués à l'ombre des collèges, alors qu'ils viennent de quitter la palestre pour l'armée ${ }^{153}$ et qu'ils ne sont pas encore habitués et formés à supporter le grand air de la vie publique, gardent je ne sais quelle mollesse de salle de classe, qu'ils ont sucée avec le lait. C'est pourquoi, avant d'en arriver au sujet principal, certains font des préliminaires trop ornés et s'étendent trop longuement. D'autres se lancent dans des digressions et des lieux communs : une fois qu'ils y sont installés, ils croient (comme on dit) qu'ils sont transportés par le char blanc de Jupiter ${ }^{154}$. D'autres encore exigent trop scrupuleusement pour chaque sujet un exorde, une narration, une confirmation, une péroraison, et, trop souvent, les font tous entrer dans leur discours, même s'ils sont froids et importuns, afin qu'on ne puisse pas leur reprocher d'avoir enfreint les règles de l'art. D'autres, sans se soucier nullement de savoir si leur discours se prête à l'ornement, y insèrent à toute force ${ }^{155}$ les figures de la grandeur, fruits de la cacozélie, jusqu'à en dégoûter l'oreille. D'autres même ne cachent nullement l'art ; ils rappellent leur exorde, leur narration, leur confirmation, etc., et promettent qu'ils vont faire une transition d'une partie à l'autre, ou disent qu'ils ont déjà fait cette transition, et en viennent à s'excuser de n'avoir pas assez perfectionné leur discours : tout cela sent l'école, et quand on soigne trop minutieusement ses discours, qu'on les arrange trop élégamment, on finit souvent par tomber dans le froid ou le puéril. 


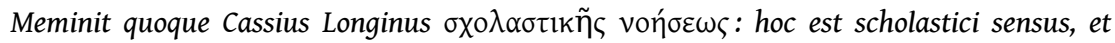
styli: fit autem, cum ea quae ciuilis esse debet oratio, ad umbratilium praeceptorum minutias putidiuscule conformatur. Accidit enim plerunque, ut adolescentes e ludo nuper egressi, uel etiam uiri scholarum umbris diutius innutriti, cum ex palaestra in aciem deuenerint, nondum ad ciuilis illius coeli tolerantiam facti, atque compositi, nescio quid umbraticae mollitiei, quam cum lacte suxerunt, retineant. Itaque alii antequam ad rem ueniant, praefantur apparatius, et excurrunt longius. Alii digressiones, et locos communes affectant, quibus cum insederint, arbitrantur se Iouis albis (quod aiunt) quadrigis uehi. Alii, in quocunque demum argumento exordia, narrationes, confirmationes, perorationes religiosius exigunt, atque ista quidem omnia, quamuis frigida, et importuna saepius ingerunt, ne uideantur artis legibus defuisse. Alii minime spectantes, an oratio ornatum

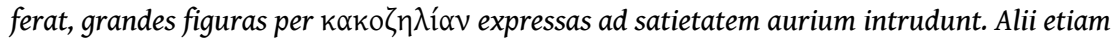
artem plenissime profitentur ; exordii sui, narrationis, confirmationis, etc. meminerunt, tum se ex una parte in alteram transituros pollicentur, aut iam transiisse dicunt, etiam excusant se, quod minus elaboratam orationem attulerint, quae omnia scholastica sunt, et ubi morosius curantur, elaboranturque concinnius, saepe in frigidum aliquid, aut puerile desinunt.

\section{[2. L'exemple d'Isocrate, dont son Panégyrique]}

75 Et en cela, je crois que les discours d'Isocrate sont très différents de ceux de Démosthène. En effet, ce dernier, et c'est cela l'essentiel, ne cherche pas du tout à paraître éloquent : il dit que le sort de la Grèce ne dépend pas de tel ou tel mouvement de sa main $^{156}$ - ou de son usage, pour prier, de tel ou tel mot. Mais Isocrate, lui, ne peut pas dissimuler son désir d'être éloquent, même dans ses discours sur les affaires. Ainsi, dans son discours délibératif à Philippe, il reconnaît être ambitieux dans sa vieillesse $e^{157}$ même et s'excuse de n'avoir pu formuler un discours très perfectionné, à cause de son grand âge : En effet nous ne l'avons pas même orné de la cadence et de la variété du style que j'employais quand j'étais plus jeune et dont j'ai donné l'exemple aux autres pour qu'ils rendent leurs discours à la fois plus agréables et plus convaincants. Mon âge m'empêche d'employer ces procédés ${ }^{158}$.

S'excusant sans qu'on le lui ait demandé, il s'accuse ${ }^{159}$.

Il commence même par parler très longuement de ses amis en racontant les jugements qu'ils ont émis sur ce discours : aucun d'entre eux n'est convaincant, et il les rapporte avec plus d'ostentation que de vigueur ${ }^{160}$.

Atque in eo, opinor, multum differunt ciuiles Isocratis, et Demosthenis [64b] Orationes, hic enim, quod maxime est, minime uult uideri eloquens, et 'fortunas Graeciae ex eo non pendere' dicit, an manum in hanc, aut in illam partem inflexerit : uel hoc, aut illo uerbo inter orandum usus fuerit; at ille in negotiosis etiam orationibus dissimulare non potest

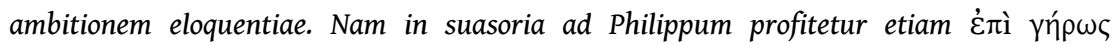
$\varphi \imath \lambda o \tau \iota \mu i ́ \alpha v$, et se excusat, quod propter aetatem ingrauescentem, tam elaborata orationis

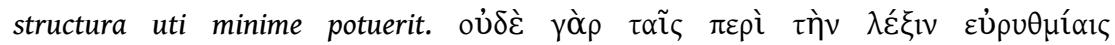

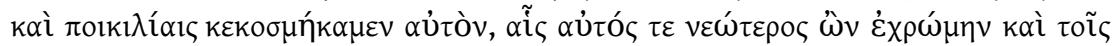

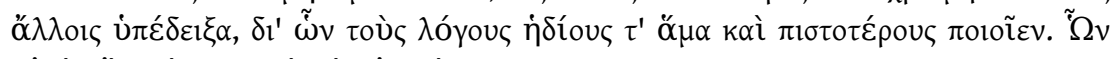

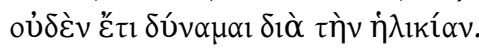
Quae excusatio non petita accusatio est. Praefatur etiam amplissime de suis familiaribus, et eorum de hac suasoria iudicia exponit, quae omnia parum ad persuasionem faciunt, et ambitiose potius quam neruose dicta sunt.

78 Mais dans son Panégyrique, qui a également une dimension délibérative ${ }^{161}$ à l'adresse des Grecs, il a une si grande idée de son éloquence, il en parle de manière si grandiose ${ }^{162}$, qu'il en vient à dire : Mais moi, si je ne parle pas de façon digne de mon sujet, de ma propre réputation et de tout le temps, non seulement que nous avons passé à notre discours (soit une 
dizaine d'années), mais que j'ai vécu, je vous recommande de ne pas me le pardonner et de me couvrir de risée et de mépris ${ }^{163}$.

\section{ans.}

In Panegyrico uero, qui et suasionem continet ad Graecos, tam magnifice de sua eloquentia sentit, et dicit, ut nisi pro rei dignitate, suaque gloria, et pro tempore, quod in hac oratione elaboranda, concinnandaque posuerit (in qua decennium ferebatur insumpsisse) peroret,

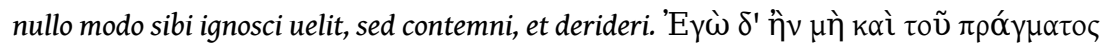

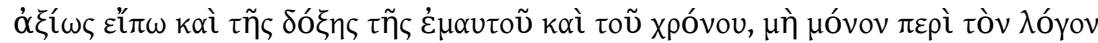

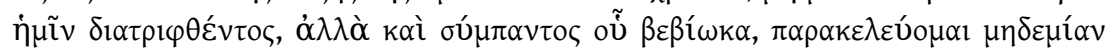

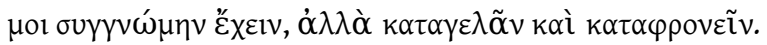

Haec quidem ostentationem habent eloquentiae non mediocrem, quae Oratori ciuili cauenda est, uel maxime.

At uero sub finem Orationis, quasi in promptu diceret, qui se comparata oratione dicturum,

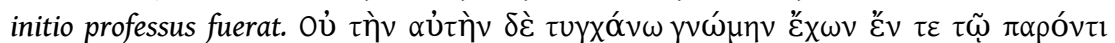

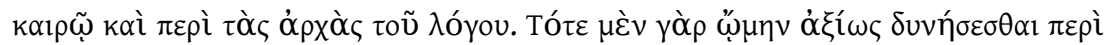

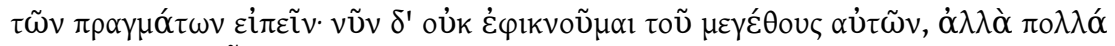

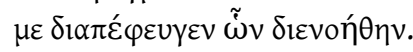

Iam uero non ita sentio, ac initio orationis meae : tunc enim pro dignitate rerum, me posse dicere existimabam, nunc magnitudinem earum non assequor, multaque mihi eorum, quae dicere institueram, exciderunt.

Nimis aperta calliditate haec sunt elaborata, quasi finem orationis non praeuidisset, qui se per decennium scripsisse gloriabatur.

\section{[3. Autre exemple, l'empereur Julien]}

Les écrits de l'empereur Julien, à peine sorti de l'enseignement des sophistes, sentent aussi beaucoup l'école. En effet, vers quoi tend, dans l'éloge d'Eusébie, son si long exorde indirect ${ }^{166}$, où il s'en prend au vice de l'ingratitude? Que faut-il donc penser des hommes, qui, après avoir contracté, pour de grands services, une grande dette de reconnaissance, je ne parle ni d'or, ni d'argent, mais de n'importe quel service reçu du prochain, n'essayent ni ne projettent même de s'acquitter, et, sans se donner la moindre peine, dédaignent de faire le possible pour éteindre leur dette? Ne doit-on pas évidemment les regarder comme des êtres méprisables et mauvais ${ }^{167}$ ? Quel est le but de cette période, ainsi que d'autres plus développées encore, si ce n'est de dire qu'il faut fuir l'ingratitude - raison pour laquelle il est justement appelé à prononcer l'éloge d'Eusébie, dont la multitude et l'importance des bienfaits reçus avaient fait de lui son obligé. Mais même si c'en est la raison, il aurait tout de même pu formuler son discours plus élégamment [rotundius], en évitant de le traîner par de si lents détours. Il ajoute ensuite un autre lieu commun, en disant qu'il faut louer les hommes illustres : Platon et Socrate l'ont fait, dit-il, et pourquoi ne feraiton pas de même pour les femmes ${ }^{168}$ ? Assurément, Homère a loué Pénélope ${ }^{169}$. Cette thès $\mathrm{e}^{170}$, qui se poursuit trop longuement, sent beaucoup son école. Il ajoute même des exemples 
tirés trop souvent des poèmes homériques, et des digressions sur la Grèce ${ }^{171}$ et sur les livres ${ }^{172}$, avec des formules d'excuse ${ }^{173}$. Tout cela marque une plume encore juvénile qui se démène comme si elle était dans un stade rempli de rhéteurs.

[65a] Habent et multum palestrae scholasticae, quae a Iuliano imperatore ex Sophistarum scholis adhuc recente scripta sunt. Quorsum enim in Eusebiae encomio tam longa insinuatio

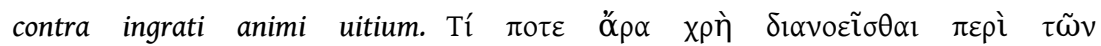

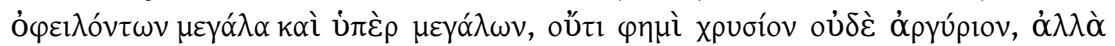

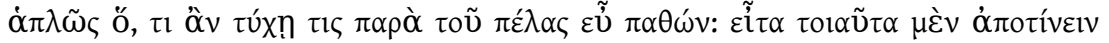

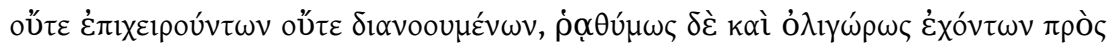

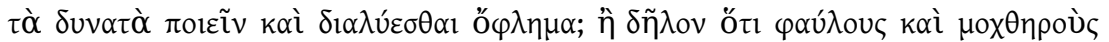

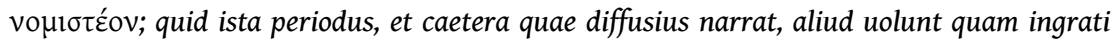
animi labem esse fugiendam, qua ratione ad laudandam Eusebiam prouocatur, cui multis, et magnis beneficiorum nominibus tenebatur adstrictus. Hoc etsi ad rem facit, poterat tamen dici rotundius, nec tanto lentitudinis anfractu trahi. Alium deinde locum communem annectit, laudandos esse summos uiros, "nam hoc (inquit) et Plato, et Socrates fecerunt, quid ne etiam inquit foeminas?' Siquidem 'Homerus Penelopem laudauit'. Haec thesis longius excurrens multum sapit de schola. Accedunt etiam exempla ab homericis saepius petita fabulis, et digressiones de Graecia, et libris cum annexis excusationibus, quae calamum iuueniliter adhuc quasi in Rhetorum stadio uolitantem arguunt.

\section{Chap. VIII. Du style poétique et mélodieux / De stylo poetico, et cantico}

\section{[1. Définition et considérations générales]}

On s'est souvent demandé pourquoi Denys d'Halicarnasse, juge et censeur très précis des talents et du style, a posé que le meilleur discours devait être très semblable à la poésie. De là vient qu'il n'a pas peur d'appeler les récits d'Hérodote et de Thucydide un beau poème: on peut qualifier de belles ces deux "créations poétiques" (je n'éprouve aucun embarras à donner à ces ouvrages d'histoire le nom de "créations poétiques ") ${ }^{174}$. Quant à Lucien, il conseille à celui qui recherche la gloire de l'éloquence de lire d'abord les meilleurs poètes, avant de se tourner vers les orateurs : il ne donnerait pas ce conseil $s^{\prime}$ il jugeait que la lecture des poètes ne pouvait servir à façonner le style ${ }^{175}$. Mais, bien qu'il paraisse recommander la lecture des poètes, qui serait très utile pour l'éducation de l'orateur ${ }^{176}$, ce discours ne doit pas être compris comme une approbation du style poétique : les deux s'en sont détournés avec véhémence, tant dans leurs jugements que dans leur manière d'écrire. Qu'ont-ils donc voulu dire? Que les poètes, et surtout les tragiques et les comiques les plus fameux, seront une aide non négligeable pour devenir orateur de métier ${ }^{177}$, pourvu que, dans l'apprentissage de la parole et de l'écriture, on en use avec discernement. Mais cela, me répondras-tu, ne correspond pas absolument à l'avis de Denys, qui a explicitement appelé le récit historique de Thucydide une création poétique ${ }^{178}$. Je dirai en peu de mots quel était l'avis de Denys d'Halicarnasse sur la question. Il recommande aux orateurs de soigner l'agencement des mots et leur rythme ${ }^{179}$, en argumentant que c'est là ce qu'il y a de plus efficace pour apaiser les esprits par les charmes de la douceur; mais pour dénoncer la négligence de ceux qui considèrent que le rythme est l'attribut des seuls poètes et débitent donc des discours apathiques, défaits et sans aucun agencement, il soutient que le meilleur discours est très semblable à la poésie, c'est-à-dire (comme il l'écrit lui-même) que, grâce à l'art ${ }^{180}$, un tel discours ne doit pas être moins précis, grâce à son agencement, pas moins beau, 
grâce à son arrangement mélodieux ${ }^{181}$, que les poèmes eux-mêmes, bien qu'il puisse couler avec un autre rythme, plus libre. Cicéron l'explique parfaitement dans L'Orateur :

Quaesitum est saepe cur Dionysius Halicarnassensis ingeniorum stylique iudex, et censor acerrimus, optimam orationem Poesi simillimam esse debere statuat, Ex quo Herodoti, et

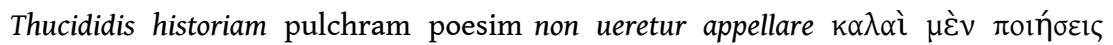

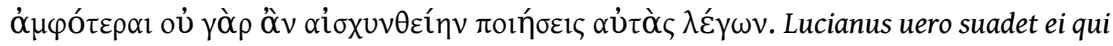
eloquentiae decora concupiscit, ut primum optimos quosque Poetas legat, deinde se conferat ad oratores: quod profecto non faceret, nisi ad conformandum stylum prodesse Poetarum lectionem arbitraretur. Sed tamen quamuis Poetas, ut ad oratoris institutionem perutiles commendare uideatur, haec oratio non est ita intelligenda, ut stylum Poeticum probet, a quo sane ambo, et sententiis et scribendi genere uehementer abhorruere. Quid igitur uterque uoluit? Poetas, maxime uero Tragicos et Comicos de meliore nota, oratoriae facultati non leui fore adiumento si quis se in eis ipso dicendi ${ }^{182}$, scribendique tyrocinio prudenter [65b] exerceat. At hoc (inquis) non plene satisfacit Dionysii menti, qui Thucididis historiam Poesim aperte nominauit. Dicam equidem et paucis, quae hac in re mens Halicarnassensis fuerit. Structuram uerborum, et numeros oratoribus commendat, quam rem unam ad mulcendos suauitatis lenociniis animos efficacissimam esse probat: Vt eorum uero incuriam redarguat, qui penes solos Poetas esse numeros arbitrati, segnem dissolutam et plane incompositam orationem effutiunt, optimam orationem poesi simillimam esse contendit, hoc est (ut ipse

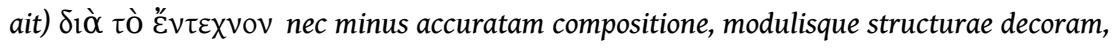
quam sint ipsa poemata, licet aliis, et liberioribus numeris effluat. Hoc Cicero in Oratore explicatissime docet.

Car les poètes ont, eux aussi, soulevé la question de savoir en quoi ils pouvaient bien différer des orateurs. Autrefois il semblait que ce fût essentiellement par le nombre et la versification; mais, aujourd'hui, chez les orateurs également, le nombre se rencontre souvent. En effet, tout ce qui offre à l'oreille une mesure, même très éloignée de celle du vers (car le vers serait un défaut en prose), s'appelle nombre < en grec rhuthmos >. Aussi je vois que le style de Platon et de Démocrite, bien que très éloigné de celui des vers, a quelquefois semblé, par la vivacité du mouvement et l'éclat particulier de la langue, mériter le nom de poétique, plutôt que celui des poètes comiques, chez lesquels, à l'exception de l'emploi de méchants vers, il n'est rien qui ne ressemble à la conversation ordinaire ${ }^{183}$.

Plus loin : Pour moi, quels que soient, dans leur style, la noblesse et l'éclat de certains poètes, je pose en principe qu'ils possèdent, plus que nous, la liberté de créer des mots ou des alliances de mots; en outre, pour plaire, ils s'attachent à la forme plus qu'au fond. À la vérité, orateurs et poètes ont beau se ressembler sur un point, un seul, je veux dire le goût dans le choix des mots, ce n'est pas une raison pour ne pas voir combien ils se ressemblent peu en tout le reste; d'ailleurs cette différence n'est pas douteuse ${ }^{184}$. Voilà ce ce que dit Cicéron. Mais Quintilien lui aussi tranche très clairement toute l'affaire, en ces mots :

Théophraste dit que la lecture des poètes peut rendre de très grands services à l'orateur, et bien des gens ont adopté cette manière de voir, non sans raison. En effet c'est chez les poètes qu'on trouve, pour les pensées l'inspiration, pour la forme la magnificence, pour les émotions la manière de toutes les provoquer, pour les caractères la convenance; de plus l'esprit, en quelque sorte usé par la pratique journalière du forum, ne trouve rien, pour se reposer, qui vaille mieux que l'agrément de tels morceaux; voilà pour quelle raison Cicéron estime qu'il faut se délasser dans cette lecture. Souvenons-nous cependant que l'orateur ne doit pas suivre en tout les poètes, ni pour le libre choix des mots, ni pour la hardiesse des figures ${ }^{185}$. Il ajoute même : ni dans la contrainte fixe de la loi métrique ${ }^{186}$.

'Nam etiam (inquit) Poetae quaestionem attulerunt quidnam esset illud quod different ab oratoribus. Numero maxime uidebantur antea, et uersu: Nunc apud oratores iam ipse numerus increbuit. Quicquid est enim, quod sub aurium mensuram aliquam cadit, etiamsi 
abest a uersu, (nam id quidem orationis est uitium) numerus uocatur qui graece $\dot{\rho} v \theta \mu$ ò $\varsigma$ dicitur. Itaque uideo uisum esse nonnullis, Platonis, et Democriti elocutionem, etsi absit a uersu, tamen quod incitatius feratur, et clarissimis uerborum luminibus utatur, potius poema putandum, quam Comicorum Poetarum : apud quos nisi quod uersiculi sunt, nihil est aliud quotidiani dissimile sermonis.'

(Deinde) 'Ego autem, etiamsi quorumdam grandis, et ornata uox est Poetarum, Tamen in ea cum licentiam statuo maiorem esse, quam in nobis faciendorum, iungendorumque uerborum, Tum etiam nonnullorum uoluptati uocibus magis quam rebus inseruiunt. Nec uero si quid est unum inter eos simile, id autem est iudicium, electioque uerborum, propterea caeterarum <rerum> dissimilitudo intelligi non potest.' Haec Cicero; sed et Quintilianus clarissime rem totam diiudicat his uerbis.

'Theophrastus, inquit, plurimum oratori dicit conferre lectionem Poetarum, multique eius iudicium sequuntur, neque id immerito: Namque ab his et in rebus spiritus, et in uerbis sublimitas, et in affectibus motus omnis, et in personis decor petitur, praecipueque uelut attrita quotidiano actu forensi ingenia, optime rerum talium blanditia reparantur : ideoque in hac lectione Cicero requiescendum putat. Meminerimus tamen non per omnia Poetas esse oratori sequendos, nec libertate uerborum, nec licentia figurarum', addit etiam pedum necessitate.

\section{[2. Exemples]}

On voit donc toute l'erreur de ceux qui abusent du style poétique dans un discours en prose [oratio soluta], soit par les mots, soit par le rythme, soit par les expressions périphrastiques qu'ils utilisent, licence qu'on rencontre chez un très grand nombre d'orateurs. À cet égard, l'historien Ammien Marcellin est maladroit, quand il dit en ouvrant grand la bouche ${ }^{187}$ :

88 Au premier éclat de l'aurore, toute l'étendue visible resplendissait d'armes scintillantes et une cavalerie bardée de fer recouvrit plaines et collines ${ }^{188}$. Transformez cela en vers: de quoi s'agit-il ici, sinon d'un poème, et même d'un poème plein d'enflure?

De même :

90 Bellone, faisant rage dans la Ville Éternelle, brûlait tout : à partir de débuts insignifiants, elle en était venue à causer de consternants massacres; le silence puisse-t-il en avoir à jamais effacé le souvenir ${ }^{189}$. Quels termes ampoulés et poétiques! pour dire : « une guerre funeste avait tout fait brûler ".

91 De même : En hiver, la terre couverte par les froids d'une croûte de glace, étant comme polie et par là même glissante, rend la marche incertaine et provoque les chutes; et les larges vallées, où en terrain plat la glace ôte toute sécurité, engloutissent parfois les voyageurs ${ }^{190}$.

Quel poète amasserait plus d'épithètes, ou s'enflerait de plus de paroles?

Ex eo apparet quantus est error eorum, qui Poetico stylo perperam in soluta oratione abutuntur, uel uerbis, uel numeris, uel periphraseon quae permultis communis esse solet licentia. Hac in re importunus est Ammianus historicus, quo enim hiatu haec dicit.

[66a] Cumque primum aurora surgeret uniuersaque uidere poteram, armis stellantibus coruscabant, ac ferreus equitatus campos opplebat et colles. Fac pedes, quid sunt ista nisi carmina eaque praetumida ?

Item

Saeuiens per urbem aeternam urebat cuncta Bellona ex primordiis minimis ad clades ducta luctuosas quas obliterasset utinam iuge silentium quae ampullae Poeticae? vt omnia nefario bello arsisse dicat.

Item Hieme uero humus crustata frigoribus, et tamquam leuigata ideoque labilis incessum praecipitantem impellit, et patulae ualles per spatia plana glacie perfidae uorant nonnumquam transeuntes.

Et ubi Poeta epithetis densior aut uerbis tumidior ? 
Il s'est tellement habitué à ces tours ampoulés que les choses qui ne devraient être prononcées que sur le ton de la conversation ordinaire, elles aussi il les amplifie et les pervertit avec des ornements clinquants, par exemple : débordent des amusements chers à la paresse ${ }^{191}$ et cherchaient à les retenir par de généreux bienfaits qui prenaient mille formes ${ }^{192}$, et encore La Renommée, nourricière perfide des rumeurs, divulgua ces événements ${ }^{193}$.

Mais, lorsqu'il met toute son habileté à s'enfler, qui pourrait supporter un tel poids ? Une vraie Mégère faite femme, toujours prête à exciter les fureurs ${ }^{194}$. De telles expressions font les délices d'Apulée et, comme ils disent eux-mêmes, sont les anémones du langage ${ }^{195}$ : ainsi celles qu'il écrit au sujet de son sol natal, terres heureuses assurées d'une éternelle durée par des ceuvres plus heureuses encore ${ }^{196}$.

L'aube du jour avait dissipé les ténèbres et le char embrasé du soleil illuminait toutes choses ${ }^{197}$.

Ita his ampullis assueuit ut quae quotidiano sermone omnino dicenda erant, etiam his phaleris augeat et peruertat ut ludibriis ignauiae torrentes exundant, et humanitatis multiformibus officiis retentabant, et fama rumorum nutrix maligna dispersit.

At ubi inflat ex industria quis molem sustineat? Megaera quaedam mortalis inflammatrix saeuientis adsidue istae sunt Apuleii deliciae et (ut ipsi aiunt) Anemonae uerborum: talia sunt quae de suo patrio solo scribit glebae felices aeternum, libris felicioribus creditae.

Vt primum tenebris abiectis dies inalbebat, et candidum solis curriculum cuncta collustrabat.

De même :

97

Tirant $d u$ fond de sa poitrine un soupir déchirant ${ }^{198}$ et ces paroles que, soulevé par une inspiration plus sublime encore, il fait sonner comme le tonnerre : L'instant d'après, la porte s'ouvre avec violence, une escouade de brigands envahit les lieux, un cordon d'hommes en armes entoure chaque corps de bâtiment, tandis que d'autres se dispersent pour tenir en respect les gens qui, de toutes parts, volent au secours. Armés tous de glaives et de torches, ils illuminent la nuit ; le fer et le feu jettent des lueurs de soleil levant ${ }^{199}$.

Item

Imo de pectore cruciabile suspiriam ducens, et haec quae grandiori spiritu intonat: Nec mora cum ui patefactis aedibus, globus latronum inuadit omnia, et singula domus membra cingit armata factio. Et auxiliis hinc inde conuolantibus obsistit discursus hostilis, cuncti gladiis, ac facibus instructi noctem illuminant, coruscat in modum ortus solis ignis et mucro.

\section{[3. Le style mélodieux]}

98 Ce n'est pas tout: parfois, le discours [oratio] dégénère dans ce vice qu'on appelle style mélodieux. Ainsi : Les astres sont dociles à ta voix, les saisons reviennent à ta volonté, les dieux se réjouissent à ta vue, les éléments sont à tes ordres. Tu fais un geste et les brises s'animent, les nuages s'enflent, les semences germent, les germes grandissent ${ }^{200}$, et les torrents qui descendent des montagnes, les sources d'eau qui se jouent sous la terre, le lit des fleuves en se couvrant de $\operatorname{limon}^{201}$ : ce type de style poétique est tout à fait dangereux pour la vraie éloquence; et pourtant, dans des siècles moins policés, il s'est répandu partout largement, entraînant, par une démangeaison fatale, nombre d'orateurs avec lui, au point d'avoir longtemps régné en maître.

Nec satis inflectit nonnunquam orationem in degeneris naturae malum quod uocant Canticum, ut Tibi respondent sidera redeunt tempora, gaudent numina seruiunt elementa, tuo nutu spirant flumina, nutriuntur nubila, germinant semina, crescunt germina et Montium scapulae decurrendo, fontium uenae ebullando, et fluminum uiae obumbrando : haec est styli poetici species verae eloquentiae admodum perniciosa, 
quae tamen rudioribus saeculis longe, lateque peruagata, fatali pruritu multos secum traxit, diuque dominata est.

\section{Chap. IX. Du style allégorique et périphrastique / De stylo allegorico, et periphrastico}

\section{[1. L'allegoria ou métaphore continuée]}

Mais puisque nous mentionnons cet auteur, il va nous fournir des exemples du style dont nous allons maintenant parler. Il a eu sa gloire à l'époque où la folie des métaphores, ou plutôt la douceur des allégories ${ }^{209}$, avait tout envahi, et où l'on appelait souvent fer de Cicéron ${ }^{210}$ la façon dont il s'exprimait, tandis que les saillies froides et les allégories dont les auteurs du temps bourraient leurs écrits étaient considérées comme de l'or.

Sed quoniam in huius auctoris mentionem incidimus, eius, quem nunc discutimus styli, exempla suppeditabit. Floruit eo tempore, quo illa insana metaphorarum, uel potius allegoriarum dulcedo cuncta peruaserat, et iam Ferrum Ciceronis Tulliana dictio, uulgo dicebatur, contra aurea putabantur frigida quaeque acumina, et allegoriae, quibus illi scriptores sua referserunt.

107 En quoi il faut sans doute moins accuser le grand et fertile Ennode, qui écrivit de telles choses emporté par son goût fervent pour la rhétorique que ses maîtres lui avaient enseignée, que les siècles barbares et incultes qui confondaient l'or avec le fer et le fer 
avec l'or, dans une si dramatique dépravation de l'éloquence. Ainsi Ennode écrit-il à Jean :

Pendant que tu cherchais à gagner le large après avoir, au mouillage, bien agencé les mots et que tu reproduisais, en un discours paisible, les sinuosités de l'élément liquide, pendant que tu réglais, en pilote diligent, l'allure de l'esquif de tes propos pour éviter les écueils de la rhétorique et que tu façonnais et pesais, en bon juge, leur course habile, tu as montré que la mer que tu représentais à mes yeux comme celle des flots était en fait celle de l'éloquence.

Dieu de bonté, à combien d'usages se prête une riche éloquence! Quand elle le veut, elle se déchaîne comme un fleuve, s'agite comme la mer profonde et, toutes les chimères qu'elle peint avec les images colorées des mots, elle les représente avec la recommandation de la vérité. Tu me fais savoir que tu as peur d'écrire comme si tu ne savais pas faire front, quand ton affirmation de fuir la louange réclame la pompe des déclamations (et se montre avide de gloire quand elle prétend épargner la pudeur en affectant une crainte qui lui est étrangère). Je te fais et t'exprime mes remerciements pour avoir consacré les nobles essais de ton éloquence à louer un ami dans la mesure où tu l'estimes ainsi. Et bien que je ne me reconnaisse pas comme miens les mérites que tu dis, je suis touché néanmoins par la délicatesse de celui qui en fait état; je loue l'affection de ton cœur, que tu as manifestée par la lumière d'une bienveillance resplendissante de clarté. C'est à toi qu'est tendue cette torche que ton éloquence flatteuse allume pour ma bonne réputation. Quant à moi, bien que je n'échappe pas à l'obscurité de mon esprit, je sais néanmoins la reconnaître ${ }^{211}$.

In quo profecto minor est error magni illius, et felicis Ennodii, qui calentibus adhuc eius, quam a magistris acceperat Rhetoricae studiis ista scripsit, quam barbari, et squallentis saeculi, cui aurum pro ferro, et ferrum pro auro, in tam grauibus eloquentiae corruptelis fuit. Sic igitur Ennodius ad Ioannem.

$\mathrm{Diu}^{212}$ salum quaeris uerbis in statione compositis, et incerta liquentis elementi placida oratione describis, dum sermonum cymbam inter loquelae scopulos rector diligens fraenas, et cursum artificem fabricatus trutinator expendis ; pelagus oculis meis, quod aquarum simulabas, eloquii demonstrasti.

Deus bone, in quantos se usus diues lingua dispargit ! Cum uoluerit saeuit ut bestia, currit ut fluuius, fluctuat ut profundum: et quamcunque fucatis uerborum imaginibus pingit speciem, ueri adstipulatione repraesentat. Timere te [67a] scriptionem, quasi fronte tener, insinuas; dum declamationum pompam refuga laudis deposcit assertio; (et fit auara gloriae, dum pudori parcere se ostendit, peregrinam mentita formidinem ${ }^{213}$.) Ago atque habeo gratias, quod nobilia rudimenta facundiae tuae, in amici quantum aestimas praeconiis consecrasti. Et licet non agnoscant mea esse, quae loqueris: religionem tamen narrantis amplector, diligentiam pectoris laudo, quam gratiae per sudum rutilantis luce dedicasti. Tibi fax ista praetenditur, quam in opinione mea blandus elocutor accendis. Ego noctem conscientiae meae, etsi non fugio noui tamen aestimare.

110 Considère chacune de ces expressions, et examine-les de près : laquelle ne contient pas d'allégorie ? Laquelle ne contient pas de similitude ? ô entêtement du style ! Tu me dis que ce sont de belles métaphores? Mais il faut aussi fixer des limites au beau. Elles sont de miel ? La douceur du miel elle aussi peut écœurer. Ce sont des pierres précieuses ? Il faut donc qu'elles ornent l'ouvrage, non qu'elles l'écrasent. Les métaphores ont été inventées pour rendre notre discours plaisant, par pour être utilisées dans l'usage quotidien: si tu les introduis partout, tu transformeras inévitablement ton style en corps monstrueux. Certes, la peinture est un art très raffiné : ses images rivalisent avec les riches présents de la nature. Pourtant, personne ne fut jamais assez fou pour penser que les ouvrages de la nature devaient être supprimés sous prétexte qu'on peut voir dans de très belles peintures des simulacres de ces mêmes images. Il est vrai que les 
peintures nous emplissent d'un bref sentiment de plaisir. Mais les dons de la nature nous comblent de manière plus durable et plus solide ${ }^{214}$.

Expende singula, et accurate dispice, quid sine allegoria? quid sine similitudine dictum inuenire? ô styli importunitatem! At dices pulchrae sunt Metaphorae? Sed et pulchrorum modus est. Melleae sunt? et mellis suauitas affert satietatem. Gemmeae sunt? distinguant igitur opus, non obruant. Ad orationis delicias, non ad communem quotidiani sermonis usum inuentae sunt metaphorae, quas si ubique uelis intrudere, styli monstrosum corpus facias necesse est. Venustissima quidem est ars picturae, quae expressis rerum imaginibus opulentas aemulatur naturae dotes, nemo tamen adeo demens est inuentus, qui naturae opera de medio tollenda esse censeret, quod eorumdem picturis, usque perelegantibus expressa simulachra intueri liceret. Siquidem manufactorum decor breui admodum uoluptatis delinimento pascit sensus. Naturae dona diutius, et solidius oblectant.

111 C'est ce que l'on remarque chez ceux qui contemplent en un tableau l'image d'une campagne peinte ou le plumage chamarré des oiseaux ${ }^{215}$.

$112 \mathrm{Au}$ premier regard, assurément, les spectateurs semblent dévorer le plaisir par les yeux, et sont extraordinairement charmés ; puis, peu à peu, quand ils se sont attardés longtemps sur la même image, le charme s'épuise, l'état de grâce ne dure pas. Mais les grands spectacles de la nature, tels l'étendue immense de la mer, les cascades glacées, l'ombre des bois et l'habit verdoyant des montagnes ravissent ceux qui les aiment d'un plaisir toujours recommencé. Ce n'est pas très différent pour le style. En effet, dans un discours, ces diadèmes qu'on appelle peinturés ${ }^{216}$ surchargent l'oreille quand aucun vide n'est ménagé. Au contraire, des mots pris dans leur sens propre, dans un discours soigné au rythme harmonieux, retiennent les sens des auditeurs par un plaisir qui, s'il n'est pas plus intense, est du moins plus durable et plus utile.

Quod licet quidem animaduertere in iis, qui picti ruris similitudinem, aut auium uersicolores plumas spectant in tabulis.

Primo quidem aspectu, quasi totam hauriant oculis uoluptatem afficiuntur quam suauissime. Paulatim uero diu occupatis eadem imagine sensibus iucunditatis gratia consenescit. At quae naturalia sunt, et magna, ut Maris exporrecta facies, gelidorum fontium lapsus, umbrae nemorum, montiumque uestitus uiridissimi, nouo semper uoluptatis aucupio suos recreant amatores. Haud quidem dissimile est, quod in hac styli materia euenire solet: Nam illa sermonum picturata (ut appellant) diademata sua crebritate fastidiosa, aures statim obruunt. Verba uero propria accuratae orationis dulcibus illigata numeris, si non acriori, diuturniori tamen, atque utiliori delectatione sensus retinent auditorum.

113 Comment se fait-il que beaucoup soient captivés par ce type de style? C'est qu'ils préfèrent un plaisir barbouillé de fard à un agrément plus solide. Car il est plaisant d'entendre ces mots assez caressants et maniérés :

Pendant que tu prononçais des paroles suaves et que, dans les demeures de cire de ton éloquence, avec le nectar de l'élément liquide, tu fabriquais des miels, tu as versé sur mes lèvres la saveur nouvelle d'une riche nourriture ${ }^{217}$.

Et dans le Panégyrique de Théodoric:

116 Tu étais encore dans la première fleur de l'adolescence, et ton chaume lacté, sans expérience, n'avait pas pu apporter sa moisson de vaillance. Tu étais toujours la délicieuse image de l'enfance, aucune ombre ne couvrait ton visage, quand la pourpre et les premières fleurs de ton nouveau règne se mirent à terrifier ceux qui s'inquiétaient de tomber en disgrâce. Alors, leur fureur brisa ses liens et s'élança pour troubler ta clémence et ta force : saisissant la pâture de l'occasion, elle soumit des esprits qu'une longue paix avait éviscérés ${ }^{218}$. 
Qui fit igitur ut multi hoc loquendi genere capiantur? quia fuco illitam [67b] uoluptatem solidae iucunditati anteponunt. Iuuat enim ista audire blandius infracta.

Dum fauos loqueris, et per domos cereas eloquentiae nectare liquentis elementi mella componis, peregrinum labiis meis saporem epuli diuitis infudisti.

Et in Panegyrico Theodorici.

Et adhuc in cano flore degebas adolescentiae, nec uirtutum messem lacteus ante experimentum culmus attulerat. Adhuc blanda erat imago pubescentis, nec tingens faciem lanugo uestiebat : quando aeui purpura, et flosculus superuenientis imperii promittebat sollicitis, de gratiae commutatione terrorem. Cum in perturbationem roboris, et clementiae tuae, ruptis uinculis furor emicuit : et euisceratas diuturna quiete mentes occasionis pabulo subiugauit.

117 Je reconnais qu'ici, certains traits brillent d'un très doux éclat; par exemple : Tu étais toujours la délicieuse image de l'enfance, aucune ombre ne couvrait ton visage. Néanmoins, ceux qui se plaisent à ce type de style obligent souvent leur public à boire la lie avec le vin.

En effet, les liens rompus de la clémence, les esprits que la paix avait éviscérés, et la pâture de l'occasion : à qui ces expressions peuvent-elles plaire, sinon à des oreilles grossières?

119 Mais qui pourrait qualifier les caresses que voici? Je voudrais, pour conclure, descendre de la cime de tes exploits et, ébloui par la lumière de tes premières gloires, passer les autres sous silence.

Nonnulla fateor hic dulcissime renident: ut, 'Adhuc blanda erat imago pubescentis, nec tingens faciem lanugo uestiebat'. Sed tamen quam saepe cum uino fecem bibere coguntur, qui isto genere delectantur.

Nam 'rupta clementiae uincula'; et 'euisceratae quiete mentes', et 'occasionis pabulum', cui tandem, nisi duris auribus placere possunt?

Quis uero blanditias nominet? Vellem ad orationis terminum uictus gestorum tuorum enormitate descendere, et nouellas adoreas hebetatus priscorum luce transire.

\section{[2. La périphrase ou loquacitas]}

Soit, de telles paroles ont pu plaire à l'époque gothique, dont, comme ils le disent euxmêmes, la sensibilité était glacée : il n'y a pas à s'en étonner. Ce dont je m'étonne plus, c'est qu'Ennode, qui était loin d'être l'égal de Cicéron, parle de l'or de Démosthène et du fer de Cicéron, et que Sidoine accuse l'Arpinate ${ }^{219}$ (comme il l'appelle) de bavardage [loquacitatis ${ }^{220}$. Existe-t-il un style plus bavard ou plus dur que celui auquel ils se sont laissés entraîner - moins d'ailleurs de leur propre volonté qu'à cause de l'époque difficile où ils ont vécu? Par exemple, là où Cicéron dit: la jeunesse se montre nonchalante $e^{221}$, Sidoine dit : nos jeunes gens murmurent de voir ainsi leur noblesse piétinée $e^{222}$. Lequel est le plus bavard ? Là où Cicéron dit que la terre ou les herbes se dessèchent ${ }^{223}$, Ennode dit: si m'étaient refusés les entretiens que je désire, je me fendillerais comme une terre qui ne reçoit aucune eau du ciel et dont les veines ne s'imprègnent d'aucune substance liquide ${ }^{224}$. Chez lequel y a-t-il le plus d'enflure ? Comme ces paroles sont à la fois enflées et rudes !

Que l'Antiquité s'en aille vanter Alexandre avec ses histoires en cothurne! Le talent des historiens a amplement servi sa réputation, si bien que son éloge, fondé sur une matière pauvre, semble croître avec l'aide de la faconde ${ }^{225}$. S'il faut louer la brièveté attique, ne pouvait-on dire en un seul $\operatorname{mot}^{226}$ : Alexandre fut plus petit que sa réputation?

Sed esto placuerunt ista Gothico saeculo, et glacialibus (ut ipsi aiunt) fibris; minime enim mirandum est. Hoc magis miror, quod Ennodius Ciceroni parum aequus 'aurum Demosthenis', et 'ferrum Ciceronis' appellet, et Arpinatem (sic enim nominat) loquacitatis Sidonius insimulet. Ecquis stylus eo, in quem temporis iniquitate magis, quam sua uoluntate 
deuoluti sunt, loquacior est, aut durior? Scilicet ubi Cicero habet, Languet iuuentus. Sidonius Mussitat iuuenum nostrorum calcata generositas, utrum loquacius? Vbi Cicero Terram, aut herbas arescere. Ennodius, Cui si uotiui negentur affatus, fatiscat ${ }^{227}$, ut terra, cui coelo nihil liquitur, nec uenas suas succo bibuli humoris infundit. Vtrum tumidius? quam uero inflata sunt, et rudia.

Eat nunc, et cothurnatis relationibus Alexandrum iactet antiquitas, cui famae opulentiam peperit dos loquentium, ut per adiutricem facundiam uideatur crescere [68a] rebus mendica laudatio si Attica breuitas, laudanda est, num uno uerbo dici poterat Alexandrum sua fama minorem extitisse.

Je me demande comment ils osent se dire attiques, ceux qui imitent ce genre de style, alors qu'ils ne font que saupoudrer sur des phrases obscures et tortueuses ces termes ampoulés qu'ils appellent des pointes, comme si c'étaient du sésame et du pavot. Ils sont tout aussi loin de l'or de Démosthène que les lupins sont loin du bronze ${ }^{228}$.

Et pourtant, à notre époque, combien ce style démange ceux qui écrivent en vernaculaire! Nul n'est besoin, parmi une telle foule d'écrivains, de nommer précisément l'un ou l'autre: ils sont trop nombreux, et trop d'entre eux, à coup de défauts séduisants pour les novices et leurs semblables, sont lus, et avec plaisir. Ah, si seulement les adeptes de cette folie pouvaient lire et imiter les écrits du très illustre cardinal du Perron et du très intègre vice-chancelier du Vair ${ }^{229}$, plutôt que d'aller là où les pousse leur talent inné ! Tous deux sont la règle à suivre pour l'éloquence des Anciens ${ }^{230}$ et leur talent est à la hauteur de la gloire de la France : notre époque a eu la chance d'avoir vu naitre des esprits aussi exceptionnels, qu'il est plus facile d'admirer que de louer.

Miror quomodo se Atticos etiam pene dicere audeant, qui hanc styli rationem imitantur, modo ampullas istas obscuris aliquot, et tortis sententiis, quas uocant acumina, tamquam sesamo, et papauere aspergant; Distant certe ista ab auro Demosthenis, ut ab aere lupina. Et tamen quantus est etiam hoc saeculo apud uernaculos scriptores huius styli pruritus? Nihil opus est in tanta scriptorum multitudine nominare quemquam, nimis occurrunt, nimis dulcibus uitiis apud imperitos, et sui similes, leguntur, et placent : utinam qui hanc insanam dicendi licentiam sequuntur, Illustriss. Cardinalis Perronii, atque integerrimi Procancellarii Verrii scripta legerent, et imitarentur potius, quam suo ingenio indulgerent. Hos enim uiros ueteris eloquentiae normam, et paria Gallicanae gloriae ingenia felix egregiarum mentium partu hoc saeculum dedit, quos mirari facilius est, quam laudare.

\section{NOTES}

1. N. Caussin (1583-1651), Eloquentiae sacrae et humanae parallela libri XVI, Paris, S. Chapelet, 1619. L'ouvrage fut composé lorsque Caussin était professeur au collège de La Flèche, et fut plusieurs fois réédité : $\mathrm{C}$. de Rochemonteix, Un collège de Jésuites aux XVII et XVIII ${ }^{e}$ siècles. Le collège Henri IV de La Flèche, t. III, Le Mans, Leguicheux, 1889, p. 31.

2. M. Fumaroli, L'Âge de l'éoquence. Rhétorique et «res literaria » de la Renaissance au seuil de l'époque classique [1980], Paris, Albin Michel, 1994, p. 287.

3. D’après la formule de S. Conte («La rhétorique sacrée dans les Eloquentiae sacrae et humanae parallela ", dans S. Conte dir., Nicolas Caussin : rhétorique et spiritualité à l'époque de Louis XIII, Berlin, Lit Verlag, 2007, p. 269-299, ici p. 290) : « la manière de procéder de Caussin est très puissante et répond à son projet de s'appuyer sur la rhétorique profane pour mieux la dépasser. » 
4. Voir Ch. Mouchel, Cicéron et Sénèque dans la rhétorique de la Renaissance, Marzburg, Hitzeroth, 1990, p. 261 ; S. Conte, «L'éloquence sacrée selon Nicolas Caussin : de la gravitas à la popularitas ", Revue Bossuet, 2011/2, vol.2, p. 71-88 et «La rhétorique sacrée dans les Eloquentiae sacrae et humanae parallela», op. cit. Voir aussi S. Di Santo Arfouilloux, Le Torrent et la foudre. Cicéron et Démosthène à la Renaissance et à l'Âge Classique, Paris, Garnier, 2020, p. 463-566.

5. Quintilien, Institution oratoire, XII, 10.

6. Caussin traite donc des vices qui pèchent contre les genera dicendi, selon la distinction opérée par C. Barbafieri et J.-Y. Vialleton ("Introduction », Vices de style et défauts esthétiques XVI ${ }^{e}$-XVIII siècles, Paris, Garnier, 2017, p. 7-20, ici p. 10) : "Sous la notion de "vices de style" peuvent être réunies deux séries de fautes, d'une part les fautes contre la virtus dicendi, la qualité de l'expression, d'autre part les fautes concernant les genera dicendi, les différents styles. " Voir également M. Baratin et F. Desbordes, "La "Troisieme Partie" de l'Ars Grammatica", Historiographia Linguistica, vol. 13, 1986, p. 215-240.

7. D'où le titre de cette notice, «Le péché par l'excès ", qui fait également référence à celui de l'ouvrage de S. Robic-de Baecque consacré à J.-P. Camus, Le Salut par l'excès, Paris, H. Champion, 1999.

8. Notre traduction n'a pas retenu le chapitre consacré au style bigarré ou antiquaire [miscellaneus antiquarius], neuvième de ces vices par excès et particulièrement pratiqué par les critiques selon N. Caussin. Voir M. Le Guern «Le style dans les rhétoriques de Caussin et de Vossius ", Littératures Classiques, 1996, n² 28, p. 61-74.

9. « Prima virtus est vitio carere » : Quintilien, Institution oratoire, VIII, 3, 41. Nous traduisons. Cette expression retrouve les termes d'un vers d'Horace, Épitres, I, 1, 41 : «Virtus est vitium fugere ».

10. Quintilien, Insitution oratoire, VIII, 3, 58, éd. et trad. H. Bornecque, Paris, Garnier Frères, 1933, t. II, p. 180.

11. Du Sublime, III, 5.

12. Voir P. Aubenque, La Prudence chez Aristote, Paris, Presses Universitaires de France, 1963 ; et F. Goyet, Les Audaces de la prudence. Littérature et politique aux XVI et XVII siècles, Paris, Garnier, 2009.

13. Sur la tradition rhétorique des vices de style, voir H. Lausberg, Handbuch der Literarischen Rhetorik. Eine Grundlegung der Literaturwissenschaft, Max Hueber, Verlag Münschen, 1960, p. 511 s.

14. Aristote, Rhétorique, 1405b34-1406b19.

15. Voir P. Chiron, «Échec éthique, échec esthétique ", dans Vices de style et défauts esthétique, op. cit., p. 23-37. Voir également les vices qui côtoient les catégories stylistiques d'Hermogène dans l'article de R. Caruso ici même dans le présent numéro d'Exercices rhétoriques ( L'atténuation de la beauté dans le discours politique hermogénien »).

16. Rhétorique à Herennius, IV, 15-17.

17. Fidèle en cela à une tendance plus générale de l'époque classique : «La notion de faute à l'âge classique est donc ambivalente: elle traduit aussi bien une obsession de perfection qu'une fascination pour ce qui outrepasse les limites » (C. Barbafieri et J-Y. Vialleton, «Introduction », op. cit., p. 19).

18. Voir B. Beugnot, «La précellence du style moyen (1625-1650) », dans M. Fumaroli dir., Histoire de la rhétorique dans l'Europe moderne (1450-1950), Paris, PUF, 1999, p. 539-601.

19. Voir infra, la conclusion du chap. IX.

20. Voir l'étude sociologique qu'A. Viala propose de cette catégorie d'écrivains qu'il appelle « les nouveaux doctes » (Naissance de l'écrivain, Paris, Éditions de Minuit, 1985, notamment p. 29).

21. S. Conte, «La rhétorique sacrée dans les Eloquentiae sacrae et humanae parallela », op. cit., p. 269. 22. Voir G. Siouffi, «Le problème du "froid" au XVII siècle. Sentiment terminologique, sentiment stylistique et sentiment linguistique », dans Vices de style et défauts esthétiques, op. cit., p. 71-87. 
23. Longin, Traité du sublime, trad. Boileau, éd. Fr. Goyet, Paris, Librairie générale française, 1995, p. 77.

24. Ce qu'a bien noté M. Le Guern ("Le style dans les rhétoriques de Caussin et de Vossius", op. cit., p. 65) : «Caussin ne veut pas être de ces juges trop sévères qui ramènent tout à des règles rigoureuses ; son idéal est celui du juste milieu, et son modèle est Cicéron. Cela ne l'empêche pas toujours de tomber dans les défauts qu'il dénonce, dans les pages même où il les dénonce : la plus grande partie de son texte est une mosaïque de citations qui ne s'affichent pas toujours comme des citations, mais qui produisent l'effet de bariolage qu'il dénonce dans le stylus antiquarius, un goût immodéré des mots rares rend sa lecture difficile, et il cède parfois à la tentation des pointes qui rendent le style froid. "

25. S. Conte, "L'éloquence sacrée selon Nicolas Caussin : de la gravitas à la popularitas ", op. cit., p. 72.

26. Fr. Goyet, «Les analyses de discours dans le livre XIII des Eloquentiae sacrae et humanae parallela », dans Nicolas Caussin : rhétorique et spiritualité, op. cit., p. 221-268, ici p. 225.

27. Comme les lettrés de son époque et comme le fera Boileau, qui traduira ce texte en 1674, Caussin croit que le Traité du Sublime est du rhéteur grec Cassius Dionysius Longin (vers 213-273).

28. Traité du sublime, IV, 1, Paris, Les Belles Lettres, éd. et trad. H. Lebègue, 2003, p. 6.

29. Ibid., III, 4, p. 6.

30. Ibid., III, 5, p. 6.

31. Sénèque, Lettres à Lucilius, XIX, 114, 1, nous traduisons. Caussin ne cite pas la réponse que donne Sénèque à cette question (ibid., t. V, éd. et trad. F. Préchac et H. Noblot, Paris, Les Belles Lettres, 1964) : «La raison, tu l'entends de toutes parts alléguer; elle est dans ce mot passé chez les Grecs en proverbe : telles les mœurs [vita] de l'homme, tel son style [oratio]. »

32. Calque du grec, littéralement « mauvaise ardeur [caco] à imiter [zélie]».

33. Calque du grec, que Boileau traduira par « la fureur hors de saison », Longin, Traité du sublime, éd. Fr. Goyet, op. cit., p. 77.

34. La perspective qui consiste à opposer les vices par excès [excessu] aux vices par manque [defectu] semble propre à Caussin. Quintilien (Institution oratoire, VIII, 5, 56, op. cit., p. 179) formule une opposition proche entre le vice du cacozelon, qui procéderait d'une recherche excessive, et les autres vices: «les autres, on les évite insuffisamment [parum uitantur], celui-là, on court après [petitur]».

35. "Phalérée ", est un calque rare du latin phaleratus, épithète également rare, mais attestée en néo-latin. Elle signifie en bonne part «ornée somptueusement» et en mauvaise part "clinquante», "pleine d'ostentation». Ici, le sens est péjoratif. L'épithète latine vient du substantif phalerae, "phalères", "plaques de métal brillant " servant de décoration militaire pour les hommes ou d'ornement pour les chevaux (voir plus loin phaleris, «ornements clinquants »). L'adjectif phaleratus renvoie à un style "orné, fleuri ", et, chez Térence, " orné et mensonger » (Phormion, III, 2, v. 499-500). Les dictionnaires modernes latin-français le traduisent, en contexte rhétorique, par «fardé»: «Phalerata dicta. Terent. Belles parolles, ou fardees, \& phalerees » (Dictionarium Latinogallicum, Paris, R. Estienne, 1570, p. 996).

36. L'ensemble de cette entrée en matière s'inspire du traité $\mathrm{Du}$ Sublime, où l'enflure est le premier des vices répertoriés: "Naturellement tous ceux qui visent à la grandeur fuient le reproche de faiblesse et de sécheresse et tombent dans ce travers, je ne sais comment, persuadés que "manquer un but élevé est encore une noble erreur" » (III, 3, trad. Lebègue, op. cit., p. 6).

37. Similitudine ducta, a praua corporis habitudine: ce passage reprend la Rhétorique à Herennius, IV, 15 ( "Nam ita ut corporis bonam habitudinem tumor imitatur saepe »). Voir n. 40.

38. La pituite est un terme médical de l'époque antique et moderne : définie comme un liquide blanc et froid, elle fait partie des quatre humeurs qui composent le tempérament. On considère qu'un excès de pituite peut provoquer des fluxions ou des abcès. Le traité Du Sublime donne également une description métaphorique et organique de l'enflure, III, 4 (trad. Lebègue, op. cit., p. 
6) : « l'ampleur n'est pas moins pernicieuse dans les mots que dans les corps; elle est boursouflée et vaine apparence, et peut-être elle nous amène à une opinion contraire à celle de la grandeur, car rien n'est, dit-on, plus sec qu'un hydropique. »

39. La syntaxe latine est étonnante. Le terme oratio, au nominatif, semble redoubler aliquid en fonction sujet (comme si Caussin commençait une phrase et oubliait que la citation de la Rhétorique à Herennius contenait déjà un sujet).

40. Il s'agit d'une référence à la Rhétorique à Herennius, IV, 15, ouvrage que Caussin, de même que tous ses contemporains, attribue à Cicéron (éd. et trad. G. Achard, Paris, Les Belles Lettres, 1989, p. 143-144) : «En effet s'apparente au style élevé [graui] (qui lui, est digne d'éloges) un genre qui doit être évité. On l'appellera correctement, je crois, en le qualifiant de boursouflé [sufflata]. En effet de même que l'embonpoint a souvent l'apparence de la bonne santé [corporis bonam habitudinem tumor imitatur] de même les ignorants prennent souvent un discours emphatique et boursouflé [turget et inflata] pour un discours de style élevé [grauis] - quand on parle en usant de néologismes [nouis vuerbis], [etc.] » Voir également Cicéron, De Oratore, III, 153-158.

41. Excessus magnitudinis : cette traduction latine par Caussin semble gloser ce passage du traité

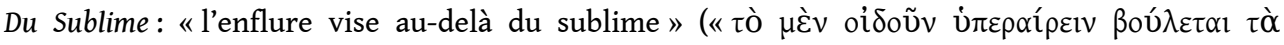
Ǔ $\psi \eta »$ : III, 4, trad. Lebègue, op. cit., p. 6). L'expression d'excessus pour désigner l'excès pernicieux, peut-être empruntée à la casuistique jésuite, semble revenir à Caussin. Nous ne l'avons pas retrouvée dans les traductions néo-latines du traité Du Sublime par Pizzimenti (Dionysius Longinus de sublimi genere oratio, 1566), Pagano (Longini de sublimi dicendi genere, 1572) et Petra (De grandi siue sublimi orationis genere, 1612), textes que nous avons consultés dans l'édition de Manolessi, Dionysii Longini Cassii de sublimi genere dicendi, Bologne, Carlo Manolessi, 1644. Quintilien n'use pas non plus du terme d'excessus, mais la notion d'excès est bien présente dans son exposé des vices de style avec l'adverbe nimium, Institution oratoire, VIII, 3, 42 : « vitium est ubique quod nimium est ", «l'excès en tout est un défaut» (op.cit., p.173). La définition du vice de cacozelon comme dépassement de la juste mesure par Quintilien retrouve cette notion d'excès avec l'adverbe ultra (voir n. 88), VIII, 5, 56, ibid., p. 178 : « il y a cacozelon partout où l'on exagère une qualité [quidquid est ultra virtutem], toutes les fois que le talent manque de goût et se laisse tromper par l'apparence du beau. ».

42. Du Sublime, III, 1, trad. Lebègue, op. cit., p. 5 ; Caussin a omis le dernier vers cité par le traité («Mais maintenant mon chant violent n'a pas encore retenti»). Ces vers sont extraits de l'Oreithya, tragédie perdue d'Eschyle: Tragicorum graecorum fragmenta, éd. Nauck, fragment 281. C'est Borée, dieu du vent, qui parle. Il a enlevé Oreithya, fille du roi d'Athènes Érechthée qui s'oppose à leur union, et il menace de déchaîner une tempête. Sous la plume du pseudo-Longin, cette citation est dans sa forme comme dans son thème un exemple d'enflure : l'enthousiasme divin, caractéristique du sublime et figuré par le souffle du dieu emportant tout avec lui, n'est en fait que du vent : voir l'édition de F. Goyet, op. cit., p. 168.

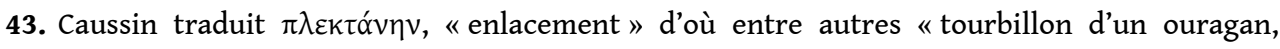
tentacules du poulpe » (sur plekô, «tresser »), par cirrum, littéralement «boucle de cheveux » d'où divers sens dont « houppe » : huppe d'oiseau, sorte de coiffure féminine, chignon ou tresses (voir l'emploi de cirro n. 130), etc., cf. le français cirrus. Cette traduction par cirrum est attestée avant Caussin chez Pagano (Longini de sublimi dicendi genere, 1572, dans l'éd. Manolessi, 1644, op. cit., p. 37) : il s'agit donc d'une source très probable de Caussin.

44. Ici, Caussin paraphrase librement le traité Du Sublime, III, 1, trad. Lebègue, op. cit., p. 5.

45. Id. Pour le tout début de la citation (le cothurne), nous traduisons la traduction latine donnée par Caussin; soit, dans la trad. Lebègue, non pas «tragiques, mais pseudo-tragiques ». Le verbe excedo de Caussin est cohérent avec le mot excessus qu'il utilise en introduction (voir n. 34) et dans ce chapitre infra (voir n. 41).

46. Référence à la Rhétorique à Herennius, IV, 15, voir n. 40. 


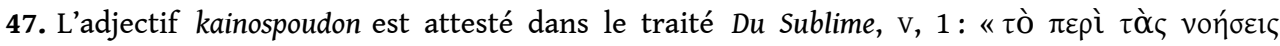

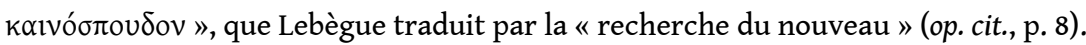

48. Héraclide Lembus (II siècle av. J.-C) : péripatéticien contemporain du roi Ptolémée VI. Il est l'une des principales sources de Diogène Laërce (Vies, doctrines et sentences des philosophes illustres), par qui il est souvent cité.

49. Littéralement « qui crie dès le point du jour ».

50. Littéralement : «qui nourrit pour la journée ». La chénice est une mesure attique pour les grains (1,08 litre).

51. Littéralement: "qui fait du bruit». Nous traduisons toutes ces citations qui sont tirées d'Athénée, Deipnosophistes, III, 54, 98e.

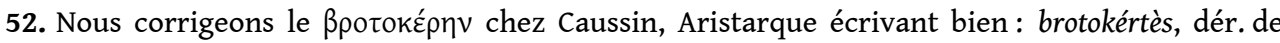
brotos et keirô (litt. : « celui qui rase tous les mortels »).

53. Lucien de Samosate, Lexiphanès, 1, nous traduisons. Voir ce passage dans Comédies humaines, éd. et trad. A.-M. Ozanam, Paris, Les Belles Lettres, 2010, p. 352.

54. Ibid. Lexiphanès use de ce verbe forgé par allusion au Banquet de Platon, pour présenter son livre.

55. Ibid.

56. «Durius» reprend la métaphore «duriter translatis» utilisée plus haut et empruntée à la Rhétorique à Herennius. Voir n. 40.

57. C'est-à-dire: les dauphins. Citation du poète romain Pacuvius (230-120 av. J.C). Varron (116-27) cite la formule donnée par Caussin (V, 7), Quintilien cite le vers en entier (Institution oratoire, I, 5, 71, éd. et trad. J. Cousin, Paris, Les Belles Lettres, 1975, t. I, p. 104) et prend ce terme comme exemple de mot composé, en insistant sur le fait que ce procédé «convient mieux aux Grecs; chez nous, il réussit moins bien; cela ne tient pas, je crois, à la nature de notre langue, mais à notre inclination pour ce qui est étranger ; ainsi avons-nous admiré kurtaúken, mais, en face d'incurvicervicum, c'est à peine si nous nous gardons de rire. »

58. Vers de l'Andromède de Livius Andronicus (280-200 av. J.-C), dans Théâtre complet des latins. Fragments des comiques et des tragiques latins, éd. J.-B. Levée, Paris, A. Chasseriau, 1823, t. XV, p. 5. Caussin cite ensuite de manière très elliptique d'autres archaïsmes tirés du théâtre antique latin (Livius Andronicus, Varron, Accius et Névius), que nous omettons.

59. Aulu-Gelle, Les Nuits attiques, XI, 7, 2-9, éd. et trad. R. Marache, Paris, Les Belles Lettres, 1989, t. III, p. 11. Nous conservons (en l'inversant) l'alternance italiques/romain de Caussin. Celui-ci a omis le passage suivant, après « les fraces, du marc d'olive » (ex oleis) : " et il l'avait lu chez Cécilius dans les Polumeni et s'était mis en réserve ces deux mots pour orner ses discours. Un autre que des lectures du même genre, aussi peu nombreuses, n'avaient pas rendu homme de goût, comme l'adversaire...".

60. Nous corrigeons la traduction Marache en fonction du texte de Caussin, qui écrit «Hic strigosus» ("maigre, efflanqué») là où le texte de l'éd. Marache donne «Si tricosus» (« chicanier »).

61. Nous omettons les exemples d'archaïsmes tirés de Tertullien et d'Arnobius (fin du III s. ap. J.C) que Caussin cite ensuite.

62. Liste de noms reprise de Longin, III, 2. Soit, après le célèbre Gorgias (né vers 480 av. J.-C.), Callisthène, historien, élève d'Aristote, qui prit part à l'expédition d'Alexandre le Grand; Clitarque d'Alexandrie (III ${ }^{\mathrm{e}}$ s. av. J.-C.), historien auteur d'une Vie d'Alexandre; Amphicratès (III ${ }^{\mathrm{e}} \mathrm{s}$. av. J.-C.), rhéteur athénien; Hégésias de Magnésie (IV siècle av. J.-C.), historien et rhéteur, de nouveau cité infra comme exemple d'auteur «froid» (voir n. 108), considéré comme le corrupteur du style attique et l'inventeur de la tendance asianiste (voir C. Wooten, «Le développement du style asiatique pendant l'époque hellénistique ", Revue des études grecques, 1988, vol. 88, nº 419-423, p. 94-104) ; Matris de Thèbes (sans doute III s. av. J.-C.), auteur d'un Éloge 
d'Héraclès (pour les difficultés posées par son identification, voir Dictionnaire des philosophes antiques, Paris, CNRS éditions, 2005, vol. 4, p. 305-306).

63. Du Sublime, trad. Lebègue, op. cit., III, 2, p. 5. Caussin dans son texte grec semble ici faire une erreur en remplaçant le mot Zeus (qui est bien celui du traité Du Sublime) par basileus « le roi », ce qui supprime justement la métaphore. Pizzimenti (1566) proposait avant lui une mauvaise traduction semblable : «Xerxes Persarum Rex », «Xerxès le Roi des Perses » (éd. Manolessi, 1644, op. cit., p. 39).

64. Du Sublime, ibid.

65. Korè en grec signifie la jeune fille, et par analogie la pupille de l'œil, à cause de la petite image qui s'y réfléchit.

66. Cité dans le traité $\mathrm{Du}$ Sublime, ibid., IV,4, p.7-8. La citation provient de Xénophon, Gouvernement des Lacédémoniens, III, 5.

67. Du Sublime, ibid., IV, 5, p. 8. Cette citation est un fragment d'une œuvre perdue du rhéteur et historien grec Timée ( 350 av. J.C ; voir Cicéron, De Oratore, II, 58). Le chapitre IV du traité Du Sublime commence par un long commentaire de Timée qui sert d'exemple au style froid (IV, 1-3). Le traité cite ensuite Xénophon (430-355 av.J.C) sur les vierges et de là revient à Timée (IV,5). Cette citation de Timée provient d'un récit où le nommé Agathocle «partit en enlevant en pleine cérémonie nuptiale sa cousine qui venait d'être mariée à un autre » (ibid.). - Nous ne traduisons pas la traduction latine de cette citation par Caussin, dont le meretrix est tout aussi violent que le grec pornè.

68. Comme l'indique la manchette, Caussin surnomme ainsi Tertullien, qui fut le premier grand théologien de langue latine en Afrique du Nord.

69. Tertullien, Le Scorpiarque, ou antidote contre la morsure des scorpions, 1, Euvres complètes, éd. et trad. A. de Genoude, Paris, Les Belles Lettres, 2017, p. 881.

70. Tertullien, Du Manteau, 3, dans ibid., p. 505. Description du caméléon.

71. Ibid., 1. Dans le passage en question, Tertullien s'adresse aux Carthaginois et regrette la sobre élégance de leurs ancêtres, et, en particulier, leur manteau carré, remplacé après leur soumission à l'empire romain par une tenue plus sophistiquée (ibid., p. 502) : «À partir de ce moment, vous portez votre tunique, plus longue qu'auparavant, avec une ceinture à volonté ; vous soutenez par étages l'immensité des plis de votre manteau [pallii iam teretis redundantiam tabulata congregatione fulcitis], pour le rendre plus commode."

72. Sidoine Apollinaire (430-486), Lettres, IV, 22, 6, éd. et trad. A. Loyen, Paris, Les Belles Lettres, 1970, tome II : «qui colubrinis oblatratorum molaribus fixi ». La métaphore renvoie aux médisances de ceux qui blâment les œuvres des clercs qui « se mêlent d'être écrivains » (ibid.).

73. Apulée, Les Métamorphoses ou l'âne d'or, III, 39, trad. P. Vallette, Paris, Les Belles Lettres, 1947, p. 70.

74. Ibid., III, 14, p. 59.

75. La métaphore de la bulle d'air est attestée en latin pour évoquer la fragilité de la vie humaine. Dans le Satiricon de Pétrone, elle est employée par Séleucus à propos de l'enterrement de son ami Chrysanthus (XLII, éd. et trad. A. Ernout, Paris, Les Belles Lettres, 1990, p. 38) : « Hélas! Nous allons comme des vessies soufflées. Nous valons moins que les mouches ; elles, au moins, elles ont une certaine force, mais nous ne sommes pas plus qu'une bulle d'air [nos non pluris sumus quam bullae]. » Varron l'utilise dans la première phrase de l'Économie rurale, alors qu'il évoque sa vieillesse et son projet d'écriture, I, 1 (éd. et trad. J. Heurgon, Paris, Les Belles Lettres, 1978, p. 8) : «Si j'en avais trouvé le loisir, Fundania, j'écrirais pour toi un meilleur livre sur ce que je vais exposer maintenant tant bien que mal, en songeant qu'il faut me hâter, puisque si, comme on dit, l'homme n'est qu'une bulle d'air [si est homo bulla], c'est d'autant plus vrai du vieillard. » Érasme développe également la métaphore dans l'adage 1248, Homo bulla. 
76. Sénèque, Hercule sur l'Oeta, I, v. 11-14, trad. M. Nisard, Théâtre complet des Latins, Paris, J. J. Dubochet et compagnie, 1844, p. 150.

77. Ibid., v. 30-32, p. 150-151.

78. Ibid., v. 34-36, p. 151.

79. Ibid., v. 87-91, p. 151.

80. Nous omettons ensuite la citation et analyse des vers tirés de Nonnos de Panopolis $\left(\mathrm{IV}^{\mathrm{e}}-\mathrm{V}^{\mathrm{e}} \mathrm{s}\right.$.), Dionysiaques, chant II, v. 334-336, puis 352-354, 325-327 et 346-347.

81. Le « même exemple » renvoie à ce qui précède et que nous avons omis, les vers du poète grec Nonnos, qui ont déjà des cas d'enflure " par les mots », par exemple asteronôton, " au dos étoilé » pour qualifier le Ciel (v. 335 : «le ciel étoilé que je vais gouverner» dans la trad. du comte de Marcellus, Paris, Firmin-Didot, 1856, sur le site Remacle). Plus haut, dans Hercule sur l'ÆEta, Caussin a noté: "Si c'était Typhon qui prononçait ces paroles, elles seraient à peine supportables ». Or ici, chez Nonnos, les paroles ridicules ont beau être celles du géant Typhon ou Typhée, elles restent aux yeux de Caussin impardonnables (58b, fin: "Peu importe que ce discours soit de Typhon ", "Nec refert, quod Typhoni tribuatur oratio »).

82. C. Naevius (275-201 av. J.-C.), Gymnasticus, dans Fragments des tragiques et des comiques latins, éd. et trad. J.-B. Levée, Paris, A. Chasseriau, 1823, t. XV, p. 78.

83. C. Naevius, Gallinaria, ibid., p.76, nous ajoutons le tiret comme supra. Caussin souligne seulement le dernier mot, comprendre toluti et loquentia : une éloquence tolutilis, litt. «qui va au trot ", qui ne s'arrête pas.

84. Lucien de Samosate, Lexiphanès, 16-17, op.cit., p.372-373. Dans cette réplique, Lycinos interrompt la lecture de Lexiphanès pour blâmer son style enflé. La citation est en grec puis Caussin en donne une traduction latine, laquelle reprend presque à l'identique celle de Jacob Micyllus (Jacob Moltzer, 1503-1558), dans Luciani Samosatensis Opera, Francfort, Egenolph, 1543, f. $163 \mathrm{v}^{\mathrm{o}}$. - Après « je ne sais où » (alicunde eruens), Caussin a omis ceci : « selon le vers iambique : Péris donc! tu choisis le malheur des mortels !»

85. Ibid., 19.

86. Aulu-Gelle (123-180), Les Nuits attiques, X, 1-4, éd. et trad. (légèrement modifiée) R. Marache, Paris, Les Belles Lettres, 1967, t. I, p. 41. Le soulignement par Caussin de la dernière phrase (« Vis donc... ») signale une maxime.

87. Citation par Aulu-Gelle de Sénèque le Rhéteur (54-39 av. J.-C.), Controverses et suasoires, IX, II, 26, éd. et trad. H. Bornecque, Paris, Garnier Frères, s.d. [1909 ?], t. II, p. 151. Le passage, qui traite de l'orateur Vibius Rufus et de sa «manière antique» [antiquo genere] (IX, 2, 25), rapporte un propos de Tite-Live sur les « orateurs qui recherchent les mots anciens et triviaux [verba antiqua et sordida] et prennent, dans le discours, l'obscurité pour la gravité [obscuritatem severitatem putant] » (IX, 2, 26). Sénèque place ces orateurs dans la catégorie de l'enflure (ibid.) : « ceux dont le style est ampoulé et qui souffrent d'exubérance verbale », "qui tument, illi, qui abundantia laborant ».

88. Nous traduisons le mot cacozelum par le calque cacozélie puisque le terme est déjà, sous la plume de Caussin, le calque d'un mot composé grec, kazo-zelos. Littéralement, le terme signifie la « mauvaise ardeur à imiter ». Sur ce vice, que Quintilien définit de manière plus large comme une «mauvaise affectation » (Institution oratoire, VIII, 5, 56), voir l'édition critique de Mosellanus par Ch. Noille dans le présent numéro d'Exercices de rhétorique, en particulier n. 65.

89. Lucien, Sur la danse, 82, nous traduisons. Voir la trad. d'A.-M. Ozanam (dans Euvres complètes, Paris, Belles Lettres, 2018, p. 788) : «on en vient à faire ce qu'on appelle communément "surjouer", si l'on dépasse la mesure de l'imitation et qu'on force le trait ». Dans ce passage, le kakozelon s'applique à la danse, qui est comparée à l'écriture. Voici la suite du passage (ibid.) : «Doit-on montrer quelque chose de grand, on le rend gigantesque, quelque chose de délicat, on l'effémine à l'excès, quelque chose de viril, on le pousse jusqu'à la sauvagerie et à la bestialité. » 90. Virgile, L'Énéide, XII, v. 897, nous traduisons. 
91. L'allusion renvoie, selon notre interprétation, à Homère dans ses Hymnes: les Nymphes qui entourent Pan « marchent sur les cimes inaccessibles aux chèvres » (hymne à Pan, v. 4). Dans ce vers, le sens de l'adjectif aigilips était déjà obscur pour les Anciens, qui rapprochaient le second terme de leipô et entendaient "qui décourage les chèvres " (Homère, Hymnes, éd. et trad. J Humbert, Paris, Les Belles Lettres, 1967, p. 211, n. 1). Marulle (1458-1500) a imité le vers homérique dans son propre hymne à Pan, v. 27 : le dieu «par les rocs inaccessibles aux chèvres / conduit les danses des Vierges" ("rupesque inaccessas capellis / virgineas agitat choreas »: dans Michel Marulle, Hymnes naturels, éd. et trad. J. Chomarat, Genève, Droz, 1995, p. 78-79). La cacozélie consiste dans ce cas à vouloir être Homère à la place d'Homère en rivalisant d'épithètes hyperboliques avec lui : la roche est si énorme qu'au lieu de faire fuir les chèvres elle leur sert de logis.

92. Lucien, Loukios ou l'âne, 13, dans Euvres complètes, op. cit., p. 641.

93. Apulée, Les Métamorphoses ou l'âne d'or, III, 24, op. cit., p. 66.

94. L'histoire est racontée par Pline, Histoire naturelle, XXXV, 67.

95. Chez Pline, c'est Zeuxis qui peint et qui se met en colère.

96. Voir Sénèque le Rhéteur, Controverses et suasoires, X, v (op. cit., t. II, p. 263) : « Lorsque Philippe vendait les Olynthiens comme prisonniers de guerre, Parrhasius, peintre athénien, acheta l'un d'eux, un vieillard; il le fit mettre à la torture, et, sur ce modèle, peignit un Prométhée. L'Olynthien mourut dans les tortures. Parrhasius mit son tableau, comme offrande, dans le temple de Minerve. On l'accuse d'avoir causé un préjudice à l'État. »

97. Chez Sénèque le rhéteur, le "trait déplorable " [turpem sententiam] de Spyridion, dû à la «jolie anecdote» [fabula eleganti] de Zeuxis, est rapporté ainsi (ibid., X, v, 27, p. 276) : «Spyridion s'imagina que les vautours pénétraient dans un temple aussi communément que des moineaux ou des colombes, car il dit : "Les oiseaux de proie étaient trompés par ton tableau." "

98. Aristote, Rhétorique, 1406a-1406b. Aristote attribue le style froid aux mots composés, aux néologismes, aux épithètes et aux métaphores, ce qui correspond à ce que Caussin définit comme l'enflure par les mots.

99. Du Sublime, III, 2, trad. Lebègue, op. cit., p. 6.

100. Caussin écrit en grec : kainospoudia. Le traité Du Sublime emploie l'adjectif kainospoudon dans

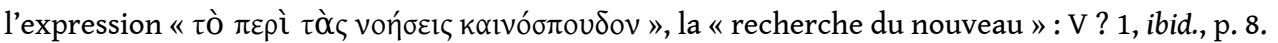

101. La temperatura en latin désigne la composition équilibrée du corps, le " tempérament » au sens ancien de ce mot. Servius commente cet adjectif à propos d'un vers des Bucoliques, VIII, v. 71 : «Frigidus in pratis cantando rumpitur anguis", "Ils [mes charmes magiques] peuvent dans les prés rompre le froid serpent» (trad. P. Valéry). Servius commente : «Frigidus: nocens : ut frigida Saturni quo sese stella recaeptet.» "Froid: pernicieux: l'endroit où se retire la froide Saturne " (Commentaire aux "Bucoliques" de Virgile, trad. F Daspet, Paris, Jouve, 2007, p. 144).

102. Denys d'Halicarnasse (60-8), «Lettre à Pompée Géminos ", XI, 2, 1. Caussin cite en manchette la formule suivante de Denys: «les gorgianismes [gorgeiois] qu'il utilise puérilement», mais Denys ne mentionne nullement les «tombeaux vivants " cités par le pseudo-Longin. Le passage en question est une critique par Denys du style de Platon (Opuscules rhétoriques, éd. et trad.G. Aujac, Paris, Les Belles Lettres, 1992, t. V, p. 83-84) : «Lorsqu'en revanche le style de Platon prend sans mesure son élan vers le raffinement et la beauté d'élocution, ce qui lui arrive fréquemment, il se gâte considérablement; il a alors moins d'agrément, un hellénisme moins pur, plus d'épaisseur; il obscurcit ce qui est clair, le transforme en ténèbres ; il étire en longueur l'idée qu'il faudrait ramasser en quelques mots. Il se répand en périphrases vulgaires, faisant étalage d'un riche vocabulaire; dédaignant les termes propres, pris dans leur acception courante, il cherche des mots fabriqués, étrangers, fleurant l'archaïsme. Surtout il se débat dans des tours figurés, prodigue les ornements ajoutés, manque d'à-propos dans les métonymies, est guindé, néglige de respecter la correspondance dans les métaphores; il regorge d'allégories qui manquent de mesure et d'à-propos ; il se complaît dans des figures poétiques totalement dénuées 
d'agrément, et tout particulièrement dans les gorgianismes qu'il utilise puérilement et hors de propos. »

103. Hermogène cite les "tombeaux vivants" (Les catégories stylistiques du discours, «La noblesse ", éd. et trad. M. Patillon, dans L'art rhétorique, s.l., L'Âge d'homme, 1997, p. 353 [Rabe 249]) sans attribuer la formule à Gorgias, mais de manière plus générale aux sophistes (ibid., p. 352-353) : « les expressions métaphoriques [...] employées avec mesure, rendent le discours noble. [...] En revanche, si elles viennent à dépasser la mesure, elles donnent de la rudesse au discours [...]. On n'en trouvera pas d'exemple chez Démosthène, car il n'y en a pas. On en trouvera une multitude en revanche chez ces maudits sophistes de pacotille; ils appellent tombeaux vivants ces vautours dont ils sont si bien dignes, et ils font une multitude d'autres froides trouvailles de ce genre."

104. Suidae Lexicon ( $2^{\text {ème }}$ moitié du $x^{\mathrm{e}}$ siècle ?), éd. E. Bekker, Berlin, Reimer, 1854, p. 332. Caussin renvoie explicitement à cet ouvrage en manchette, en précisant «s. v. psukhros ».

105. Nous corrigeons la leçon de 1619, qui donne callidus, par calidius, comparatif de caldus attesté dans les éditions de 1630 et 1637.

106. Nous reprenons la correction en dicta de l'édition 1630 des Parallela (Paris, Henault et al.). Littéralement : «À partir des choses qui ont été dites », soit : " De tout ce qui vient d'être dit ».

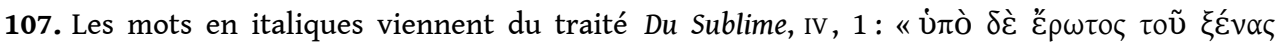
vońбદı५», "la manie de vouloir exprimer toujours des pensées neuves", éd. Lebègue, p. 7. Ensuite, notre «nouvelles et étonnantes » traduit les deux adjectifs latins, nouus et peregrinus, par lesquels Caussin rend tout ce qu'il perçoit dans le grec xenos, qui signifie au propre "étranger », d'où « étrange, insolite, étonnant ».

108. En dépit de cette formulation, l'exemple qui suit est tiré du seul Plutarque - en italiques, sa citation, en romain, les mots ajoutés par Caussin. Plutarque nommant Hégésias, Caussin à son tour nomme Longin, qui n'a mentionné qu'au passage Hégésias (voir n. 62).

109. Plutarque (46-120), "Alexandre», III, 5-6, Vies parallèles, éd. F. Hartog dir., trad. A.M. Ozanam, Paris, Gallimard, 2001, p. 1229.

110. Voici le passage complet du traité Du Sublime, IV, 2, op. cit., p. 7 : «Je ne citerai qu'un ou deux exemples; aussi bien Cécilius en a déjà relevé la plus grande partie. Timée s'exprime ainsi dans son éloge d'Alexandre le Grand : “Il a conquis l'Asie entière en moins d'années qu'Isocrate n'en a mis pour écrire le Panégyrique sur la guerre à faire aux Perses." Étonnante comparaison, certes, entre le héros macédonien et le rhéteur ! Évidemment, ô Timée, les Lacédémoniens le cédaient de beaucoup en valeur à Isocrate : ne mirent-ils pas trente ans pour s'emparer de Messène, tandis que celui-ci n'en employa que dix pour faire son discours d'apparat? " Caussin fait suivre sa brève citation («Étonnante comparaison...») de sa propre traduction en latin, où il rend thaumastè par admirabilis et sophistè par sophista.

111. Caussin paraphrase en latin le traité Du Sublime en reprenant plutôt les expressions de la trad. Pagano (1572, dans éd. Manolessi, 1644, op. cit., p. 49) : « Asiam paucioribus annis subegit, quàm quot Panegyricam orationem de bello contra Persas scripsit Isocrates. »

112. Cité dans le traité Du Sublime, Iv, 3, trad. Lebègue, op. cit., p. 7.

113. La Bible de Sacy traduit : «Car toutes les bêtes qui sont dans les bois m'appartiennent ; aussi bien que celles qui sont répandues sur les montagnes, et les bœufs» (psaume 49:10 - le «61» mentionné par Caussin semble être une erreur). Le commentateur est le rabbin Rachi (aussi nommé Rabbi Salomon de Troyes). Il commente le texte biblique hébreu «Behemot beharare elef ", litt. « des bêtes dans les montagnes mille », où mille peut syntaxiquement se rapporter à bêtes ou à montagnes-est mis par Caussin ou son typographe en tête de la citation. Le (mille) אלף commentaire de Rachi, qui imagine une seule bête se nourrissant des herbes de mille montagnes, se justifie par l'existence, en hébreu, d'un pluralis excellentiae (un pluriel « d'excellence », comme on dit « de majesté »), qui permet d'exprimer la grandeur en faisant figurer le nom au pluriel. 
114. Exode ( $4: 10)$. Dieu vient de répéter à Moïse qu'Israël écoutera sa voix. Voici le verset dans la trad. Sacy : «Moïse dit alors : “Seigneur, je vous prie de considérer que je n'ai jamais eu la facilité de parler ; et depuis même que vous avez commencé à parler à votre serviteur, j'ai la langue encore moins libre et plus empêchée [impeditioris et tardioris linguae sum, Vulgate]. »

115. Le commentaire vient du Midrash Rabba, sans doute rédigé au $\mathrm{XI}^{\mathrm{e}}$ siècle, un ensemble de commentaires traditionnels de la Torah. Caussin déforme l'histoire et omet un élément essentiel à la compréhension de la glose : dans le Midrash, Moïse, âgé de trois ans, ne jette pas la couronne à terre mais, en jouant avec le Pharaon, la met sur sa propre tête. Les conseillers ont alors pris peur, et pour savoir si ce geste montrait un désir de remplacer le Pharaon, on a présenté à l'enfant de l'or et du charbon: Moïse a saisi le charbon et l'a mis dans sa bouche.

116. Philon d'Alexandrie (20 av. J.-C-45), philosophe juif né à Alexandrie. Origène (185-253), le théologien qui fut le premier grand commentateur de l'Ancien Testament, né à Alexandrie et mort à Tyr.

117. Dans le passage qui suit, Caussin cite des interprétations allégoriques du livre de Job et des évangiles, dont nous avons relevé les sources chez Origène et Grégoire le Grand (540-605). Toutes ces allégories sont répertoriées dans le trésor collecté et référencé par le bénédictin J. de Llauret (1506-1571) : Sylva allegoriarum totius Sacrae Scripturae, Barcelone, 1570. Nous citons l'édition de Paris, S. Nivelle, 1583 : «Arcturus» fol. $79 \mathrm{r}^{\circ}-\mathrm{v}^{\circ}$, «Culex, Cynips» fol. $178 \mathrm{r}^{\circ}$ (renvoi de "Sciniphes vide Culex» $536 \mathrm{v}^{\circ}$ ), «Ibices» fol. $318 \mathrm{v}^{\circ}-319 \mathrm{r}^{\circ}$, «Perdix» fol. $470 \mathrm{v}^{\circ}$, «Porticus» fol. $485 \mathrm{v}^{\circ}$, «Saliva» fol. $527 \mathrm{v}^{\mathrm{o}}-528 \mathrm{r}^{\circ}$, «Sapphirus» fol. $534 \mathrm{v}^{\mathrm{o}}$, « Sudes» fol. $570 \mathrm{v}^{\mathrm{o}}-571 \mathrm{r}^{\circ}$.

118. Origène, Peri Archôn, II, 6, 1 (Traité des principes, éd. H. Crouzel et M. Simonetti, Paris, Les Éditions du Cerf, 1978, t. I, p. 309) ; nous traduisons, ici et ensuite. Le passage commente Jean (10 : 23-25).

119. Grégoire le Grand, Morales sur Job, xxix, xxxviII, 73 (Patrologie latine, t. 76/2, éd. J.-P. Migne, 518). Le passage commente Job (38:31-32).

120. Grégoire le Grand, Morales sur Job, XXXIII, VIII, 15, ibid., p. 681. Le passage commente Job (41 : 2).

121. Grégoire le Grand, Morales sur Job, vIII, Xxx, 49 (Patrologie latine, t. 75/1, éd. J.-P. Migne, 832). Le passage commente Job $(7: 19)$.

122. Grégoire le Grand, Morales sur Job, XXX, x, 36 (Patrologie latine, éd. citée, t. 76/2, op. cit., 544). Le passage commente Job $(39: 1)$.

123. Grégoire le Grand, Morales sur Job, XVIII, XLVII, 76 (Patrologie latine, t.76/2, ibid., 83). Le passage commente Job $(28: 6)$.

124. Origène, Homélies sur Jérémie, t. 2, éd. et trad. P. Nautin, Paris, les Éditions du Cerf, 1977, XVII, 2, p. 163. Le passage commente Jérémie $(17: 11)$.

125. Origène, Homélies sur l'Exode, IV, 6, nous traduisons. Voir l'éd. de W.A. Baehrens, Paris, Éditions du Cerf, 1985, p. 135. Le passage commente Exode (8:12-15).

126. Ibid. Nous traduisons.

127. Les trois adjectifs sont employés dans le traité Du Sublime, III, 2 (trad. Lebègue, op. cit., p. 6) :

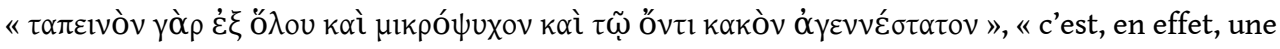
marque complète de bassesse, de petit esprit; et c'est en réalité le plus ignoble des défauts de style. »

128. Les «jardins d'Adonis" sont des graines que, durant les Adonies (fêtes en l'honneur du défunt Adonis), on plantait en les arrosant d'eau chaude pour accélérer leur croissance, si bien qu'elles mouraient très rapidement, à l'image de la brève vie du héros et de son énergie sexuelle. Platon mentionne les jardins d'Adonis dans le dialogue du Phèdre: le sage laboureur est invité à planter ses graines dans un terrain plus sain $(276 \mathrm{~b})$.

129. Sénèque, Lettres à Lucilius, op.cit., XIX,114,5-6 - nous introduisons dans le latin des guillemets pour isoler les phrases de Mécène citées par Sénèque. Caussin suivant le texte latin et 
la ponctuation de l'édition des Lettres dans la trad. Mathieu de Chalvet (Paris, L'Angelier, 1609, fol. $265 \mathrm{v}^{\mathrm{o}}-266 \mathrm{r}^{\circ}$ ), nous reprenons cette traduction d'époque, en modernisant ses graphies et en y ajoutant les guillemets - mais sans la modifier au seul endroit où son texte latin diffère de celui de Caussin (Chalvet écrit « rimantur, epulis lagoenaque »). Au tout début, le quid turpius de Sénèque présente les expressions de Mécène comme étant "dégoûtantes»: Caussin et déjà Chalvet écrivent quid purius, ce qui revient à les qualifier de "pures ", en jouant sur la paronomase latine. L'image du pur, en partie ironique sous la plume de Caussin (elle sera contredite plus loin par l'adverbe impurius, voir n. 134), fait peut-être écho au thème de l'eau et des reflets dans les citations qui suivent. Elle connote également l'imaginaire bucolique du style moyen, qui, selon Quintilien, ressemble à " un cours d'eau assez paisible et transparent certes, mais ombragé sur les deux rives par de la verdure ", Institution oratoire, XII, 10, 60 (« lenior tamquam amnis et lucidus quidem sed uirentibus utrimque ripis inumbratus »: t. V, trad. J. Cousin, Paris, Les Belles Lettres, 1980). Il est possible que Caussin songe aussi, dans ce chapitre où il est fait référence à la littérature profane de leur temps, aux divers styles "puristes» d'Europe (purismo espagnol, puristes français), affectionnés en particulier par les jeunes écrivains.

130. Nous suivons ici, comme partout ailleurs, le texte tel qu'il est donné par Caussin, mais ici celui de Sénèque diffère sensiblement du texte des éditions actuelles, le sens lui-même n'étant par définition pas très clair. Par exemple, au début, la traduction F. Préchac et H. Noblot rend par « le galant qui se crispe le visage des clins d'yeux à sa maîtresse », et P. Veyne par « celui qu'une liqueur féminine fait frissonner» (dans Sénèque, Entretiens, Lettres à Lucilius, Paris, Laffont, «Bouquins ", 1993, p. 1039-1040, avec, en note : «Si vraiment le texte portait cinnus et si le cinnus est bien un alcool de grain, [...] le personnage frissonne à la liqueur d'une bouche où l'amour se pavane »). La trad. Chalvet lit cirro et non cinno et rend par " se frise les cheveux » : c'est le cirrus (voir n. 43), qui désigne ici une sorte de coiffure féminine, difficile à préciser mais certainement élégante: un chignon que l'on frise ou "crêpe " (latin crispare) ? La seule discussion que nous ayons trouvée à ce sujet est à propos du mot grec sisoè de la Septante dans Lévitique 19 : 27 (mais c'est un hapax, que le Bailly rend par «cheveux tressés»). Le texte de ce verset serait, selon Cyprien: "Non facietis cirrum ex coma capitis vestri», "Vous ne ferez pas de cirrus [tresses, chignon ?] avec vos cheveux" (Cyprien, Ad Quirinum, III, ch. 83, Patrologie Latine, t. 4, éd. J.-P. Migne, 773 ; voir le développement ad locum dans Vetus Testamentum secundum LXX latine redditum, Rome, G. Ferrari, 1588, p. 158B).

131. Hadrien (76-138), « Vies d'Hadrien, Aelius, Antonin », Xxv, 9, Histoire Auguste, éd. et trad. J.-P. Callu, Paris, Les Belles Lettres, 1992, t. I, p. 47.

132. Voir Apulée, Florides, I, 3, éd. P. Vallette, Paris, Les Belles Lettres, 1924, p. 128-129. Caussin cite Apulée en tronquant le passage à plusieurs endroits.

133. Chez Ovide, Vénus fait naître du sang de son amant défunt une anémone, fleur odorante mais trop légère, dont le vent fait tomber les pétales (Métamorphoses, X, v. 735-739). Ces fleurs font écho à l'imaginaire du style moyen et fleuri du début de la section ; voir n. 129.

134. Allusion au cinquième des travaux d'Hercule, qui consiste à laver les écuries du roi Augias, que ce dernier négligeait depuis trente ans. Ce développement se clôt sur l'adverbe impurius (immonde, pestilentiel), que nous ne pouvons pas rendre, pour qualifier l'odeur de l'écurie. Cet impurius dément le prétendu style "pur » (purius) ironiquement prêté à Mécène au début du chapitre (voir n. 129).

135. Oppien d'Apamée ( $\mathrm{III}^{\mathrm{e}} \mathrm{s}$. ap. J.-C.), Cynégétique, dans L'Art de la chasse. Cynégétiques, éd. et trad. L. L'Allier, Paris, Les Belles Lettres, 2009, v. 220-233, p. 101 ; nous modifions son « loué les dieux » en " prié les dieux ». La parenthèse qui interrompt le poème est une raillerie énoncée par Caussin.

136. Caussin fait également référence à la murène de Crassus dans Polyhistor Symbolicvs, Electorum Symbolorum \& Parabolarum historicarum..., Paris, de Beauvais, 1618, p.459, où il renvoie à Cl. Aelianus (175-235), De natura animalium, VIII, 4. 
137. Le texte original porte : "psittacum, melioris », comme s'il s'agissait d'un comparatif. Mais il s'agit sûrement d'une faute de l'imprimeur, qui n'a pas vu que Melioris était un nom propre (nom que le Gaffiot ne mentionne pas). Il s'agit d'une allusion aux Silves de Stace (40-96), où le poète déplore la mort du perroquet d'Atédius Mélior (II, 4).

138. Démosthène, Oraison funèbre, 34 , dans Discours d'apparat, éd. et trad. R. Clavaud, Paris, Les Belles Lettres, 1974, p. 65.

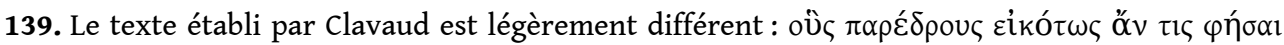

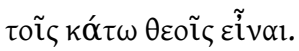

140. Longtemps identifié à Théodore de Gadara, le professeur de Tibère, le Théodore cité par le traité Du Sublime serait plutôt Théodore de Byzance : voir Traité du sublime, éd. Fr. Goyet, op. cit., p. 170.

141. Boileau traduira le parenthyrson du Traité du sublime par « une fureur hors de saison » (ibid., p. 77).

142. Sabinus le Grammairien, dans Anthologie grecque. Anthologie palatine, VI, 158, éd. et trad. P. Waltz, t. III, Paris, Les Belles Lettres, 1931, p. 88. Il s'agit de la seule épigramme connue de cet auteur, dont l'époque n'a pas été déterminée.

143. Du Sublime, III, 5, trad. Lebègue, op. cit., p. 6. Suit la traduction latine par Caussin, très proche, et que nous ne traduisons donc pas (Caussin y rend «pathétique " par affectibus puis affectu).

144. Localité antique de Syrie proche d'Antioche. Constantius Gallus y fit bâtir, devant le temple d'Apollon qui tombait alors en ruine, une église consacrée à saint Babylas où se trouvaient ses reliques. En 362, son frère l'empereur Julien fit restaurer le temple païen et quelques jours après un incendie se déclara dans le temple. Jean Chrysostome prétendit que la cause en était un éclair tombé du ciel. Julien mourut peu après et le temple d'Apollon, complètement détruit, ne fut jamais restauré.

145. Voir J. Chrysostome (344 ?-407), Discours sur Babylas, Paris, Éditions du Cerf, 1990, p. 247. Dans ce discours, Chrysostome cite longuement la Lamentation de Libanios (314-393 ?), son maître, sur l'incendie du temple de Daphné (ibid., 112, p. 247) : «le gouverneur, dont les yeux venaient de goûter le sommeil, à la triste nouvelle se leva de son lit. Fou furieux il s'élança, demandant à Hermès des ailes, et se mit à la recherche de la racine du mal, non moins embrasé intérieurement que le temple [...]. » Libanios est qualifié de « libertin et infâme » (ibid., 113, p. 249).

146. Aelius Aristide (117-185 ?), rhéteur et sophiste grec. Lorsque Smyrne, la cité où il s'était installé, fut ravagée par un séisme, il prononça un discours qui incita Marc Aurèle à la reconstruire. Pour l'édition de ses discours, voir Aristides, éd. W. Dindorf, Leipzig, G. Reimer, 1829. 147. Nous nous inspirons de la manchette : «Parenth. character.».

148. Le terme paratragôda (cité précédemment par Caussin, voir supra n. 45), est attesté dans le traité Du Sublime. Lebègue le traduit par « pseudo-tragique », III, 1, op. cit., p. 5.

149. Apulée, Les Métamorphoses ou l'âne d'or, III, 3, op. cit., p. 51 (exorde d'un long discours).

150. Ibid., III, 7, p. 54. Caussin abrège le discours, et reprend à l'effet produit sur le public, plus longuement décrit chez Apulée (qui écrit exactement « risu maximo dissolutum »).

151. Ibid., III, 8, p. 54-55.

152. Dans ce chapitre Caussin appelle Longin « Cassius » et non plus « Dionysius ».

153. La palestre est un lieu public où les jeunes gens de l'Antiquité s'entraînaient à la lutte ou en gymnastique. L'opposition de ces exercices ludiques au combat à l'armée (palaestra vs acies) se trouve notamment chez Cicéron, dans Brutus, IX, 37-38 (éd. J. Martha, Paris, Les Belles Lettres, 1973, p. 13) : «Démétrius, le plus savant assurément de la série, mais qui, moins formé par la pratique des combats que par les exercices de la palestre, charmait les Athéniens plutôt qu'il ne les enflammait : c'est qu'il était venu braver le soleil et la poussière en sortant non pas d'une tente, comme un soldat, mais des ombrages d'une école, celle du très savant Théophraste. Démétrius fut le premier qui abaissa le ton de l'éloquence ; il lui donna son nerf et sa vigueur ; il 
aima mieux paraître agréable que puissant et il le fut en effet, mais d'un agrément propre à imprégner les âmes et non à leur faire violence. »

154. Voir l'adage 320, Citis quadrigis. Jovis quadrigis ("Sur un char rapide : le char de Jupiter») : Homère, dit Érasme, "attribue aux dieux des chars sur lesquels, là où il leur plaît, ils sont emportés en un clin d'œil de l'olympe sur la terre, et à nouveau de la terre au ciel ». Le char «blanc " est dans l'adage 321 (Equis albis praecedere, "En tête sur des chevaux blancs »), où est cité Plaute («albis quadrigis»): l'adage signifie «la nette supériorité de quelqu'un dans un quelconque domaine » (Érasme, Les Adages, éd. et trad. sous la dir. de J.-C. Saladin, Paris, Les Belles Lettres, 2011).

155. Rare emploi par Caussin d'un mot qui n'est pas du latin classique. Intrudo est un mot du latin médiéval, formé à partir du verbe classique trudo, " pousser avec force " (d'où fr. intrus, intrusion). 156. Allusion à un passage du discours Sur la Couronne de Démosthène, où ce dernier dénonce l'argumentation de son adversaire Eschine (Plaidoyers politiques, t. IV, «Sur la couronne », 232-233, éd. et trad. G. Mathieu, Paris, Les Belles Lettres, 1989, p. 100) : «Et d'ailleurs je n'hésiterai même pas à dire que qui voudrait examiner avec justice, sans faire le sycophante, ce qu'est l'orateur, ne lancerait pas une accusation comme la tienne d'il y a un instant, en imaginant des exemples, en parodiant des expressions et des attitudes (c'est bien sûr à cela, ne le vois-tu pas ? que tenait le sort de la Grèce, que j'aie employé cette expression, et non pas cette autre, que j'aie allongé le bras par ici, et non pas par là); en s'appuyant sur les faits eux-mêmes, il examinerait quelles ressources et quelles forces avait notre cité lorsque je suis arrivé aux affaires, ce que je lui ai apporté après cela par mon activité et quelle était la situation de nos adversaires. »

157. Isocrate (436-338), "Philippe», 12, dans Discours, éd. et trad. G. Mathieu et É. Brémond, Paris, Les Belles Lettres, 1987, t. IV, p. 22.

158. Ibid., 27-28, p. 26.

159. L'expression latine « excusatio non petita accusatio est » équivaut à « qui s'excuse s'accuse ».

160. Ibid., 23, p. 25.

161. Litt., " qui contient aussi une suasion ». Le mot suasio ne désigne pas de façon générale la persuasion, mais l'un des principaux discours délibératifs, appelé aussi oratio suasoria (ou " suasoire») - adjectif utilisé auparavant par Caussin pour caractériser le discours à Philippe. Une suasio conseille de prendre telle décision plutôt que telle autre, par exemple faire la guerre (ou la paix), là où la dissuasio le déconseille ou en « dissuade ».

162. On retrouve ici, avec « sentit et dicit », le couple habituel de Caussin, les sensus et les uerba (les «pensées » et les « mots »).

163. Isocrate, Panégyrique, IV, 14, dans Discours, op.cit., p. 18. Caussin traduisant la citation, nous faisons figurer uniquement la traduction du texte grec, où nous avons introduit, sous forme de parenthèse en romain, un propos qui est de Caussin (sur les dix années passées à écrire le Panégyrique).

164. Ce n'est pas le sens classique de la locution in promptu, qui signifie plutôt « sous les yeux, sous la main", mais le français «impromptu» (attesté au XVII ${ }^{\mathrm{e}}$ siècle) vient bien de cette locution. On peut supposer que Caussin emploie ici la locution latine dans le sens qu'elle a en français.

165. Ibid., IV, 187, p. 63. Nous ne traduisons pas la traduction latine de Caussin qui vient ensuite.

166. Sur ce sens rhétorique d'insinuatio, " exorde indirect ", voir Cicéron, De Inuentione, I, 23 : c'est un type d'exorde par lequel l'orateur, face à un auditoire hostile, ne va pas droit au but. La citation donnée ensuite se situe justement au début du discours de Julien.

167. L'empereur Julien (331-363), « Éloge de l'impératrice Eusébie », II, 1, Cuuvres complètes, éd. et trad. J. Bidez, Paris, Les Belles Lettres, t. I, 1932, p. 73. Eusébie (morte en 360) fut la protectrice de Julien.

168. Caussin paraphrase et abrège le discours de Julien, ibid., I-II, p. 75. 
169. Paraphrase de nouveau abrégée : ibid., II, p. 75. L'éloge de Pénélope revient en XVII, ibid., p. 102-103.

170. Le terme de thèse (thesis chez Caussin, calque grec dont l'équivalent latin est propositio) est utilisé ici comme synonyme de « lieu commun ». Son sens rhétorique est cependant sensiblement différent, puisqu'il renvoie, en ce qui concerne l'époque antique et moderne, à une considération générale. La formule il faut louer [laudandum est] était traditionnellement utilisée en rhétorique pour décrire la proposition ou thèse d'un discours d'éloge.

171. Les exemples d'Homère abondent dans le chapitre II, mais aussi dans la suite du discours, dont au chap. Ix. La digression sur la Grèce commence chap. III (plus exactement, sur la Macédoine) : mais en fait de digression, c'est là le développement, attendu dans un éloge, sur la patrie de la personne louée, Eusébie en l'occurrence.

172. Ibid., XV.

173. Ibid., XVI, p. 99 : «Quand on a trouvé dans ces livres des trésors variés de pensées finement exprimées, il n'est que juste de tâcher d'en chanter les louanges, fût-ce avec des expressions mesquines et triviales et dans des phrases pleines de gaucherie et de rusticité. »

174. Denys d'Halicarnasse, «Lettre à Pompée Géminos ", XI, 3, 21, Opuscules rhétoriques, op. cit., t. V, p. 93.

175. Allusion au dialogue Lexiphanès de Lucien de Samosate, où Lycinos, après avoir prescrit un vomitif à Lexiphanès avec l'aide du médecin Sopolis afin de purger son langage (voir ci-dessus), lui donne ce conseil (22, op. cit., p. 377-379) : «Si tu désires vraiment être loué sincèrement pour ton éloquence et obtenir du succès devant le public, fuis absolument tous les mots de ce genre et détourne-t-en. Commence par étudier les meilleurs poètes et lis leurs œuvres sous la conduite de professeurs ; passe ensuite aux orateurs et quand tu te seras nourri de leur langage, il sera temps de passer à Thucydide et à Platon, après t'être exercé longuement à la belle comédie et à la noble tragédie. Une fois que tu auras cueilli toutes les plus belles fleurs de ces auteurs, tu seras quelqu'un en littérature, car pour le moment, tu es devenu sans t'en apercevoir semblable à ces figures fabriquées par les gens qui les modèlent pour le marché : tu es coloré de vermillon et de bleu, mais à l'intérieur, c'est de l'argile friable. "

176. La formule, en latin, évoque le titre de Quintilien, Institutio oratoria, traditionnellement calquée en français par L'Institution oratoire, et dont une traduction plus fidèle serait « l'éducation oratoire ».

177. En latin, oratoriae facultati, «la compétence (la facilité) oratoire ». La facultas est le mot qu'emploie régulièrement Quintilien pour rendre le mot grec hexis (en latin scolastique, habitus), terme qui désigne dans l'éthique de l'Antiquité une disposition stable, acquise à force d'entraînement et de réflexion sur sa technique (soit, en latin, usus et ars).

178. Denys d'Halicarnasse, «Lettre à Pompée Géminos ", XI, 3, 21, Opuscules rhétoriques, op. cit., t. v, p. 93. Voir n. 174.

179. Les numeri, littéralement " nombres », désignent des combinaisons de mètres insérées dans la prose : les plus connus se trouvent dans les clausules de périodes. Cicéron chérit tout particulièrement cette partie de l'elocutio, notamment dans l'Orateur (168-236).

180. Nous n'avons pas retrouvé chez Denys cette citation que Caussin lui attribue : aucune des trois occurrences d'entekhnos données par l'index de l'éd. Aujac n'y correspond. Le mot apparaît, en revanche, chez Aristote (Rhétorique, 1404a16), pour désigner de manière générique l'art de la

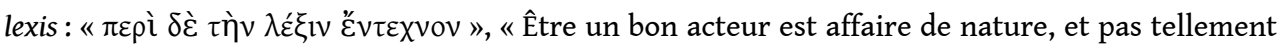
de technique, mais ce qui touche au style est technique» (éd. et trad. P. Chiron, Paris, Flammarion, 2007, p. 428). Le mot tekhnè apparaît dans La Composition stylistique de Denys d'Halicarnasse (Opuscules rhétoriques, VI, 5, 13, op.cit., p. 80) pour désigner l'art de bien agencer des mots (voir la note ci-dessous) : «Les anciens, poètes ou prosateurs, philosophes ou orateurs, se préoccupaient à l'extrême de la composition stylistique ; ils pensaient qu'il ne faut pas laisser 
au hasard le soin de joindre les mots aux mots, les membres de phrase aux membres de phrase, les périodes aux périodes; ils en faisaient une sorte de métier [ $\tau \dot{\varepsilon} \chi v \eta]$, avec certains principes à observer pour bien composer. "

181. Dans la terminologie de l'Orateur de Cicéron, la compositio et la structura (ou encore la constructio) sont de stricts synonymes, comme on le voit dès le $\S 150$. Le phénomène qu'ils désignent est l'agencement des mots dans la phrase. Cet agencement est «précis » : la place de chaque mot est soigneusement calculée. Et ce, à la fin de produire de la beauté, comme l'exprime bien Denys d'Halicarnasse : il faut "voir quel élément ajuster à quel autre pour produire une combinaison qui produise beauté et agrément» (La Composition stylistique, dans Opuscules rhétoriques, VI, 6, 1, op. cit., p. 81). Caussin en passant de compositio à structura évite une répétition, et le deuxième terme de son balancement désigne peut-être, avec modulis, les "nombres » produits par l'agencement: modulus, diminutif de modus, signifie «module» en architecture, « mesure » au sens musical, d'où « mélodie ». On retrouverait ainsi, à la fin du développement, le couple initial, agencement et rythme («nombres»). - Cf. la synthèse de Germaine Aujac sur « discours politiques » et musique chez Denys d'Halicarnasse (Opuscules rhétoriques, éd. et trad. G. Aujac, Paris, Les Belles Lettres, t. I, 1978, p. 176) : «les logoi politikoi désignent les discours, la plupart du temps fictifs (c'est Isocrate qui en a été l'initiateur) dont le contenu relève de la philosophie politique (qui n'est pas vain bavardage) et dont la forme, travaillée, s'apparente au discours musical. »

182. L'éd. de 1619 donne discendi (discere, « apprendre »), ce qui fait double emploi avec tyrocinio, de façon difficilement compréhensible. Nous adoptons la leçon de l'éd. 1637 (la numérisation disponible de l'éd. 1630 n'a pas cette page).

183. Cicéron, L'Orateur, Xx, 66-67, éd. et trad. H. Bornecque, Paris, Les Belles Lettres, 1921, p. 26-27 (nous ajoutons entre chevrons la formule omise par Bornecque).

184. Ibid., Xx, 68, p. 27.

185. Quintilien, Institution oratoire, X, 1, 27-28, éd. et trad. H. Bornecque, Paris, Garnier, 1933-1934, t. IV, p. 13-15. À la fin, Caussin souligne les deux éléments de « liberté » ou « licence ».

186. Ibid., X, 1, 29, p. 15.

187. Allusion au célèbre passage de l'Art poétique d'Horace (v. 138, trad. F. Villeneuve, Paris, Les Belles Lettres, 2002, p. 209) : “"Je chanterai la fortune de Priam et une guerre illustre." Qu'a-t-il à nous dire, notre faiseur de promesses, pour ouvrir si grand la bouche [hic promissor hiatu] ? La montagne va accoucher, ce sera la naissance ridicule d'une souris. »

188. Ammien Marcellin (vers 330-395), Histoire, XIX, 1, 2, éd. et trad. G. Sabbah, Paris, Les Belles Lettres, t. II, 1970, p. 121.

189. Ammien Marcellin, Histoires, XXVIII, 1, 1, éd. et trad. M.-A. Marié, Paris, Les Belles Lettres, t. v, 1984,p. 146.

190. Ammien Marcellin, Histoires, xv, 10, 5, éd. et trad. É. Galletier, Paris, Les Belles Lettres, t. I, 1968, p. 138.

191. Ibid., XIV, 6, 18, t. I, p. 77. Dans ce passage, Ammien Marcellin décrit la décadence de la Rome qui lui est contemporaine (ibid.) : « un petit nombre de maisons, célèbres auparavant par la pratique des études sérieuses, débordent aujourd'hui des amusements chers à l'indolence et à la paresse. »

192. Ibid., XIV, 6, 21, t. I, p. 78.

193. Ibid., XXX1, 5, 8 , éd. et trad. G. Sabbah, Paris, Les Belles Lettres, t. VI, 1999, p. 114.

194. Ammien Marcellin, t. I, op. cit., XIV, 1, 2, p. 58.

195. La métaphore des anémones est attestée chez Lucien, où elle renvoie au style inconsistant des sophistes dont Lycinos essaye de détourner Lexiphanès (Lexiphanès, dans Comédies humaines, op. cit., 23, p. 379) : « Ne te laisse pas envoûter par ces discours que le vent emporte [anémônai tôn logôn], mais, à la manière des athlètes, habitue-toi à prendre une nourriture consistante ; sacrifie- 
toi surtout aux Charites et à la Clarté, dont actuellement tu t'es bien trop écarté. » Pour la symbolique de l'anémone, fleur odorante mais trop légère, associée au mythe d'Adonis, voir n. 133.

196. Apulée, Les Métamorphoses ou l'âne d'or, I, 1, op. cit., p. 1.

197. Ibid., vII, 1, p. 147.

198. Ibid., I, 7, p. 6.

199. Ibid., III, 28, p. 69.

200. Ibid., XI, 24, p. 289.

201. Tertullien, Du Manteau, 2, op. cit., p. 502.

202. Sidoine Apollinaire, «Sidonius Evodio suo salutem », Lettres, op. cit., t. II, IV, 8, 3, p. 128.

203. Sidoine Apollinaire, «Sidonius probo suo salutem », ibid., IV, 1, 4, p. 112.

204. Sidoine Apollinaire, «Sidonius Ecdicio suo salutem », ibid., III, 3, 2, p. 86.

205. Ennode de Pavie (473 ?-521), Panégyrique de Théodoric, XII, 67, nous traduisons. Éd. Chr. Rohr, Der Theoderich-Panegyricus des Ennodius, Hanovre, Hahnsche Buchhandlung, 1995, p. 244-245; les mots inhabituels sont pennatae et cornipedum (« empennées » et «cavales », cornipes, litt. «aux pieds de corne $")$.

206. Ibid., v, 44, p. 228-229. Nous traduisons. Le texte de l'éd. Chr. Rohr est un peu différent: «excepit te tergo sonipes, lituorum desideriis inquietus »; le mot inhabituel est sonipes, litt. " au pied bruyant ".

207. Ibid., XII, 65, p. 242-243 et 244-245. Nous traduisons. Le mot inhabituel est, dans ce contexte, imber, « orage, averse ».

208. Tertullien, Du Manteau, 4, op. cit., p. 507. Le mot inhabituel est l'archaïsme rupex, "rustre » (chez Lucilius, mort en 103 av. J.-C.), recueilli uniquement par le grammairien Pompeius Festus (II ${ }^{\mathrm{e}}$ siècle).

209. Allégorie a ici le sens de «métaphore continuée » que lui donnent Cicéron dans Orator 94 et Quintilien (VIII, 6, 44, trad. Cousin, «l'allégorie [...] est surtout une suite continue de métaphores »), sens qu'elle a encore parfois à l'époque de Caussin. Au sujet de la métaphore, Quintilien écrit en effet (VIII, 6, 14, trad. Cousin,) : " continuus uero in allegorian et aenigmata exit ", « autant, employé avec mesure et à propos, ce trope illumine le style, autant, prodigué, il le rend obscur et fort ennuyeux ; un emploi continu [c'est-à-dire : filé] finit par créer allégories et énigmes ».

210. Dans une lettre adressée à Faustus, Ennode de Pavie écrit, à propos d'Aviénus qui vient d'être nommé consul (« Ennode à Faustus », dans Lettres, I, 5, 10, éd. et trad. S. Gioanni, Paris, Les Belles Lettres, 2006, t. 1, p. 16) : « Tout ce que la langue attique, tout ce que la langue romaine a de meilleur, il le connaît : l'or de Démosthène et le fer de Cicéron, il sait les apprécier ; tout en parlant latin, il n'en a pas moins accompli l'une et l'autre série des exercices rhétoriques. Il a embrassé comme une liberté les contraintes de l'enseignement grammatical et ces fameuses difficultés de l'expression juridique. En s'attachant à la majesté oratoire, il a provoqué ses compagnons d'âge au combat à la force du bras d'une mâle éloquence. »

211. Ennode de Pavie, Lettres, I, 1, 1-3, op. cit., p. 6-7.

212. Dans l'éd. Chr. Rohr d'Ennode : « dum ».

213. Nous remplaçons les crochets droits de Caussin par des parenthèses.

214. La manchette porte ici: "Praeclarum discrimen inter naturalia \& artefacta", "Éclatante différence entre les choses naturelles et artificielles. "

215. Ce passage rend particulièrement bien compte de l'apartenance de Caussin au courant jésuite de ce que M. Fumaroli appelait la « sophistique sacrée " (L'Âge de l'éloquence, op. cit., p. 257 et $s q$.$) : il est notamment imprégné des Images de Philostrate (première moitié du III { }^{\mathrm{e}}$ siècle) et du goût du rhéteur pour la description des «merveilles ». Sur cette fortune de la description au XVII ${ }^{\mathrm{e}}$ siècle, voir R. Romagnino, Théorie(s) de l'ecphrasis entre Antiquité et première modernité, Paris, Classiques Garnier, 2019. En français, on voit cette veine se déployer dans l'œuvre du jésuite 
Étienne Binet (1569-1639): Essay des merveilles de la nature, et des plus nobles artifices [1621], éd. M. Fumaroli, Évreux, « Des opérations », Association du théâtre de la ville d'Évreux, 1986.

216. «Peinturé » est la traduction adoptée par R. Estienne dans son Dictionarium Latinogallicum, op. cit., entrée « picturatus».

217. Ennode de Pavie, Lettres, 9, 1, op. cit., t. I, p. 23.

218. Ennode de Pavie, Panégyrique de Théodoric, III, 11, nous traduisons (éd. Chr. Rohr, op. cit., p. 202).

219. C'est-à-dire « originaire d'Arpinum » (la ville natale de Cicéron).

220. Allusion à une lettre de Sidoine Apollinaire $(\mathrm{V}, 5,2)$ où ce dernier, non sans ironie, félicite Syagirus d'avoir appris la langue germanique après avoir été formé au latin classique dans sa jeunesse (op.cit., p.180): «je voudrais que tu me dises par suite de quelles circonstances ton intelligence s'est brusquement pénétrée des accents d'une langue étrangère, pour permettre à l'élève formé, avec le secours de la férule, à la lecture de Virgile et à l'étude harassante de la phrase puissante et abondante du variqueux orateur d'Arpinum [uaricosi Arpinatis opulentiam loquacitatemque] de s'élancer aujourd'hui, sous mes yeux, tel un jeune faucon, hors de sa vieille aire. » Varicosus étant très dépréciatif, le contexte amène à comprendre : « la phrase trop riche et trop abondante ». Voir R. Estienne dans son Dictionarium Latinogallicum, op. cit., entrée «loquax, loquacior, loquacissimus » : " Qui parle trop, Trop abondant en paroles, Grand parleur. »

221. « Nonchalante »... de faire ce que l'on attend d'elle : "C'est, traditionnellement, le rôle des orateurs jeunes que de se faire les porte-parole de l'accusation », note Pierre Grimal (dans Cicéron, Contre Pison, dans Discours, éd. et trad. P. Grimal, Paris, Les Belles Lettres, 1966, t. XVI, p. 143). En ne jouant pas ce rôle, cette jeunesse, dit la suite du texte cicéronien (ibid., XxxIII, 82), " ne témoigne pas autant qu'elle le devrait du désir d'acquérir estime et gloire ».

222. Sidoine Apollinaire, Lettres, I, 3, 2, op. cit., t. II, p. 9.

223. Citation approximative de la traduction par Cicéron de l'Économique de Xénophon, III, 1 (dans Cuvres complètes de Cicéron, M. Nisard dir., Paris, J. J. Dubochet, 1843, t. IV, p. 586) : « Nullo modo facilius arbitror posse neque herbas arescere et interfici ", "Je ne vois pas de moyen plus facile de dessécher les mauvaises herbes et de les faire périr, et en même temps de mieux ouvrir le sein de la terre à la chaleur pénétrante du soleil. »

224. Ennode de Pavie, Lettres, I, 3, 6, op. cit., t. I, p. 11.

225. Ennode de Pavie, Panégyrique de Théodoric, XVII, 78, nous traduisons (éd. Chr. Rohr, op. cit., p. 252-253).

226. La formule (" uno uerbo dici poterat») renvoie au uno... dici potest de Quintilien dans sa définition de la périphrase (VIII, 6, 59, nous soulignons) : «Plurimis autem uerbis cum id quo uno aut paucioribus certe dici potest explicatur ». Soit : « La Periphrase [...] exprime en plusieurs paroles ce qui se peut dire en vne seule " (Pierre Jacob, La Clavicule, ou la Science de Raymond Lulle, avec toutes les figures de rhétorique, Paris, J. Remy, 1647, p. 189). En un seul mot ou parole (uno), « ou du moins, en un plus petit nombre », ajoute Quintilien (" aut paucioribus»).

227. Dans l'éd. Chr. Rohr, fasticam. Dans l'éd. And. Schott des Opera d'Ennode (Tournai, N. Laurent, 1591, p.6), le texte est fasticat puis linquitur, avec en marge les variantes fasticam et liquitur.

228. Souvenir d'Horace : «L'homme de bien, l'homme de sens [...] n'ignore pas cependant quelle différence il y a entre la monnaie et les lupins " «quid distent aera lupinis » (dans Épîtres, I, 8, 22-23, op. cit., p. 69, trad. un peu modifiée). Comme l'explique F. Villeneuve en note (ibid.), « les acteurs sur la scène employaient les lupins en guise de monnaie ». Cette plante servait donc d'or au théâtre, selon la formule de Plaute (Poenulus, 597, éd. et trad. A. Ernout, Paris, 1970, Les Belles Lettres, t. V, p. 204) : «C'est bien de l'or, spectateurs, mais de l'or de comédie. C'est avec cet or, quand il est trempé, qu'on engraisse les bœufs en Italie. Mais, pour jouer notre scène, ce sont des Philippes ; nous ferons comme si c'en était ». 
229. Jacques Davy du Perron (1556-1618), prélat, diplomate et poète; Guillaume du Vair (1556-1621), prélat, homme politique et écrivain moraliste. Tous deux sont considérés au début $\mathrm{du} \mathrm{XVII}^{\mathrm{e}}$ siècle comme les fleurons de l'éloquence de la chaire et du barreau. Voir R. Zuber, Les belles infidèles et la formation du goût classique, Paris, A. Colin, 1968.

230. Les mots veteris eloquentiae normam sont en caractères romains, ce qui signale d'habitude chez Caussin une citation. Mais peut-être est-ce ici un simple soulignement à valeur exclamative. L'expression eloquentiae norma se trouve en tout cas chez le jésuite Giulio Negrone (1553-1625), Orationes quinque \& viginti, Milan, De Ponte et Piccaglia, 1608, p. 495.

\section{AUTEURS}

\section{LISE CHARLES}

Université de Nantes

SUZANNE DUVAL

Université Gustave Eiffel 